VITOR YONAMINE LEE

\title{
INFLUÊNCIA DO EXERCÍCIO MATERNO ESPONTÂNEO E DA ANÓXIA NEONATAL NO DESENVOLVIMENTO, NA MEMÓRIA ESPACIAL E NO HIPOCAMPO DE RATOS
}

Dissertação apresentada ao Programa de PósGraduação em Ciências Morfofuncionais do Instituto de Ciências Biomédicas da Universidade de São Paulo, para obtenção do título de Mestre em Ciências. 
INFLUÊNCIA DO EXERCÍCIO MATERNO ESPONTÂNEO E DA ANÓXIA NEONATAL NO DESENVOLVIMENTO, NA MEMÓRIA ESPACIAL E NO HIPOCAMPO DE RATOS

Dissertação apresentada ao Programa de Pós-Graduação em Ciências Morfofuncionais do Instituto de Ciências Biomédicas da Universidade de São Paulo, para obtenção do título de Mestre em Ciências Morfofuncionais.

Área de concentração: Ciências Morfofuncionais.

Orientadora: Profa. Dra. Maria Inês Nogueira

Versão original 
DADOS DE CATALOGAÇÃO NA PUBLICAÇÃO (CIP)

Serviço de Biblioteca e Informação Biomédica do Instituto de Ciências Biomédicas da Universidade de São Paulo

reprodução não autorizada pelo autor

Lee, Vitor Yonamine.

Influência do exercício materno espontâneo e da anóxia neonatal no desenvolvimento, na memória espacial e no hipocampo de ratos / Vitor Yonamine Lee. -- São Paulo, 2015.

Orientador: Profa. Dra. Maria Inês Nogueira.

Dissertação (Mestrado) - Universidade de São Paulo. Instituto de Ciências Biomédicas. Departamento de Anatomia. Área de concentração: Ciências Morfofuncionais. Linha de pesquisa: Neurociências.

Versão do título para o inglês: Influence of spontaneous maternal exercise and neonatal anoxia in the development, spatial memory and in the hippocampus of rats.

1. Anóxia 2. Exercício 3. Desenvolvimento 4. Reflexo 5. Memória 6. Hipocampo I. Nogueira, Profa. Dra.Maria Inês II. Universidade de São Paulo. Instituto de Ciências Biomédicas. Programa de PósGraduação em Ciências Morfofuncionais III. Título. 
Título da

Influência do exercício materno espontâneo e da anóxia neonatal no desenvolvimento, na memória espacial e no hipocampo de ratos.

Orientador(a): $\quad$ Profa. Dra. Maria Inês Nogueira.

A Comissão Julgadora dos trabalhos de Defesa da Dissertação de Mestrado, em sessão pública realizada a considerou
( ) Aprovado(a)
( ) Reprovado(a)

Examinador(a): Assinatura:

Nome:

Instituição:

Examinador(a): Assinatura:

Nome:

Instituição:

Presidente: Assinatura:

Nome:

Instituição: 


\section{Certificado}

Certificamos que o protocolo registrado sob n 190 nas fls. 139 do livro 02 para uso de animais em experimentaçăo, sob a responsabilidade do Prof(a) Dr(a)) Maria Inês Nogueira, Coordenador (a) da Linha de pesquisa "Estudo da organização e dinåmica neural: no encéfalo de ratos após anóxia neonatal" do qual participam o(s) aluno(s), Silvia Honda Takada, Mike Yoshio Hamasaki, Vitor Yonamine Lee, está de acordo com os Princípios Éticos de Experimentação Animal adotado pela Sociedade Brasileira de Ciência de Animais de Laboratório (SBCAL) e foi aprovado pela COMISSÃO DE ÉTICA NO USO DE ANIMAIS (CEUA) em 12.12.2012, com validade de 4 anos.

São Paulo, 14 de dezembro de 2012.
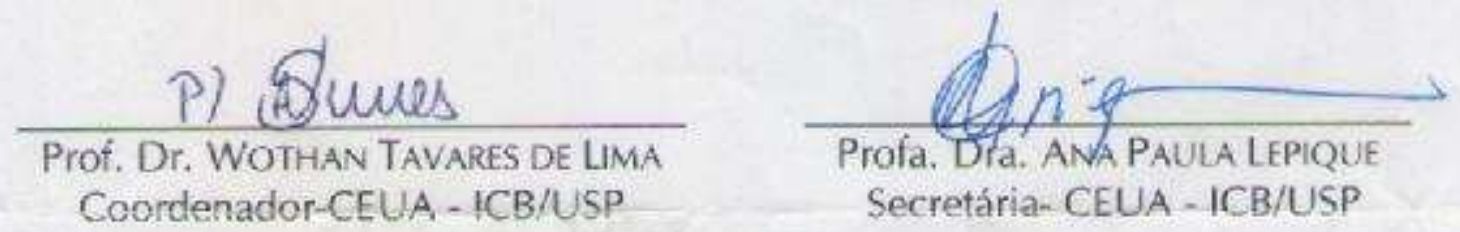


\section{AGRADECIMENTOS}

Agradeço à Prof. ${ }^{a}$ Maria Inês Nigueira pelo apoio e pela compreensão e realço o seu lado humano.

Agradeço especialmente à Dr. ${ }^{\text {a }}$ Sílvia Honda Takada, por sempre se dispor a me ensinar e a me ajudar quando precisei, pela sensatez e por ser uma amiga valorosa.

Agradeço, também, à Aline Vilar Machado pela indispensável e significativa contribuição nos experimentos, na estatística e na discussão dos dados.

Agradeço à Lívia Clemente Teixeira, por me ajudar nos experimentos, nas discussões e pela companhia.

Agradeço aos demais amigos que conheci no laboratório, Carlos Alexandre dos Santos Haemmerle, Mike Yoshio Hamasaki, Leila Maria Guissoni Campos, Carolina de Souza Goulart e Amrita Jha, pela amizade, pelos bons momentos e pelo espírito cooperativo.

Agradeço à técnica Kelly Patrícia Nery Borges pela ajuda nos experimentos, na manutenção do laboratório e no auxílio aos estagiários.

Agradeço, de forma especial, ao Prof. Jackson Cioni Bittencourt e à Prof. a. Luciane Valéria Sitta pelo compartilhamento do criostato, do sistema de estereologia, do microscópio de fluorescência e do pHmetro.

Também agradeço à técnica Joelcimar Martins da Silva e aos alunos Giovanne Baroni Diniz e à Daniella Sabino Batagello pelo auxílio no manuseio no criostato, no sistema de estereologia e no microscópio de fluorescência.

Agradeço ao Prof. Gilberto Fernando Xavier pela colaboração e pela disponibilização do espaço no laboratório para a locação dos animais e a execução das perfusões, das dissecações e do Labirinto Aquático de Morris.

Agradeço aos alunos do Laboratório de Neurociências e Comportamento do IB-USP Cyrus Villas-Boas, Leopoldo Barletta, Elisa Jordão, Daniel Giura da Silva, Mateus Torres Cruz, Priscila Moreira e Victor Daniel Vasquez Matsuda pelos diversos auxílios no laboratório.

Agradeço, também, ao técnico Manoel Ferreira de Britto, pelo cuidado e preocupação com os animais.

Agradeço ao Prof. Luiz Roberto Giorgetti de Britto, ao técnico Adílson da Silva Alves e às alunas Priscila Crespo Garcia e Caroline Real Gregório pelo grande auxílio com a técnica de Western Blot.

Agradeço à Prof. a Camila Squarzoni Dale pelas conversas. 
Agradeço aos funcionários Roberto Bandeira, pelos vários favores prestados, Rosana Duarte Prisco, pelo auxílio estatístico, Reginaldo Souza, pelo cuidado com os animais no biotério do Depto. de Anatomia do ICB-USP e Renaide Rodrigues Ferreira, pela disponibilidade em prestar os serviços do Biotério Central do ICB-USP.

Por fim, agradeço à minha mãe Keiko Yonamine e à minha família, que são as pessoas que estarão sempre ao meu lado. 


\section{RESUMO}

Lee VY. Influência do exercício materno espontâneo e da anóxia neonatal no desenvolvimento, na memória espacial e no hipocampo de ratos. [dissertação (Mestrado em Ciências Morfofuncionais)]. São Paulo: Instituto de Ciências Biomédicas, Universidade de São Paulo; 2015.

A anóxia neonatal ocorre quando há falta de oxigênio nos tecidos do feto ou do recém-nascido. Ela atinge cerca de 0,1 a $0,3 \%$ das crianças nascidas a termo e aproximadamente $60 \%$ das crianças prematuras com baixo peso ao nascer. Dentre os indivíduos que apresentam encefalopatia hipóxico-isquêmica, 20 a 50\% morrem no período neonatal e $25 \%$ dos sobreviventes exibem algum problema neurológico permanente, como epilepsia, déficit cognitivo e dificuldade de aprendizagem. Pesquisas com exercício físico, crioproteção e drogas buscam tratar indivíduos afligidos pela anóxia, mas há poucos trabalhos voltados para a prevenção. Neste projeto foi avaliado se o exercício físico em ratas gestantes é capaz de prevenir os efeitos da anóxia neonatal nos seus filhotes. Para isso, as ratas prenhas foram alocadas em gaiolas de atividade com roda giratória para realizarem exercício espontâneo, a fim de minimizar estresse experimental. Os filhotes sofreram anóxia neonatal em P2 e o seu desenvolvimento somático e sensorimotor foram avaliados. $\mathrm{Na}$ idade adulta, P60, o seu comportamento e a sua memória espacial foram avaliados no teste do Labiritno aquático de Morris. Também analisamos a densidade de neurônios maduros por imunohistoquímica e a expressão relativa de sinapsina I por Western Blot de animais jovens e adultos. O exercício materno espontâneo foi capaz de reverter o atraso provocado pela anóxia neonatal no aparecimento de várias características do desenvovlimento somático e sensoriomotor. Ele também atenuou a diminuição da densidade neuronal no giro dentado e a diminuição da expressão relativa de sinapsina I no hipocampo, promovidas pela anóxia neonatal, em animais com 21 dias de vida. Entretanto, as alterações provocadas pela anóxia neonatal e pelo exercício materno na imunorreatividade do hipocampo aparentemente sumiram nos animais adultos, talvez por efeito da recuperação dos sujeitos. Além disso, não houve feito do exercício materno nem da anóxia neonatal na latência e no percurso no teste de memória. A anóxia aumentou a velocidade de nado dos animais, provavelmente por hiperatividade. Este estudo indica que o exercício materno espontâneo tem potencial ação preventiva contra os efeitos da anóxia neonatal.

Palavras-chave: Anoxia neonatal. Exercício materno. Desenvolvimento somático. Desenvolvimento sensoriomotor. Labirinto aquático de Morris. Sinapsina I. 


\begin{abstract}
Lee VY. Influence of spontaneous maternal exercise and neonatal anoxia in the development, spatial memory and hippocampus of rats. [Masters thesis (Morphofunctional Sciences)]. São Paulo: Instituto de Ciências Biomédicas, Universidade de São Paulo; 2015.

Neonatal anoxia occurs when oxigen lacks in tissues of fetus or newborn. It reaches about 0,1 to $0,3 \%$ of children born in term and approximately $60 \%$ of premature children with low birth weight. Among individuals with hipoxic-ischemic encephalopaty, 20 to $50 \%$ die at the neonatal period and $25 \%$ of survivors exhibit some neurological permanent problem as epilepsy, cognitive deficits and difficulty of learning. Researches with physical exercise, cryoprotection and drugs seek to treat individuals afflicted by anoxia, but there are few researches that deal with prevention. This project evaluates if the physical exercise in pregnant rats is capable of prevent the effects of neonatal anoxia in pups. Pregnant rats was alocated inside activity cages with running wheel to perform spontaneous exercise, therefore minimizing the experimental stress. Pups suffered neonatal anoxia in P2 and their somatic and sensorymotor development were evaluated. At adult age, P60, their behaviour and their spatial memory were evaluated in Morris water maze task. We analysed also the mature neuronal density by immunochemistry and the relative expression of synapsin I by Western Blot of youngers and adults animals. The spontaneous maternal exercise was able to reverse the delay induced by neonatal anoxia related to the appearance of various caracteristics of the somatic and sensorymotor development. It also attenuated the decrease of neuronal density on the dentate gyrus and on the decrease in relative expression of synapsin I in the hippocampus, promoted by neonatal anoxia, in 21 days old animals. However, the changes caused by neonatal anoxia and maternal exercise in the hippocampus immunoreactivity apparently disappear in adult animals, maybe by effect of recuperation of the subjects. Furthermore, groups didn't exhibited differences between themselves at latency and traject. Anoxia increased the swim velocity, probability because hyperactivity stimuli. This project shows that the spontaneous maternal exercise has potential preventive action against the effects of neonatal anoxia.
\end{abstract}

Keyworlds: Neonatal anoxia. Maternal exercise. Somatic development. Sensorymotor development. Morris water maze. Synapsin I. 


\section{LISTA DE FIGURAS}

Figura 1 - Períodos estimados de proliferação celular ........................................21

Figura 2 - Gaiola de atividade com roda giratória ..............................................27

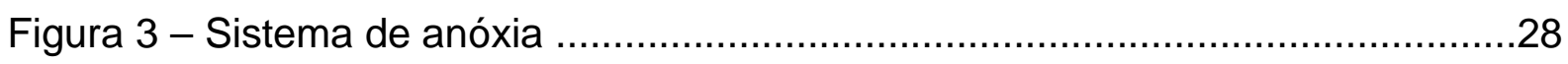

Figura 4 - Medição do eixo látero-lateral da cabeça (ELLC) …………………......29

Figura 5 - Medição do eixo ântero-posterior da cabeça (EAPC) ………….............29

Figura 6 - Medição do eixo longitudinal do corpo (EL) ...........................................30

Figura 7 - Verificação do aparecimento das características físicas ..........................31

Figura 8 - Avaliação da resposta ao decúbito (RD) …….....................................32

Figura 9 - Avaliação da colocação pelas virbrissas (CV) .......................................32

Figura 10 - Avaliação da aversão ao precipício (AP) ..........................................33

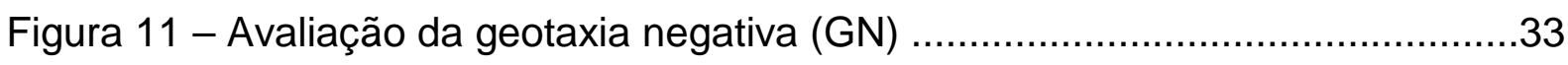

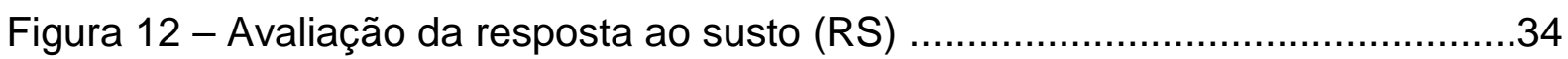

Figura 13 - Esquema do Labirinto aquático de Morris ..........................................35

Figura 14 - Esquema da vista superior do Labirinto aquático de Morris ...................36

Figura 15 - Secções analisadas do encéfalo do rato Wistar ....................................39

Figura 16 - Quadro de contagem ............................................................... 40

Figura 17 - Medida do eixo látero-lateral da cabeça (ELLC) (média \pm EP) ...............43

Figura 18 - Medida do eixo longitudinal do corpo (EL) (média \pm EP) .......................44

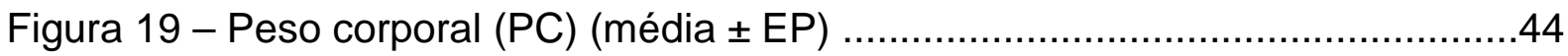

Figura 20 - Eixo ântero-posterior da cabeça (EAPC) (média \pm EP) …......................45

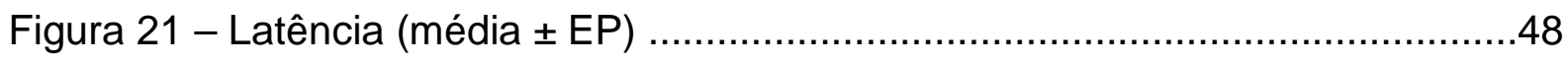

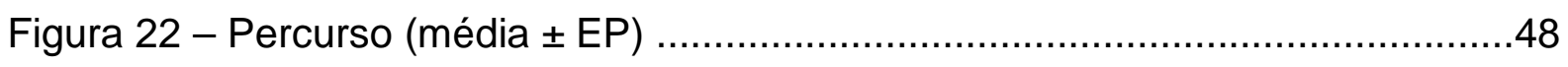

Figura 23 - Velocidade (média \pm EP) ……………....................................... 49

Figura 24 - Fotomicrografias da formação hipocampal mostrando células

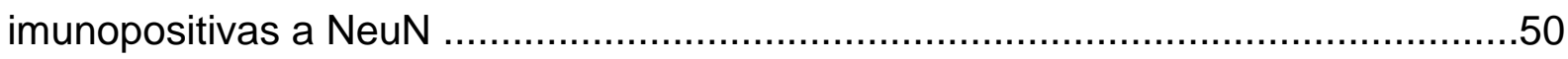

Figura 25 - Densidade de células imunopositivas para NeuN na formação

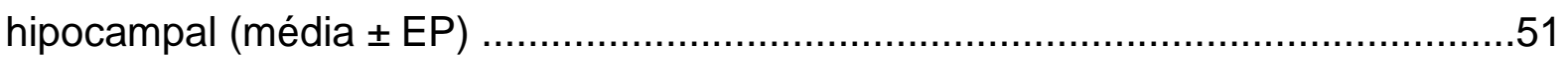

Figura 26 - Densidade de células imunopositivas para NeuN no giro dentado (GD) (média $\pm \mathrm{EP}$ ) 
Figura 27 - Densidade de células imunopositivas para NeuN na camada piramidal de CA3 .....

Figura 28 - Densidade de células imunopositivas para NeuN na camada piramidal de CA1

Figura 29 - \% de sinapsina I no hipocampo (média \pm EP) .53 


\section{LISTA DE TABELAS}

Tabela 1 - Grupos experimentais e os estímulos recebidos ………......................25

Tabela 2 - Número de animais utilizados em cada grupo, idade e experimento ......26

Tabela 3 - Valores dos parâmetros utilizados na contagem....................................41

Tabela 4 - Surgimento ontogenético dos índices de maturação em dias

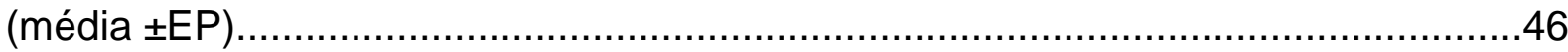




\section{LISTA DE ABREVIATURAS}

A - Aceleração

ABC - Avidin-biotin complex

ACA - Abertura do conduto auditivo

AO - Abertura dos olhos

AP - Aversão ao precipício

BDNF - Brain derived neurotrofic

factor

CA1 - Região Corno de Amon 1

CA3 - Região Corno de Amon 3

CV - Colocação pelas vibrissas

DAB - 3,3'-Diaminobenzidina

DG - Dia de gestação

DPA - Desdobramento do pavilhão

auditivo

DPX. - Dybutil phthalate in xylene

DTT - Ditiotreitol

EA - Exercício-anóxia

EAPC - Eixo ântero-posterior da

cabeça

EC - Exercício-controle

$E C L$ - Enhanced .chemiluminescence

$E L$ - Eixo longitudinal

ELLC - Eixo látero-lateral da cabeça
EP - Erro padrão

FT4 - Free tyroxin

GD - Giro dentado

GN - Geotaxia negativa

III - Irrupção dos incisivos inferiores

IIS - Irrupção dos incisivos superiores

MA - Massachusetts

NDS - Normal donkey sérum

NeuN - neuronal nuclear antigen

PBS - Phosphate buffered saline

PC - Peso corporal

$\mathrm{pH}$ - Potencial hidrogeniônico

PP - Preensão palmar

RD - Resposta ao decúbito

RS - Resposta ao susto

SA - Sedentarismo-anóxia

SC - Sedentarismo-controle

SG - Semana de gestação

T3 - Triiodotironina

T4 - Tiroxina

TBS - Tris bufered saline

TSH - Thyroid-stimulating hormone 


\section{LISTA DE SIGLAS}

ACOG - "American College of Obstetricians and Gynecologists"

ANOVA - "Analysis of variance"

CA - "California"

HCFMUSP - "Hospital das Clínicas da Faculdade de Medicina da USP"

Seade - "Sistema Estadual de Análise de Dados"

HE - "Hessen"

$\mathrm{OH}$ - "Ohio"

UK - "United Kingdom"

USA - "United State of America" 
1 INTRODUÇÃO

1.1 Redução do suprimento de oxigênio no período perinatal ..........................15

1.2 Exercício materno espontâneo …………….......................................18

1.3 Desenvolvimento neural da formação hipocampal ...................................20

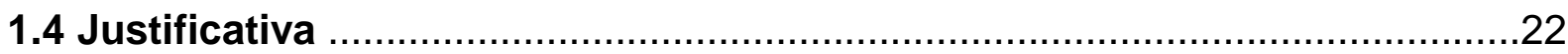

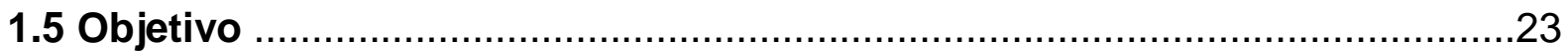

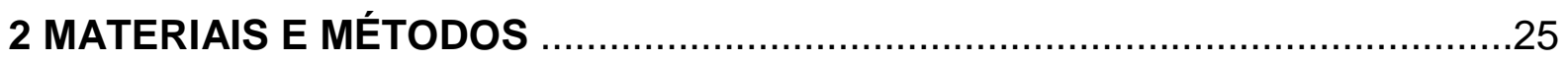

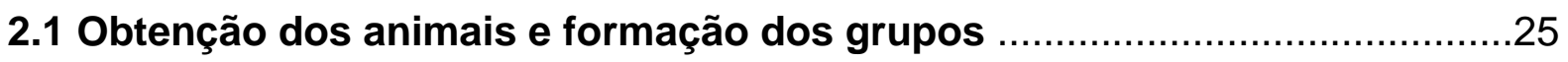

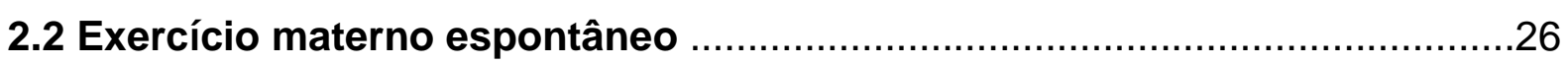

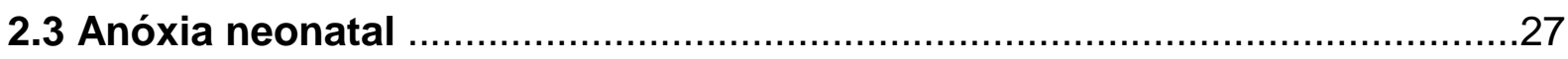

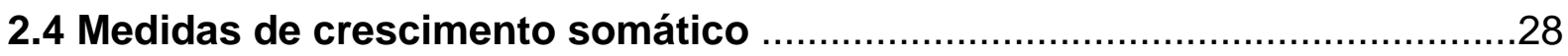

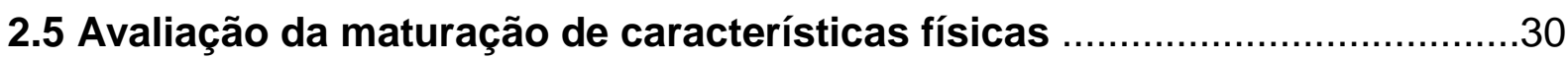

2.6 Avaliação da ontogênese de reflexos .....................................................

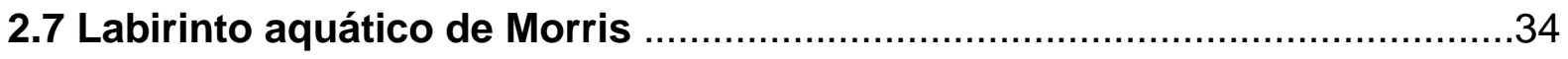

2.8 Processamento do material biológico para imunohistoquímica ..................37

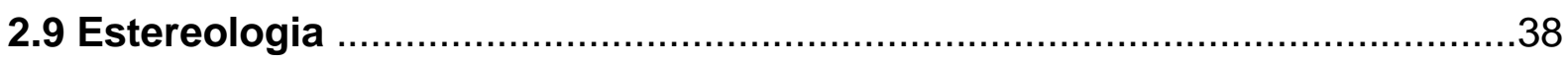

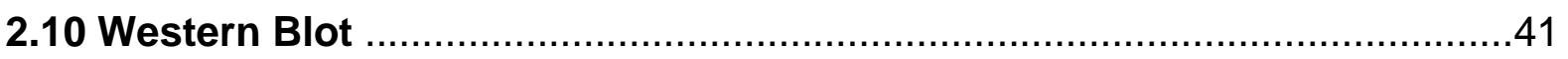

3 RESULTADOS

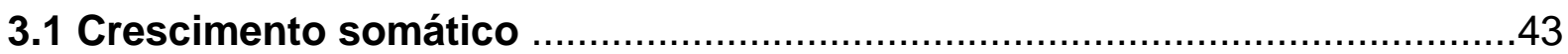

3.2 Maturação de características físicas e ontogênese de reflexos ……..........45

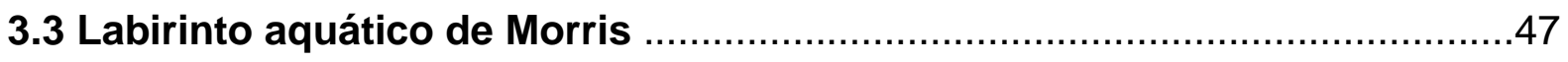

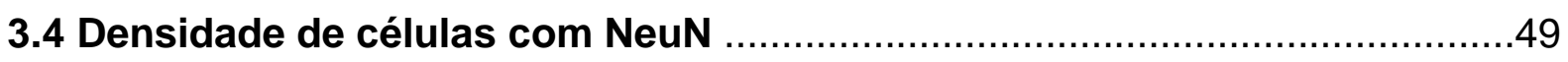

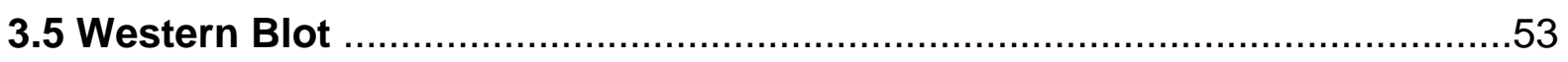

4 DISCUSSÃO

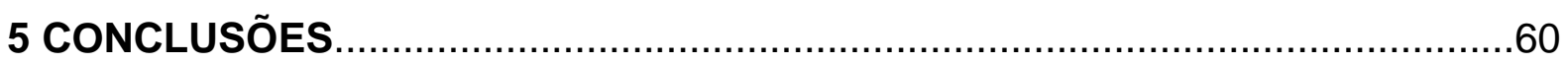

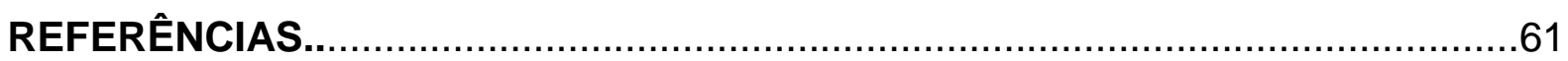

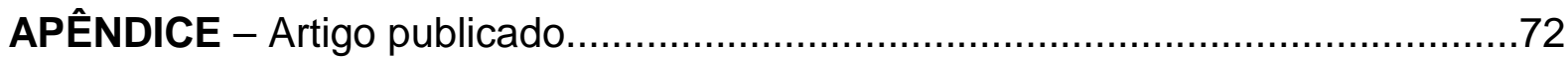




\section{INTRODUÇÃO}

\subsection{Redução do suprimento de oxigênio no período perinatal}

Anóxia neonatal ou perinatal é um termo utilizado clinicamente para casos de redução do nível de oxigênio no período perinatal (FUNAYAMA, 2005). Ela é diagnosticada, principalmente, pela classificação do concepto no índice ou escore de Apgar (APGAR, 1953; FUNAYAMA, 2005), que atribui menor pontuação aos recémnascidos que apresentam maior grau de depressão do estado geral. A baixa pontuação neste escore, entretanto, não indica necessariamente ocorrência de anóxia neonatal, pois as alterações fisiológicas avaliadas pelo método podem decorrer de outros tipos de injúrias (CRAWFORD; DAVIES; PEARSON, 1973; FINSTER; WOOD, 2005; FUNAYAMA, 2005; SYKES et al., 1982).

Devido a seu perfil epidemiológico heterogêneo o diagnóstico da anóxia neonatal pode se basear também em outros critérios (CLEIRICI; LUZZIETI; DI RENZO, 2001; FRANCISCO et al., 2000; NOMURA et al., 2003; SYKES et al., 1982), contribuindo para que o termo abranja casos clínicos com diferenças entre si, como a hipóxia-isquemia perinatal, em que há obstrução do fluxo sanguíneo para alguma região do corpo do feto ou do recém-nascido (VANNUCCI, 2000), e a asfixia perinatal (BOOG, 2010; HERRERA-MARSCHITZ et al., 2014; PIN; ELDRIDGE; GALEA, 2009; SHEVELL, 2004).

Estudos e pesquisas específicos sobre a hipóxia-isquemia e a asfixia perinatal são abundantes na literatura (BOOG, 2010; HERRERA-MARSCHITZ et al., 2014; PIN; ELDRIDGE; GALEA, 2009; PUYAL; GINET; CLARKE, 2013; SHEVELL, 2004; TAYLOR; EDWARDS; MEHMET, 1999; VANNUCCI, 2000), mas situações de anóxia neonatal não decorrentes de hipofluxo sanguíneo nem oriundas da interrupção de oxigênio materno também são clinicamente relevantes para a saúde pública, pois bebês prematuros, especialmente os de baixo peso, possuem alta susceptibilidade a complicações perinatais e neonatais, sendo que a imaturidade pulmonar aumenta 0 risco de anóxia ao nascimento (SUGUIHARA et al., 2005).

Apesar das diferenças entre os episódios de anóxia perinatal, eles apresentam em comum a falta de oxigênio e a frequente ocorrência de prejuízos posteriores em manifestações neurológicas, tais como paralisia cerebral (BACK; 
ROSENBERG, 2014; BOOG, 2010; SHEVELL, 2004; VANNUCCI, 2000), epilepsia (MOROZOVA; BELOZOUVA, 2009; VANNUCCI, 2000), hiperatividade (MOROZOVA; BELOUSOVA, 2009), dificuldades de aprendizagem e prejuízos na memória (VANNUCCI, 2000; PIN; ELDRIDGE; ARMSTRONG-WELLS et al., 2010) e déficit de atenção (ARMSTRONG-WELLS et al., 2010). Assim a falta de oxigênio assume papel fundamental no desenvolvimento das patologias da anóxia e para entender melhor a sua atuação é necessário estuda-lo de forma isolada dos demais fatores.

Diversos estudos em modelos animais reproduzem as sequelas neurológicas induzidas pela anóxia perinatal observadas em seres humanos (DELL'ANNA et al., 1991; GALEANO et al., 2011; SIMOLA et al., 2008; TAKADA et al., 2015; WEITZDOERFER et al., 2004; WEITZDOERFER; POLLAK; LUBEC, 2004). A falta de oxigenação em neonatos leva morte celular por apoptose, autofagia, excitotoxicidade e necrose em neurônios, astrócitos e células progenitoras de oligodendrócitos (pre-OLs) na formação hipocampal e em outras estruturas corticais (BACK; ROSENBERG, 2014; DELL'ANNA et al., 1991; LOREK et al., 1994; NAKAJIMA et al., 2000; NORTHINGTON; CHAVEZ-VALDEZ; MARTIN, 2011; PUKA-SUNDVALL et al., 2000; PUYAL; GENET; CLARKE, 2013; SCHMIDT-KASTNER; FREUND, 1991; TAKADA et al., 2015; TAYLOR; EDWARDS; MEHMET, 1999; VOLPE, 1998), bem como distúrbios na sinaptogênese da formação hipocampal (OTELLIN; KHOZHAI; SHISHKO, 2014), estrutura que está intimamente relacionada com a consolidação de diversos tipos de memória (MORRIS et al., 1982; SQUIRE, 1992).

A anóxia neonatal atinge de 0,1 a $0,3 \%$ das crianças nascidas a termo (KURINCZUK et al., 2010) e aproximadamente 60\% das crianças prematuras com baixo peso ao nascer (VANNUCCI, 2000; VOLPE, 1998, 2009), sendo a prematuridade o principal fator de risco associado à anóxia neonatal (MACDONALD et al., 1980, VANNUCCI, 2000; VOLPE, 1998). Dentre os indivíduos que apresentam encefalopatia hipóxico-isquêmica, 20 a $50 \%$ morrem no período neonatal e $25 \%$ dos sobreviventes exibem algum problema neurológico permanente (WILSONCOSTELLO et al., 2005). No Estado de São Paulo, durante o triênio de 2001 a 2003, dos 14.597 óbitos precoces, 3.247 (22\%) foram associados à anóxia neonatal, sendo que 2873 também foram considerados evitáveis (DARIPA et al., 2013). 
Pesquisas epidemiológicas levantaram outros fatores de risco para 0 nascimento com anóxia neonatal (CUNHA et al., 2004; MAJEED et al., 2007) e para a prematuridade (RAMOS; CUMAN, 2009) que, como fora citado (MACDONALD et al., 1980; VANNUCCI, 2000; VOLPE, 1998), está fortemente correlacionada com a incidência de anóxia. Entre os fatores de risco podemos destacar: baixa condição socioeconômica da mãe e o seu baixo nível de escolaridade, a falta de cuidado antenatal, dieta insuficiente ou inadequada, fumo, alcoolismo, ocorrência de infecções e toxemia e sangramento vaginal durante a gestação, nascimentos múltiplos, apresentação não-cefálica do bebê, ruptura prolongada da membrana, intervalo gestacional baixo ou muito longo e com elevado número de partos prévios, principalmente se eles tiverem sido prematuros, cesarianos ou com antecedente natimorto, baixa estatura materna, antecedente de anemia materna, interrupção de gestação anterior, hemorragia anteparto e parto caseiro (CUNHA et al., 2004; MAJEED et al., 2007; RAMOS; CUMAN, 2009).

Na cidade de São Paulo, a Fundação Sistema Estadual de Análise de Dados (Seade), em 2001, registrou incidência de 7\% de partos prematuros. Na Clínica Obstétrica do Hospital das Clínicas da Faculdade de Medicina da USP (HCFMUSP), devido à grande prevalência de gestações de alto risco e também ao baixo nível socioeconômico dos pais, a incidência média de prematuridade entre os anos de 1993 e 2002 foi de 22\% (RADES; BITTAR; ZUGAIB, 2004). Outros serviços públicos terciários da mesma região apresentaram taxas semelhantes de prematuridade (SOUZA et al., 1995).

Por conta da alta frequência de anóxia neonatal e da gravidade das suas consequências no sistema nervoso central, há diversas linhas de pesquisas que buscam minimizar ou solucionar estes problemas, como tratamento com drogas antiepilépticas, eritropoietina, melatonina e xênon, (LOBO; YANG; RIZVI, 2013) células-tronco (CASTILLO-MELENDEZ et al., 2013; TITOMANLIO et al., 2011), hipotermia (GULCZYŃSKA; GADZINOWSKI, 2012; JACOBS et al., 2013; LOBO; YANG; RIZVI, 2013) e exercício físico (CHEN; JIANG, 2010; CHOI et al., 2013; PARK, C., et al., 2013; TSUJl et al., 2010). Estas pesquisas propõem tratamentos aplicados em organismos que sofreram anóxia neonatal. Neste projeto avaliamos a possibilidade de um tratamento aplicado antes de os organismos sofrerem anóxia 
perinatal. O tratamento escolhido foi o exercício materno espontâneo pelas razões apresentadas a seguir.

\subsection{Exercício materno espontâneo}

A atividade física pode ser benéfica para o sistema nervoso central de muitas formas (PLOUGHMAN, 2008). No comportamento, ela protege contra o declínio cognitivo, principalmente em relação ao planejamento executivo e à memória operacional (BARNES et al., 2003; KRAMER et al., 1999), e melhora a atenção e o desempenho de humanos e outros primatas em testes cognitivos (HILLMAN; SNOOK; JEROME, 2003; KAMIJO et al., 2007).

A nível tecidual e celular, a atividade física aumenta a saturação de oxigênio (KRAMER et al., 1999) e a angiogênese (KLEIM; COOPER; VANDENBERG, 2002) nas regiões encefálicas importantes para o bom desempenho das habilidades cognitivas, aumenta a síntese e a liberação de neurotransmissores como a serotonina e a norepinefrina, facilitando o processamento de informações (MCMORRIS et al., 2008; WINTER et al., 2007), e, ainda, regula neurotrofinas, como o fator neurotrófico derivado do cérebro (BDNF), que são importantes para a sobrevivência neuronal, para o desenvolvimento do sistema nervoso e para a neuroplasticidade (SCHINDER; POO, 2000). A administração de BDNF nas células da formação hipocampal de ratos melhora a sinalização e a responsividade sinápticas, aumenta o número de sinapses e amplia a ramificação axonal intracortical (JI et al., 2005; VICARIO-ABEJON et al., 1998). O exercício físico tem sido reportado, ainda, como estimulante de biogênese de mitocôndrias e como produtor de fatores antioxidantes (MARQUES-ALEIXO et al., 2012).

Por contrapor os efeitos deletérios da privação de oxigênio, o exercício físico é estudado como tratamento contra as sequelas da anóxia neonatal no sistema nervoso (CHEN; JIANG, 2010; CHOI et al., 2013; PARK, C., et al., 2013; TSUJI et al., 2010). O exercício físico realizado por gestantes e fêmeas prenhas também gera efeitos para o feto ou filhote dentro da mãe, além da própria. O impacto do exercício depende da intensidade, da duração e do grau de estresse, como mostrado a seguir.

De acordo com Ezmerli (2000), em mulheres grávidas saudáveis, sem complicações clínicas ou obstétricas, os benefícios do exercício materno moderado 
(como o controle do excessivo ganho de peso, o aumento do senso de controle e da energia, a melhora do sono e da postura, a diminuição das dores nas costas e a promoção do tônus, da força e da resistência musculares) superam os seus riscos (como hipertensão induzida, ruptura das membranas fetais, sangramento persistente no segundo ou no terceiro trimestre, incompetência cervical e retardo do crescimento intrauterino), desde que durante a realização da atividade sejam seguidas as diretrizes da American College of Obstetricians and Gynecologists (ACOG). Estas diretrizes prescrevem prática regular de exercícios ao invés de atividades intermitentes, sem, contudo, chegar à exaustão, e dão preferência a atividades que diminuam o suporte do próprio peso, como natação e ciclismo, aliados à dieta adequada e hidratação constante.

O exercício físico aeróbico moderado também pode beneficiar a mãe por manter e aprimorar sua capacidade aeróbica (UZENDOSKI et al., 1990), o que reduz os desconfortos associados à gravidez (HEFFERNAN, 2000), diminui o risco de parto cesariano em mulheres nulíparas (BUNGUM et al., 2000) e aumenta a frequência e a amplitude dos movimentos respiratórios do feto (MARSÁL; LÖFGREN; GENNSER, 1979).

Quanto ao peso dos descendentes a literatura apresenta resultados que dependem da intensidade e frequência dos exercícios: pode haver redução (BELL; PALMA; LUMLEY, 1995; DWARKANATH et al., 2007; HOPKINS et al., 2010), não alteração (STERNFELD et al., 1995) ou aumento (CLAPP et al., 2000; HATCH et al., 1993) do peso.

Em relação à intensidade e ao estresse, atividades espontâneas ou voluntárias em ratas prenhas não prejudicam a prole (LOKEY et al., 1991) e ainda aumentam o número de neurônios e a angiogênese no encéfalo dos filhotes (AKHAVAN et al., 2012). Mesmo exercícios maternos forçados em esteira motorizada, quando moderados, melhoram a memória espacial, a memória de curta duração, a capacidade cognitiva, aumentam a sobrevivência neuronal na formação hipocampal de filhotes de ratas prenhas (DAYI et al., 2012; KIM et al., 2007; PARK, C., et al., 2013; PARPIANSIL et al., 2003; SHIN et al., 2013), a atividade enzimática e a biogênese mitocondriais na formação hipocampal (PARK, J., et al., 2013). O nado materno durante a gestação também aumenta a memória de curta duração nos 
filhotes de ratos (LEE et al., 2006) e as defesas antioxidantes, além de induzir a produção de mitocôndrias em suas formações hipocampais (MARCELINO et al., 2013). O uso de variados tipos de exercício induzem efeitos diferentes nas adaptações neuronais e no desempenho da memória (LIN et al., 2011), além de aumentarem os níveis de RNAm do BDNF no hipocampo da prole de ratas exercitadas durante a gestação (PARPIANSIL et al., 2003), constatando-se, assim, os efeitos benéficos do exercício materno, que, ao contrário do exercício físico realizado no próprio indivíduo, atua em um período crucial do desenvolvimento.

\subsection{Desenvolvimento neural da formação hipocampal}

A fase de desenvolvimento é o período de maior sensibilidade do sistema nervoso a fatores externos (RICE; BARONE, 2000). Uma parte considerável dos processos de desenvolvimento neural (neurogênese, sinaptogênese, apoptose, gliogênese e mielinização) ocorre no período pós-natal nos roedores, enquanto que nos primatas acontece no período pré-natal (RICE; BARONE, 2000).

Na formação hipocampal é possível estabelecer um paralelo temporal entre a neurogênese do rato e do ser humano (Fig. 1). No rato a escala é dada em dias e, no humano, em semanas. Além disso, o nascimento do rato ocorre antes que o do humano nessa comparação. A proliferação celular nas regiões CA1, CA2 e CA3 da formação hipocampal começa a ocorrer entre a $6^{\underline{a}}$ e a $7^{\mathrm{a}}$ semana de gestação (SG) em humanos e a partir do $15^{\circ}$ dia de gestação (DG) em ratos, finalizando na $15^{\text {a }} \mathrm{SG}$ no primeiro e no 19 $\mathrm{DG}$ no segundo. No giro dentado, outra região da formação hipocampal, a proliferação tem início entre a $10^{\underline{a}}$ e a $12^{\mathrm{a}} \mathrm{SG}$ em humanos e a partir do $19^{\circ} \mathrm{DG}$ em ratos e continua até a vida adulta (RICE; BARONE, 2000).

A densidade de sinapses hipocampais em ratos é baixa do nascimento até 0 $4^{\circ}$ dia de vida pós-natal (P4), mas começa a aumentar firmemente entre P5 e P14 a uma taxa submáxima e alcança a maior taxa de crescimento entre P15 e P28, período em que atinge a estabilidade (LOHMANN; KESSELS, 2013). 
Figura 1 - Períodos estimados de proliferação celular.

\begin{tabular}{|c|c|c|c|}
\hline Humanos (semanas) & Ratos (dias) & $\begin{array}{l}\text { Regiões } \\
\text { CA1-CA3 }\end{array}$ & $\begin{array}{c}\text { Giro } \\
\text { dentado }\end{array}$ \\
\hline $3,5-4,0$ & DG 11 & & \\
\hline $4,1-5,2$ & DG 12 & & \\
\hline $5,3-5,7$ & DG 13 & & \\
\hline $5,8-6,6$ & DG 14 & & \\
\hline $6,7-7,0$ & DG 15 & & \\
\hline $7,1-7,4$ & DG 16 & & \\
\hline $7,5-7,9$ & DG 17 & & \\
\hline $8,0-9,9$ & DG 18 & & \\
\hline $10,0-11,9$ & DG 19 & & \\
\hline $12,0-14,9$ & DG 20 & & \\
\hline $15,0-18,9$ & DG 21-22 & & \\
\hline $19,0-23,9$ & $\mathrm{P} 0-3$ & & \\
\hline $24,0-27,9$ & P4-7 & & \\
\hline $28,0-31,9$ & P6-11 & & \\
\hline $32,0-35,9$ & P12-15 & & \\
\hline $36,0-40,0$ & P16-19 & & \\
\hline
\end{tabular}

$\mathrm{DG}=$ dia de gestação; $\mathrm{P}$ = dia de vida pós-natal. Fonte: adaptado de Rice e Barone (2000).

A ontogenia dos reflexos e o crescimento somático também são afetados durante o período perinatal e tanto a privação de oxigênio quanto o exercício materno promovem alterações em diversos tipos de respostas sensoriomotoras e características físicas ao longo do período de desenvolvimento pós-natal do animal (DOBBING, SMART; 1974; FOX; 1965; HORVATH et al., 2015).

Considerando que a anóxia perinatal afeta principalmente recém-nascidos pré-termos (MACDONALD et al., 1980, VANNUCCI, 2000; VOLPE, 1998), neste projeto foram estudados os impactos da anóxia neonatal na quantidade relativa de neurônios e sinapses hipocampais em animais com idade equivalente ao de um prematuro humano extremo nascido com 23 semanas de gestação, em termos de maturidade neural. Em ratos, isso corresponde aproximadamente ao $1^{\circ}$ ou $2^{\circ}$ dia de vida pós-natal (P1-2) (RICE; BARONE, 2000) (Fig. 1). Também avaliamos o desenvolvimento dos reflexos após a anóxia neonatal, bem como a memória na idade adulta. 
Como foi demonstrado por Akhavan et al. (2012), o exercício materno voluntário realizado durante toda a gestação provê proteção contra hipóxia crônica na prole. Neste projeto, o exercício materno espontâneo foi realizado antes do início da proliferação celular hipocampal (do $5^{\circ}$ ao $15^{\circ}$ dia de gestação nos ratos) (Fig. 1) para avaliar se há efeito antecipado.

\subsection{Justificativa}

$\mathrm{Na}$ literatura existem muitas formas de simular a anóxia neonatal em animais. A injúria pode ocorrer em períodos antenatais ou pós-natais, com oclusão ou não da artéria carótida e ocorrer de forma aguda ou crônica (DELL'ANNA et al., 1991; SCHMIDT-KASTNER; FREUND, 1991; VANNUCCI, 2000). Todos os modelos assumem algum grau de correspondência com casos clínicos, apesar da heterogeneidade de suas causas e efeitos e da variabilidade nos parâmetros envolvidos. O modelo de anóxia neonatal desenvolvido no Laboratório de Neurociências do Instituto de Ciências Biomédicas da Universidade de São Paulo e validado por Takada et al. (2011).é apropriado para promover a privação aguda de oxigênio em um organismo sem a interferência de outros fatores geralmente presentes nos casos de anóxia perinatal, como a falta de glicose, íons e neurotrofinas nos tecidos com hipofluxo sanguíneo. O modelo promove alterações celulares, histológicas, morfológicas, fisiológicas e comportamentais importantes nos organismos lesados (ALLEMANDI, 2011; HAMASAKI, 2013; ITO, 2010; TAKADA et al., 2011, 2015; VASCONCELOS, 2013). Pesquisas que seguem esse modelo ainda são raras, mas os seus resultados podem servir para explicar a ação da falta de oxigênio em outros modelos.

O exercício materno espontâneo ou voluntário protege o sistema nervoso da prole dos efeitos da anóxia neonatal e não ativa o sistema de estresse nas mães (YANAGITA et al., 2007), característica importante para um estímulo considerado benéfico para o sistema nervoso central. Até o momento, apenas Akhavan et al. (2012) estudou os efeitos do exercício materno voluntário sobre as consequências de algum tipo de privação de oxigênio na prole, que no caso é a hipóxia crônica. Entretanto, há diferenças entre a hipóxia crônica e a anóxia aguda no modelo usado 
neste estudo, demonstrado por Takada et al. (2011), as quais devem ser exploradas com diferentes metodologias.

Outra diferença metodológica deste estudo com a de Akhavan et al. (2012) é o período de gestação em que o exercício materno é realizado. Enquanto Akhavan et al. (2012) segue um protocolo de exercício durante todo o período de gestação (do $1^{\circ}$ ao $21^{\circ} \mathrm{DG}$ ), neste estudo optou-se por submeter as ratas prenhas em regime de atividade antes da proliferação celular na formação hipocampal dos fetos (do 5은 ao $\left.15^{\circ} \mathrm{DG}\right)$, para avaliar se o efeito do exercício materno continua influenciando na quantidade de neurônios mesmo após o término do seu regime.

Além disso, a anóxia perinatal e o exercício físico também atuam sobre a ontogênese dos reflexos e a maturação de características físicas (DOBBING, SMART, 1974; FOX, 1965; HORVATH et al., 2015) motivo pelos quais tais aspectos também foram abordados.

Com isso buscamos contribuir para a criação de tratamentos preventivos ou terapêuticos que atenuem os efeitos da privação neonatal de oxigênio. Como mostrado pelas referências epidemiológicas, muitas gestantes pertencem ao grupo de risco de anóxia neonatal e podem beneficiar os seus filhos e a si mesmas com algum tipo de prevenção.

\subsection{Objetivo}

O objetivo foi verificar se, em ratos, o exercício materno espontâneo é capaz de atenuar os efeitos prejudiciais da anóxia neonatal em relação aos seguintes parâmetros:

a) crescimento somático, entre P2 e P21. O crescimento somático foi avaliado por meio da medida do eixo látero-lateral da cabeça (ELLC), do eixo ânteroposterior da cabeça (EAPC), do eixo longitudinal do corpo (EL) e do peso corporal (PC) em cada dia;

b) maturação de características físicas, entre P2 e P21. A maturação foi avaliada observando-se o dia do desdobramento do pavilhão auricular (DPA), 
da abertura do conduto auditivo ( $A C A)$, da irrupção dos incisivos superiores (IIS), da irrupção dos incisivos inferiores (III) e da abertura ocular (AO);

c) ontogênese de reflexos, entre P2 e P21. A ontogênese foi avaliada observando-se o dia do aparecimento da recuperação do decúbito $(R C)$ da colocação pelas vibrissas (CV), da aversão ao precipício (AP), da geotaxia negativa (GN), da resposta ao susto (RS), da aceleração $(A)$ e da preensão palmar (PP);

d) memória espacial operacional, memória de curta duração, memória de longa duração e flexibilidade comportamental, a partir de P60. Estes parâmetros foram avaliados por meio do desempenho no Labirinto Aquático de Morris em relação ao tempo (latência) levado para concluir as tentativas, ao comprimento do trajeto em cada tentativa e à velocidade média de nado;

e) estimativa da densidade sináptica em toda a formação hipocampal (exceto subículo) dos animais em P21 e P75 por meio de Western Blot com anticorpo contra sinapsina I;

f) estimativa da densidade de neurônios maduros nas camadas de células piramidais das regiões CA1 e CA2-3 e na camada granular do giro dentado do hipocampo em P21 e P75, por meio de imunohistoquímica com anticorpo contra NeuN e contagem por estereologia. 


\section{MATERIAIS E MÉTODOS}

\subsection{Obtenção dos animais e formação dos grupos}

Ratos (Rattus norvegicus) da linhagem Wistar foram obtidos do Biotério Central de Ratos do Instituto de Ciências Biomédicas (ICB) da Universidade de São Paulo (USP) e alocados no biotério do Laboratório de Neurociências do Instituto de Biociências (IB) da mesma universidade. Neste biotério, a temperatura é mantida a $21^{\circ} \mathrm{C} \pm 11^{\circ} \mathrm{C}$, em ciclo claro-escuro $12 / 12 \mathrm{~h}$, com iníc io às $6 \mathrm{~h}$ e término às $18 \mathrm{~h}$, e a comida e a água são fornecidos ad libitum. Os animais transferidos passaram por um período de 10 dias de adaptação antes do início dos experimentos. Todos os procedimentos descritos neste projeto estão de acordo com os Princípios Éticos de Experimentação Animal adotado pelo Colégio Brasileiro de Experimentação Animal (COBEA) que foram aprovados pela Comissão de Ética em Experimentação Animal (CEEA) (Protocolo $n^{\circ}$ 190, fls. 139 do livro 02 para uso de animais em experimentação).

Ratas prenhas com aproximadamente 60 dias de vida (P60) foram alocadas em gaiolas de atividade (com a roda de atividade livre ou travada) e, após o nascimento da prole, os filhotes machos foram arranjados em quatro grupos, conforme a Tabela 1.

Tabela 1 - Grupos experimentais e os estímulos recebidos.

\begin{tabular}{lcc}
\hline & $\begin{array}{c}\text { Filhotes de ratas que se } \\
\text { exercitaram (E) }\end{array}$ & $\begin{array}{c}\text { Filhotes de ratas } \\
\text { sedentárias (S) }\end{array}$ \\
\hline $\begin{array}{c}\text { Filhotes submetidos à } \\
\text { anóxia neonatal (A) }\end{array}$ & EA (exercício-anóxia) & SA (sedentarismo-anóxia) \\
$\begin{array}{c}\text { Filhotes não submetidos } \\
\text { à anóxia neonatal (C) }\end{array}$ & EC (exercício-controle) & $\begin{array}{c}\text { SC (sedentarismo- } \\
\text { controle) }\end{array}$ \\
\hline
\end{tabular}

Ao todo foram utilizados 108 filhotes machos, de 23 a 39 por grupo. Em cada grupo, foram avaliados o crescimento somático, a maturação de características físicas e a ontogênese de reflexos em 5 animais, sendo que alguns deles foram perfundidos ao final da avaliação, em P21, para imunohistoquímica. Outros 4 ou 5 
animais P21 foram decapitados para Western Blot. Ainda, em cada grupo, de 10 a 17 animais P60 realizaram o teste do Labirinto Aquático de Morris, dentro dos quais 5 foram perfundidos ao final dos quinze dias de teste, em P75, para imunohistoquímica. Outros 4 ou 5 animais P75 foram decapitados para Western Blot. Essas informações estão resumidas na Tabela 2.

Tabela 2 - Número de animais utilizados em cada grupo, idade e experimento.

\begin{tabular}{|c|c|c|c|c|c|c|}
\hline \multirow{2}{*}{ Idades } & \multirow{2}{*}{ Experimentos } & \multicolumn{4}{|c|}{ Grupos } & \multirow{2}{*}{ TOTAL } \\
\hline & & SC & EC & SA & EA & \\
\hline \multirow{2}{*}{$P 21$} & ADSS e imuno & 5 & 5 & 5 & 5 & 20 \\
\hline & Western Blot & 4 & 5 & 4 & 5 & 18 \\
\hline \multirow{3}{*}{$\begin{array}{c}\text { P60/ } \\
\text { P75 }\end{array}$} & LA e imuno & 10 & 17 & 11 & 14 & 52 \\
\hline & Western Blot & 4 & 5 & 4 & 5 & 18 \\
\hline & TOTAL & 23 & 32 & 24 & 29 & 108 \\
\hline
\end{tabular}

ADSS: avaliação do desenvolvimento somático e sensoriomotor. LA: Labirinto Aquático. Imuno: imunohistoquímica.

Quanto ao número de animais para acasalamento, foram utilizados 20 fêmeas em torno de P60 (cada fêmea obteve, em média, 5 filhotes machos) e 10 machos também por volta de P60, todos com aproximadamente 250-260 g.

\subsection{Exercício materno espontâneo}

O ciclo estral das ratas para acasalamento foi acompanhado diariamente a partir de P60, analisando-se a proporção dos tipos celulares da secreção vaginal (MARCONDES; BIANCHI; TANNO, 2002). Durante o período fértil (do começo do proestro ao final do diestro) duas fêmeas foram alocadas com um macho e, nos dias seguintes, foi verificada a presença de espermatozoides na secreção vaginal. Em caso afirmativo, este dia foi considerado o primeiro dia de gestação da mãe.

Do $5^{\circ}$ ao $15^{\circ} \mathrm{DG}$ cada rata foi alocada em uma gaiola de atividade com roda de corrida para exercício voluntário (Fig. 2). 
Figura 2 - Gaiola de atividade com roda giratória.

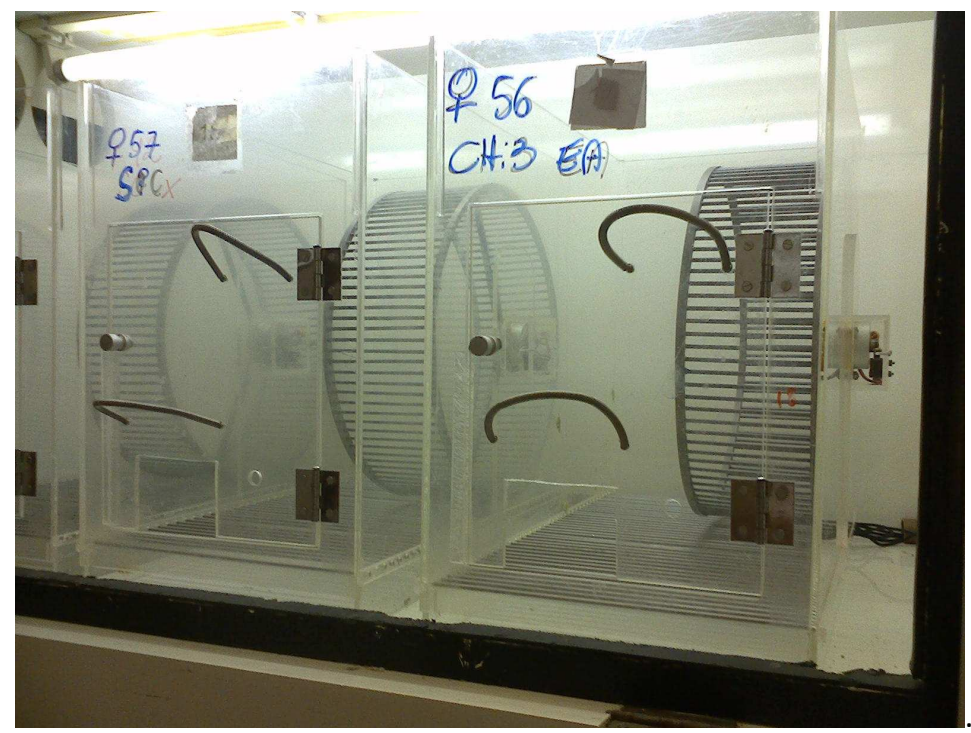

As ratas em regime sedentário foram alocadas no mesmo modelo de gaiola, mas com a roda travada. Nas gaiolas com a roda livre, a quantidade de rotações a cada minuto foi registrada por meio de um sistema eletrônico durante toda a estadia dos animais. Após o regime de exercício, cada rata foi alocada em uma gaiola a parte.

\subsection{Anóxia neonatal}

O modelo de asfixia utilizado neste projeto foi aplicado em ratos com 24 horas de vida (ou com 6 a $8 \mathrm{~g}$ ). O sistema consiste em câmara semihermética de policarbonato $(31,0 \times 14,0 \times 19,5 \mathrm{~cm})$ parcialmente imersa em água, para a regulação da temperatura, e com controle de entrada, saída, fluxo e pressão de gás nitrogênio $\left(\mathrm{N}_{2}\right)$ (Fig. 3). Dentro da câmara os neonatos foram expostos a um ambiente com $100 \%$ de $\mathrm{N}_{2}$, entrando a um fluxo de $3 \mathrm{~L} /$ minuto e a uma pressão de $101,7 \mathrm{kPa}$. Estes parâmetros foram estipulados com base em outras pesquisas (COQ et al., 2008; ROGALSKA; DANIELISOVA; CAPUTA, 2006; TANG; NAKAZAWA, 2005). A anóxia neonatal durou 25 minutos - tempo suficiente para causar danos ao encéfalo (DELL'ANNA et al., 1995; TAKADA et al., 2011) - e aconteceu a $37^{\circ} \mathrm{C}$ para evitar neuroproteção, que oc orre na temperatura basal dos neonatos de $33^{\circ} \mathrm{C}$ (CAPUTA et al., 2005; ROGALSKA; D ANIELISOVA; CAPUTA, 
2006). Os animais dos grupos controle, EC e SC, passaram pelos mesmos procedimentos que os animais dos grupos SA e EA, nas mesmas condições, exceto pela privação de oxigênio.

Figura 3 - Sistema de anóxia.

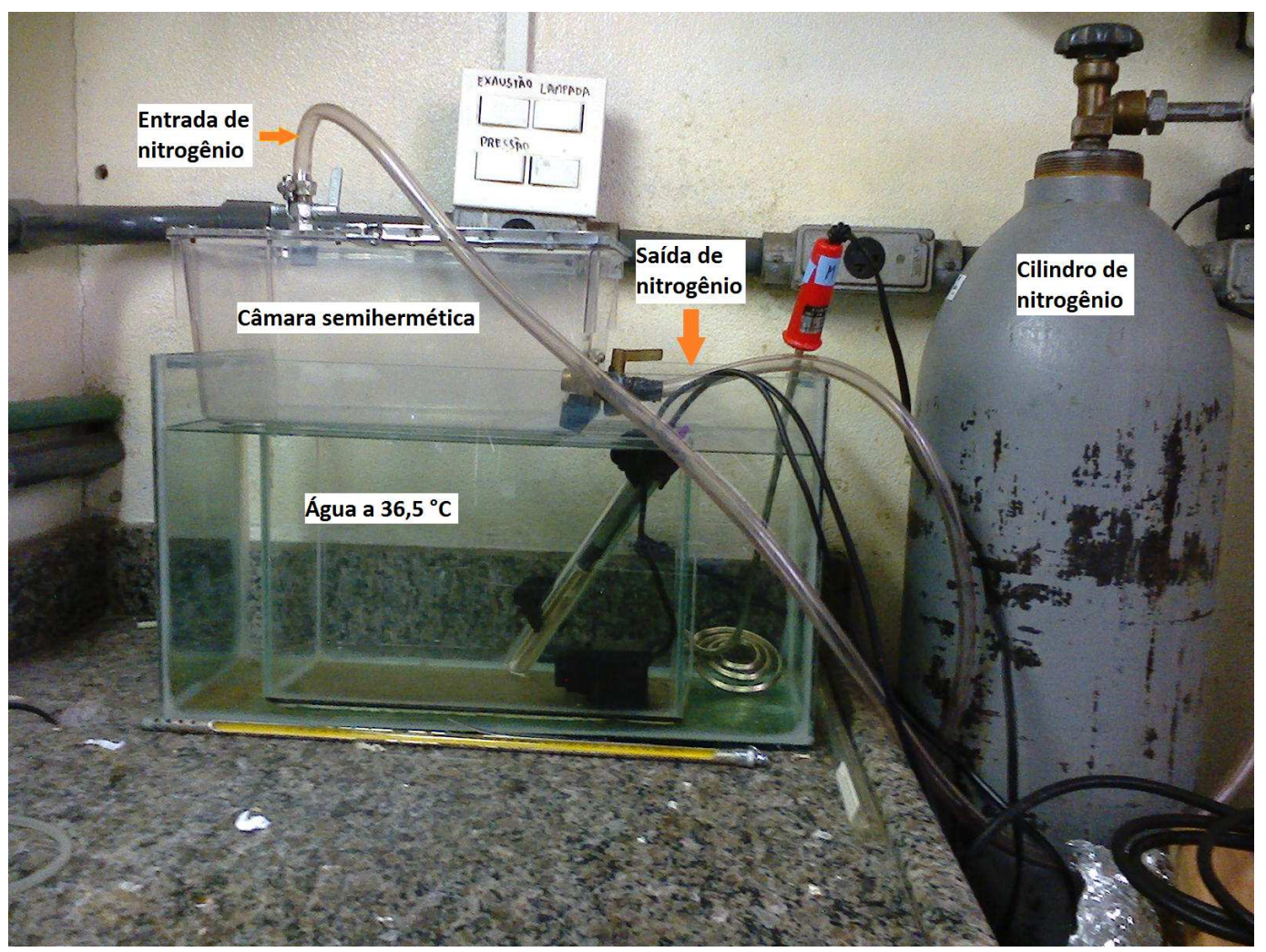

Após o insulto, no máximo 8 animais de cada ninhada foram devolvidos à mãe para não haver o risco de algum deles não conseguir amamentar, pois as fêmeas possuem no máximo 8 mamas funcionais. Além disso, todos os animais da mesma ninhada receberam o mesmo estímulo (anóxia ou controle) para evitar possível desigualdade na sucção de leite. Os filhotes permaneceram com a mãe até o desmame (P21).

\subsection{Medidas de crescimento somático}

O acompanhamento do crescimento somático foi realizado de P2 a P21, entre $10 \mathrm{~h}$ e $12 \mathrm{~h}$. Os parâmetros avaliados foram: 
a) eixo látero-lateral do crânio (ELLC): Para obtenção desta medida, o pesquisador segurou o filhote na mão e mediu a distância entre as suas duas orelhas com um paquímetro (Fig. 4);

Figura 4 - Medição do eixo látero-lateral da cabeça (ELLC).

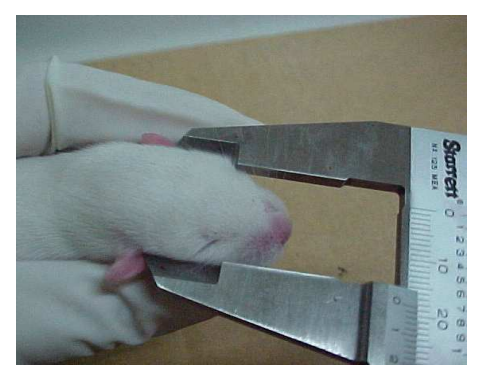

Fonte: Vasconcelos (2013).

b) eixo ântero-posterior do crânio (EAPC): Para obtenção desta medida, o pesquisador segurou o filhote na mão e mediu a distância entre o focinho e a articulação atlantoccipital com um paquímetro (Fig. 5);

Figura 5 - Medição do eixo ântero-posterior da cabeça (EAPC).

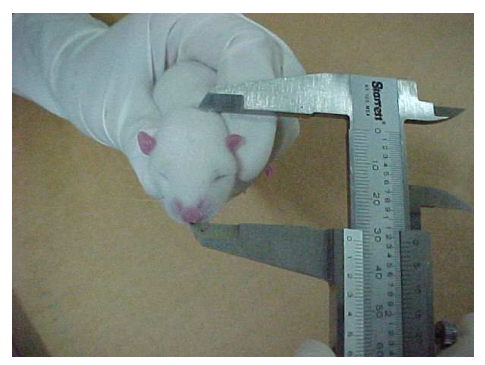

Fonte: Vasconcelos (2013).

c) eixo longitudinal do corpo (EL): Para obtenção desta medida, o pesquisador imobilizou o filhote estendido, prensando-o delicadamente a uma superfície plana com a mão, e fez duas marcas na superfície; uma rente ao focinho e outra rente à base da cauda. Então ele mediu a distância das duas marcas com um paquímetro (Fig. 6); 
Figura 6 - Medição do eixo longitudinal do corpo (EL).

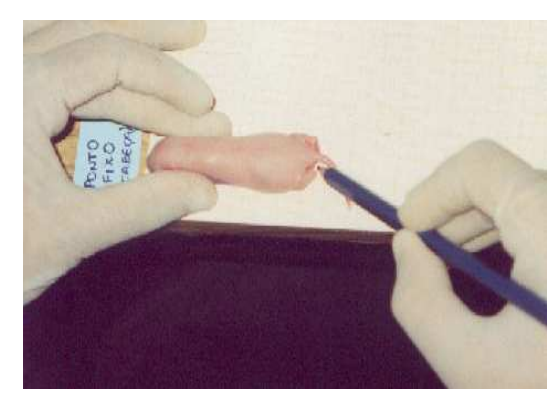

Fonte: Vasconcelos (2013).

d) peso corporal (PC): Obtido com uma balança digital.

Todos os dados foram avaliados com ANOVA de medidas repetidas com teste post-hoc de Tukey-Kramer $(p \leq 0,05)$.

\subsection{Avaliação da maturação de características físicas}

O registro da maturação das características físicas seguiu os critérios estabelecidos por Fox (1965) e Deiró et al. (2004; 2006). Foi anotado o dia em que a característica surgiu em cada animal. As características avaliadas foram:

a) desdobramento do pavilhão auricular (DPA): Ao nascer, o pavilhão auditivo do rato está fletido sobre a abertura que irá apresentar no desenvolvimento ou, após o desenvolvimento completo, sobre o óstio acústico externo. O DPA foi considerado no dia em que a dobra, uma vez desfeita, tornou o pavilhão livre (Fig. 7무);

b) abertura do conduto auditivo (ACA): A abertura do conduto auditivo foi considerada no dia em que o óstio acústico externo pôde ser visualizado (Fig. 7B); 
c) irrupção dos incisivos superiores (IIS) e inferiores (III): Considerou-se o dia da irrupção dos incisivos superiores e inferiores quando houve o rompimento da gengiva com exposição incisal (Fig. 7C);

d) abertura ocular (AO): Durante algum tempo após o nascimento, os olhos do rato permanecem fechados, totalmente encobertos pelas pálpebras. Considerou-se que os olhos se abriram no dia em que eles foram expostos (Fig. 7D).

Todos os dados foram avaliados com ANOVA multifatorial com teste post-hoc de Tukey-Kramer $(p \leq 0,05)$.

Figura 7 - Verificação do aparecimento das características físicas.

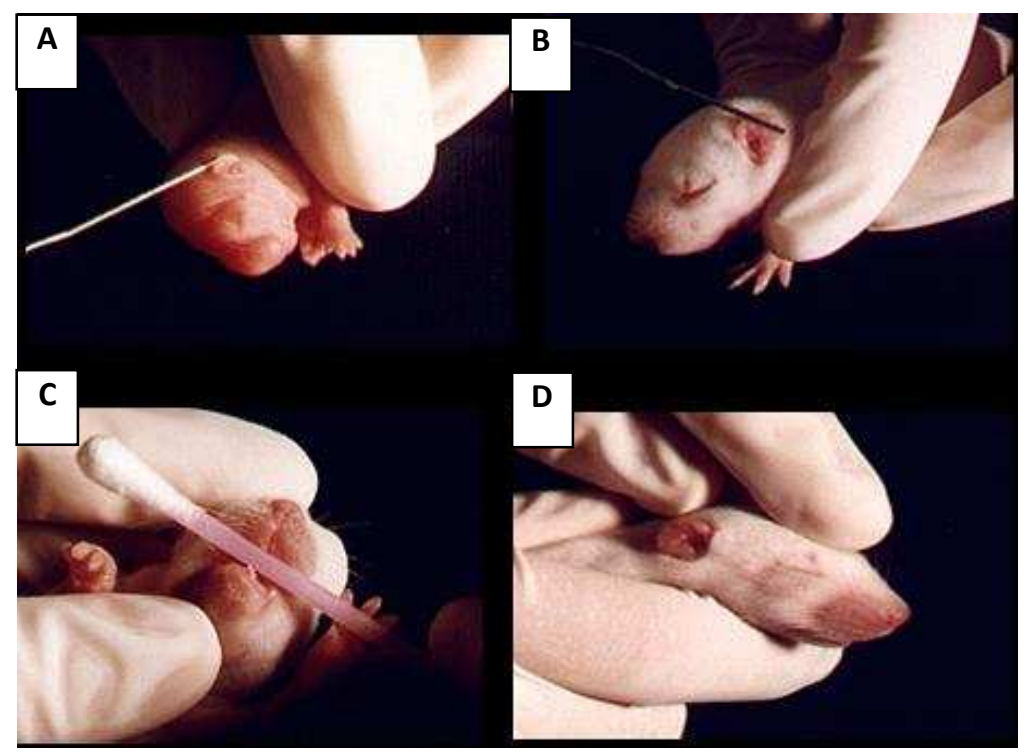

A: desdobramento do pavilhão auditivo (DPA). B: abertura do conduto auditivo (ACA). C: irrupção do incisivo inferior (III) e superior (IIS). D: abertura dos olhos (AO). Fonte: Vasconcelos (2013).

\subsection{Avaliação da ontogênese de reflexos}

A maturação de reflexos foi realizada com parâmetros anteriormente descritos por Deiró et al. $(2004,2006)$ : 
a) recuperação do decúbito $(\mathrm{RD})$ : O rato foi colocado em decúbito dorsal sobre uma superfície plana. Considerou-se resposta positiva quando o animal girou o corpo e assumiu o decúbito ventral apoiado nas quatro patas dentro de um período de $10 \mathrm{~s}$ (Fig. 8);

Figura 8 - Avaliação da recuperação do decúbito (RD).

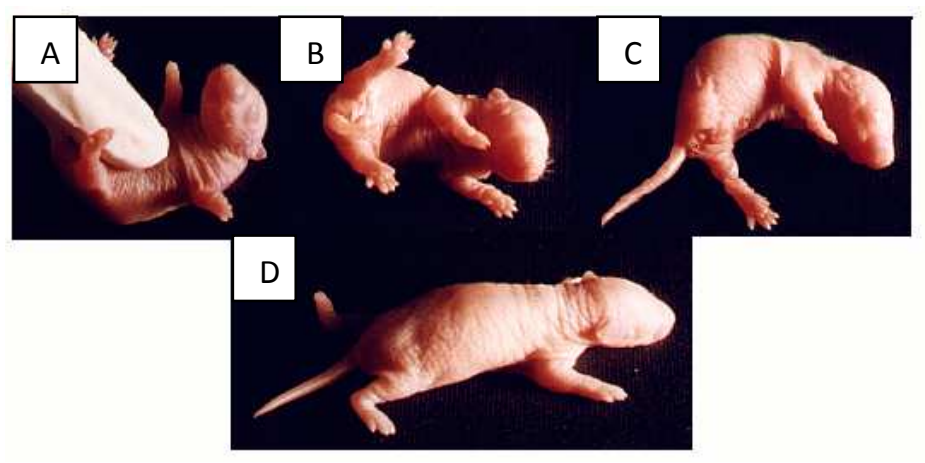

De A a D: sequência do movimento de RD. Fonte: Vasconcelos (2013).

b) colocação pelas vibrissas (CV): O rato foi suspenso pela cauda de tal forma que suas vibrissas tocassem levemente a borda de uma mesa. Considerou-se resposta positiva quando o animal colocou as patas anteriores sobre a mesa tentando caminhar dentro de um período de $10 \mathrm{~s}$ (Fig. 9);

Figura 9 - Avaliação da colocação pelas vibrissas (CV).

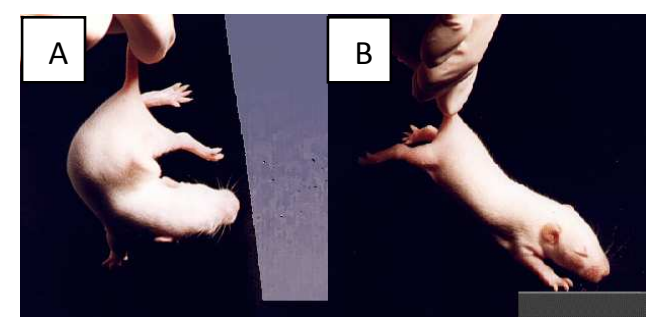

A: contato das vibrissas com o estímulo. B: resposta do indivíduo ao contato. Fonte: Vasconcelos (2013).

c) aversão ao precipício (AP): O animal foi colocado com as patas dianteiras sobre a borda de uma superfície plana e alta de maneira a detectar o precipício. Considerou-se resposta positiva quando o animal deslocava-se pelo menos $45^{\circ}$ para um dos lados em $10 \mathrm{~s}$ (Fig. 10); 
Figura 10 - Avaliação da aversão ao precipício (AP).

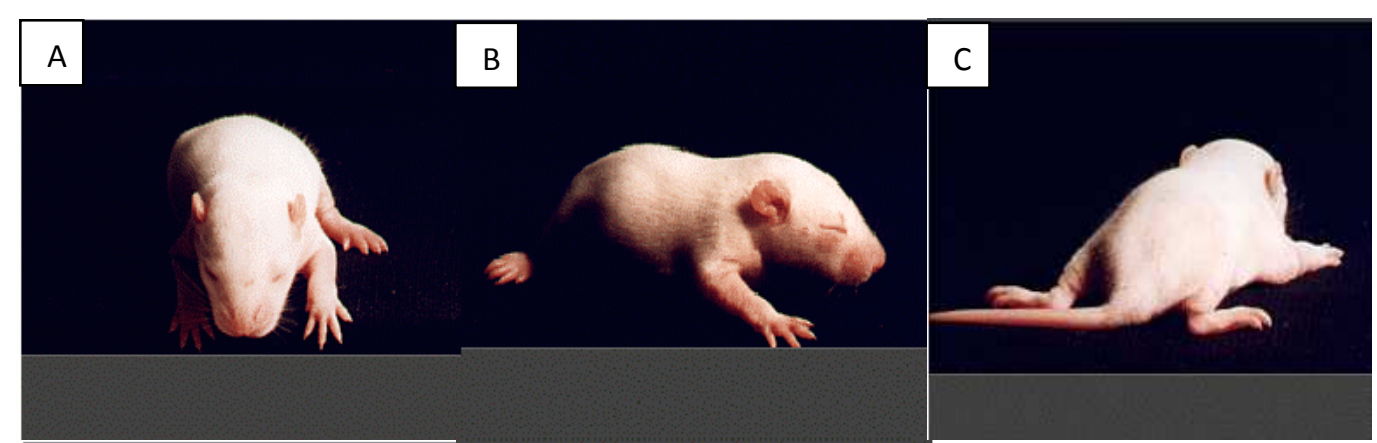

A: indivíduo com as patas sobre a borda de uma superfície plana. B e C: movimento de resposta à AP. Fonte: Vasconcelos (2013).

d) geotaxia negativa (GN): O animal foi colocado no centro de uma rampa com $45^{\circ}$ de inclinação, com a cabeça no sentido descende nte. Considerou-se resposta positiva quando o animal foi capaz de girar o corpo posicionando a cabeça no sentido ascendente dentro de $10 \mathrm{~s}$ (Fig. 11):

Figura 11 - Avaliação da geotaxia negativa (GN).

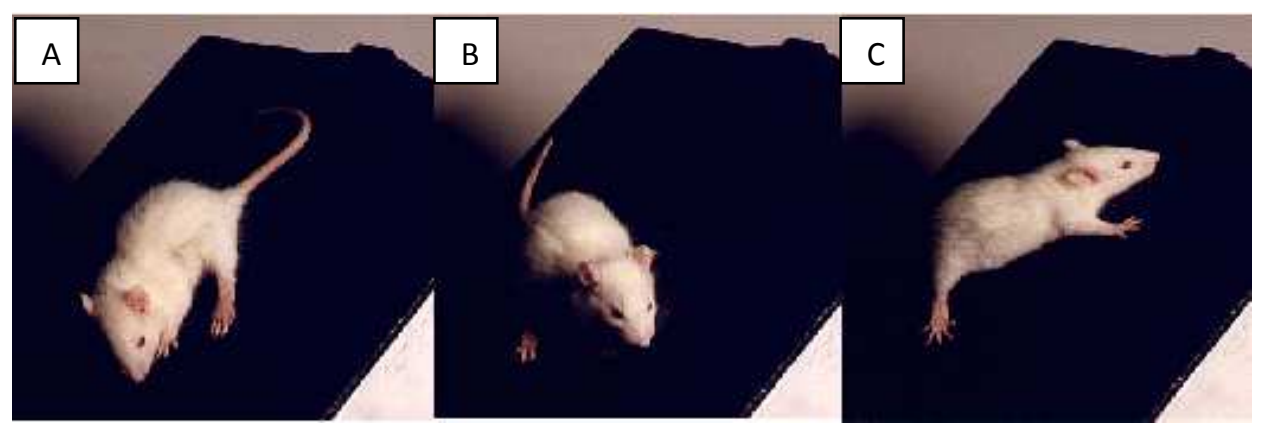

De A a C: movimento de resposta à geotaxia negativa em uma superfície inclinada. Fonte: Vasconcelos (2013).

e) resposta ao susto (RS): O rato foi exposto a um estampido agudo produzido pela percussão de duas estruturas metálicas a uma distância aproximada de $10 \mathrm{~cm}$. Considerou-se resposta positiva quando ocorreu uma retração simultânea com imobilização rápida e involuntária do corpo do animal, característica do susto (Fig. 12); 
Figura 12 - Avaliação da resposta ao susto (RS).

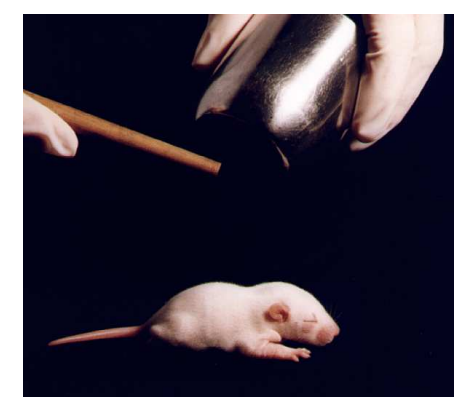

Fonte: Vasconcelos (2013).

f) aceleração (A): $O$ rato foi segurado pelas quatro patas com o dorso voltado para baixo a uma distância de $30 \mathrm{~cm}$ de um leito de espuma sintética $(30 \times 12$ $\mathrm{cm}$ ). Então o animal foi solto e observou-se a sua queda livre. Considerou-se resposta positiva quando, durante a queda, o animal girou completamente $o$ corpo, apoiando-se sobre as quatro patas na espuma;

g) preensão palmar (PP): Colocou-se uma haste fina em contato com a palma das patas anteriores do rato. Considerou-se resposta positiva quando ele realizou um movimento de preensão na haste.

Os dados foram avaliados com ANOVA multifatorial com teste post-hoc de Tukey-Kramer $(p \leq 0,05)$.

\subsection{Labirinto aquático de Morris}

O labirinto utilizado consistiu em uma piscina circular com $200 \mathrm{~cm}$ de diâmetro, $50 \mathrm{~cm}$ de profundidade (Fig. 13) e com as paredes internas e o assoalho pintados de preto. A piscina foi preenchida até a altura de $27 \mathrm{~cm}$ e a água foi mantida entre 23 e $26^{\circ} \mathrm{C}$, para não produzir estresse ou inatividade nos animais. Uma plataforma de acrílico, circular e preta, com $9 \mathrm{~cm}$ de diâmetro e suportada por uma haste com base de apoio, era colocada na piscina a $1,5 \mathrm{~cm}$ abaixo da superfície da água durante os testes, para não ser visível ao animal, pois o objetivo era que $o$ animal encontrasse a plataforma usando um mapa espacial formado a partir de experiências anteriores, e não visualmente. Uma câmera instalada acima 
da piscina, conectada ao programa de computador Etho Vision $\circledast$, registrou o tempo (em segundos) que cada indivíduo utilizou para encontrar a plataforma (latência), o tempo que eles passaram em cada região da área da piscina, descritas no próximo parágrafo, o comprimento do trajeto realizado (em centímetros) e a velocidade média $(\mathrm{cm} / \mathrm{s})$. Quanto menores o percurso feito e o tempo dispendido para chegar até a plataforma, melhor o desempenho do animal (MORRIS et al., 1982). O aumento da velocidade média de uma tentativa para outra também pode ser um indício de melhora cognitiva.

Figura 13 - Esquema do Labirinto aquático de Morris.

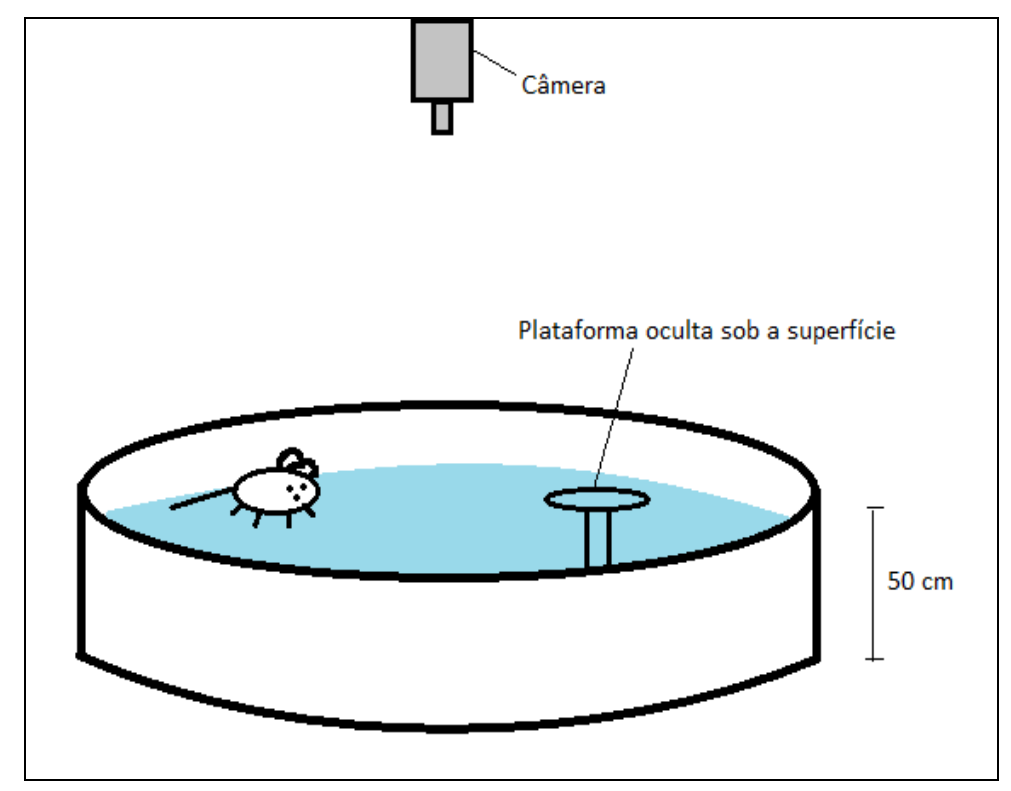

A plataforma sempre se localizou no centro de um dos quatro quadrantes da piscina (Fig. 14). Circundando as regiões onde a plataforma podia se encontrar, havia áreas circulares chamadas contadores. Ao longo da borda da piscina existiam oito pontos de partida onde os animais eram colocados para o início dos testes. 
Figura 14 - Esquema da vista superior do Labirinto Aquático de Morris.

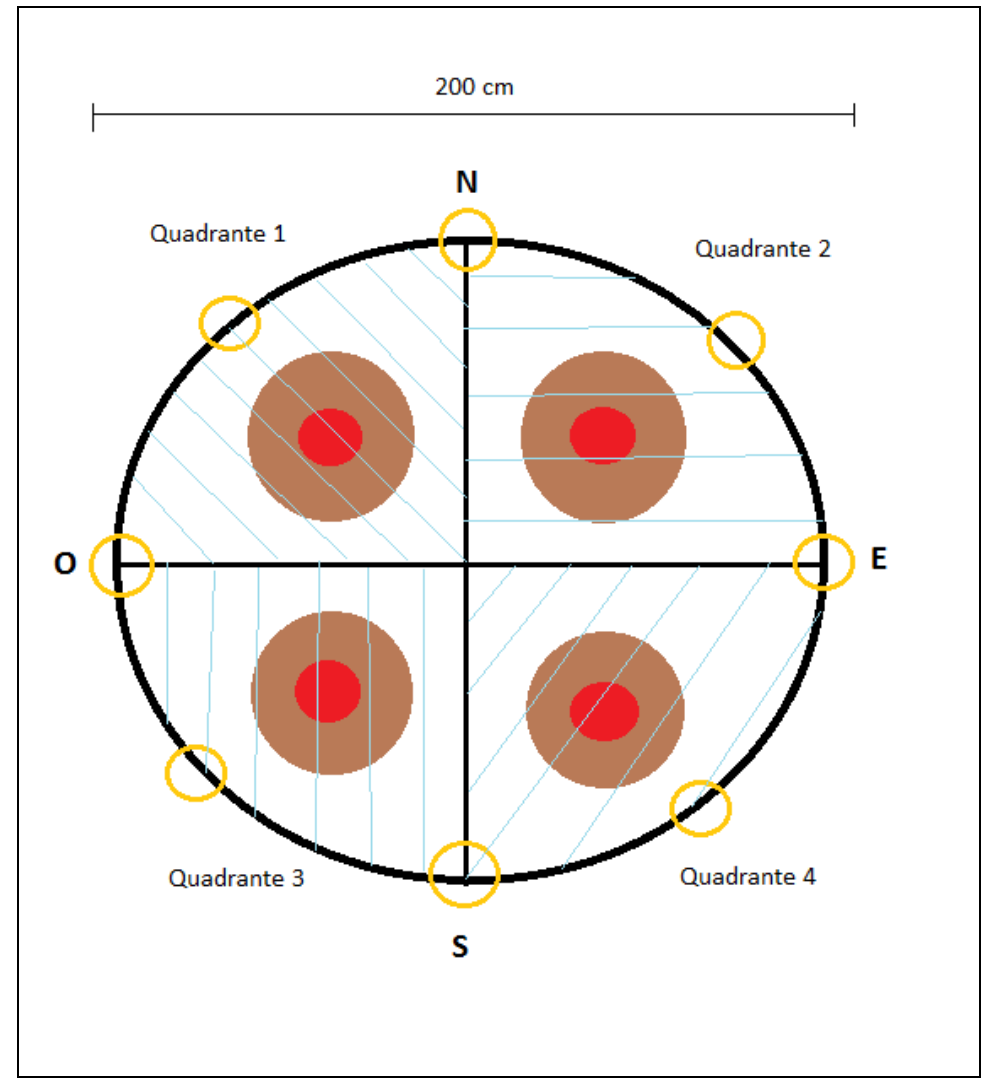

A área da piscina foi dividida em quatro quadrantes (hachurados em azul). No centro de cada quadrante, havia uma região (em vermelho) onde a plataforma podia se localizar. Circundando essas regiões, havia outras regiões (em marrom), os contadores. Os círculos amarelos representavam os locais onde os animais podiam ser colocados no início de cada tentativa. N: norte. E: leste. S: sul. O: oeste.

Vários objetos conspícuos foram estrategicamente posicionados nas paredes da sala do teste para servirem de pistas distais, permitindo que os ratos formassem um mapa espacial enquanto estivessem na piscina.

O teste, iniciado em P60, durou 15 dias (cada dia correspondeu a uma sessão) e em cada dia os animais foram colocados 3 vezes na piscina (cada vez correspondeu a uma tentativa). Em cada tentativa os animais possuíam 2 minutos para alcançar a plataforma. Nas primeiras tentativas das sessões, quando os animais não sabiam que havia uma plataforma ou onde ela estaria, eles poderiam ter encontrado ela por acaso. Se não conseguissem encontra-la dentro de 2 minutos, eles eram conduzidos até a mesma. Uma vez sobre a plataforma, eram mantidos ali por 10 segundos. Depois, eram retirados e submetidos à próxima tentativa 10 minutos depois, partindo de uma posição diferente da anterior. A 
plataforma permaneceu no mesmo quadrante durante as três tentativas da mesma sessão para avaliação da memória espacial de curto prazo, mas foi mudada de quadrante nas outras sessões, para avaliação da memória de longo prazo e flexibilidade comportamental. O quadrante onde estava a plataforma em uma determinada sessão foi chamado de quadrante crítico. Da mesma forma, o contador contido nesse quadrante, foi denominado contador crítico.

Em todos os dados foi avaliada a memória operacional, uma memória onde informações preexistentes (vindas da memória de longa duração) e adquiridas recentemente (memória de curta duração) são utilizadas por certo período de tempo para a tomada de decisões ou execuções de tarefas (JENESON; SQUIRE, 2011).

Os dados foram analisados por ANOVA de medidas repetidas com teste posthoc de Tukey-Kramer ( $p \leq 0,05)$. Para melhor análise e visualização dos dados as sessões foram agrupadas em blocos. O primeiro bloco compreende as primeiras cinco sessões, o segundo bloco abrange as sessões de 6 a 10 e o terceiro bloco é composto pelas demais sessões.

\subsection{Processamento do material biológico para imunohistoquímica}

Após a avaliação do desenvolvimento (P21) ou após o Labirinto Aquático de Morris (P75) os animais foram perfundidos transcardiacamente com solução salina 0,9\% ( $\mathrm{pH} 7,4$, a temperatura ambiente) e solução fixadora de formaldeído (4\% em tampão fosfato, $\mathrm{pH} 7.4$, a $4{ }^{\circ} \mathrm{C}$ ). Após a perfusão os encéfalos foram dissecados, pós-fixados na mesma solução fixadora por 24 horas e crioprotegidos em solução tampão (PBS 0,1 M, pH 7,4) mais sacarose 30\%, por 8 a $12 \mathrm{~h}$. Depois os encéfalos foram cortados em secções de $40 \mu \mathrm{m}$ de espessura em micrótomo (Leica SM2000R), dividindo-se os cortes em 12 séries, preservados em solução antifreeze.

Uma das séries de cada animal foi utilizada para reação de imunohistoquímica com anticorpo primário monoclonal feito em camundongo contra NeuN (Millipore Corporate Headquarters, Billerica, MA, USA) - proteína encontrada em neurônios maduros. Os cortes foram lavados 3 vezes durante 10 minutos em PBS $0,1 \mathrm{M}(\mathrm{pH} 7,4)$, depois foram incubados em solução composta por PBS 0,1 M, soro normal de burro (NDS) (Vector Laboratories, Burlingame, CA, USA) e Triton X- 
100 (Amresco inc., Solon, OH, USA) por 40 minutos para bloqueio. Então, adicionouse o anti-NeuN nesta mesma solução na concentração de 1:60.000 e aguardou-se 24 horas a temperatura ambiente ou 48 horas a $4{ }^{\circ} \mathrm{C}$.

Após este período, os cortes foram lavados 3 vezes com PBS 0,1 M, incubados com solução com anticorpo biotinilado feito em burro contra camundongo (Abcam Inc., Cambridge, MA, USA) na concentração de 1:1000 por 90 minutos, lavados novamente em PBS $0,1 \mathrm{M}$, incubados em solução $A B C$ standard (Vector Laboratories, Burlingame, CA, USA) por 90 minutos, lavados novamente e imersos em solução com DAB (Abcam Inc., Cambridge, MA, USA), para a reação de coloração. O tempo na solução com DAB foi controlado visualmente. Depois, os cortes foram lavados novamente em PBS $0,1 \mathrm{M}$, montados em lâminas, desidratados e as lâminas foram cobertas com lamínulas usando DPX (SigmaAldrich Inc., UK) como meio de montagem.

\subsection{Estereologia}

As quantidades de células marcadas positivamente para NeuN nas secções dos encéfalos de animais em P21 e P75 foram realizadas por estereologia por meio do programa Stereo Investigator (MBF-MicroBrightfield) nas camadas de células piramidais das regiões CA1 e CA3 e na camada granular do giro dentado (GD), na formação hipocampal direita de 4 secções de cada encéfalo (Fig. 15).

Este trabalho baseou-se na anatomia da formação hipocampal conforme apresentada no atlas The rat brain in stereotaxic coordinates (4eeição) de Paxinos e Watson (1998) e no $21^{\circ}$ capítulo do livro The rat nervous system (3a edição) de Paxinos (2004). Neste livro a formação hipocampal é formada pelas regiões CA1, CA2 e CA3, pelo GD e pelo subículo. Porém, neste projeto, a região CA2 foi considerada junto com a região $\mathrm{CA} 3$, dada a dificuldade de distinguir precisamente uma região da outra com as técnicas histológicas empregadas. Além disso, o subículo não foi considerado. 
Figura 15 - Secções analisadas do encéfalo do rato Wistar.

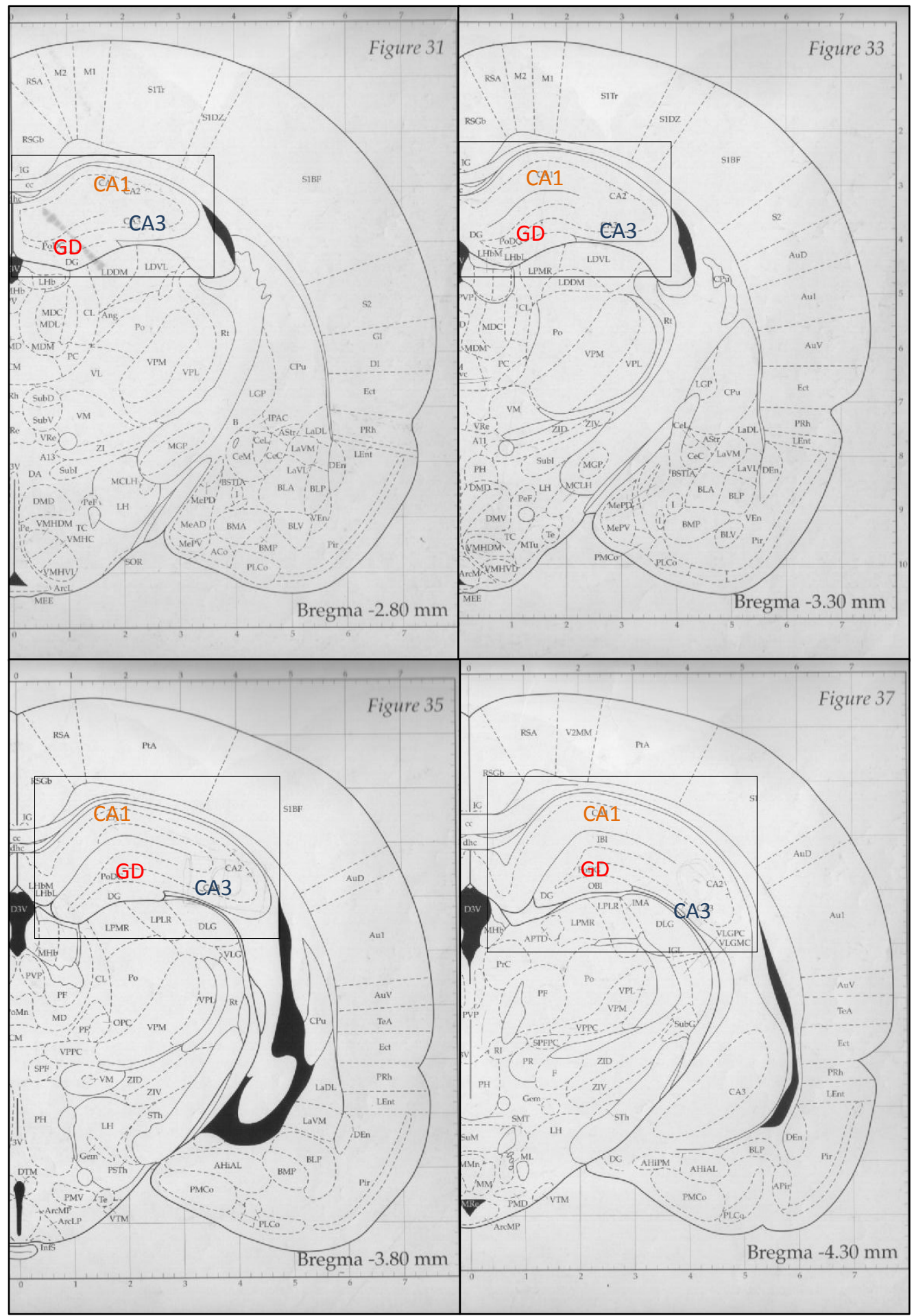

O desenho mostra os níveis das secções utilizadas para as reações de imunohistoquímica e a contagem por estereologia. Dentro dos quadros situam-se as formações hipocampais. $O$ nível da secção está indicado no canto inferior direito de cada imagem. Fonte: Paxinos e Watson (1998) (adaptado). GD: giro dentado. CA3: região CA3. CA1: região CA1. 
O programa dispôs aleatoriamente quadros de contagem posicionados dentro de retículos nas regiões da formação hipocampal delineadas pelo experimentador. $O$ dissector óptico do microscópio foi ajustado para varrer um espaço de $10 \mu \mathrm{m}$ de profundidade em cada quadro de contagem, com zonas de segurança de $1 \mu \mathrm{m}$ no topo e na base da secção. As células contabilizadas foram aquelas dentro do quadro de contagem ou que eram cortadas ou tangenciadas pelas bordas superior e direita do quadro (verdes), exceto aquelas cortadas ou tangenciadas pelas bordas inferior e esquerda (vermelhas) (Fig. 16).

Figura 16 - Quadro de contagem.

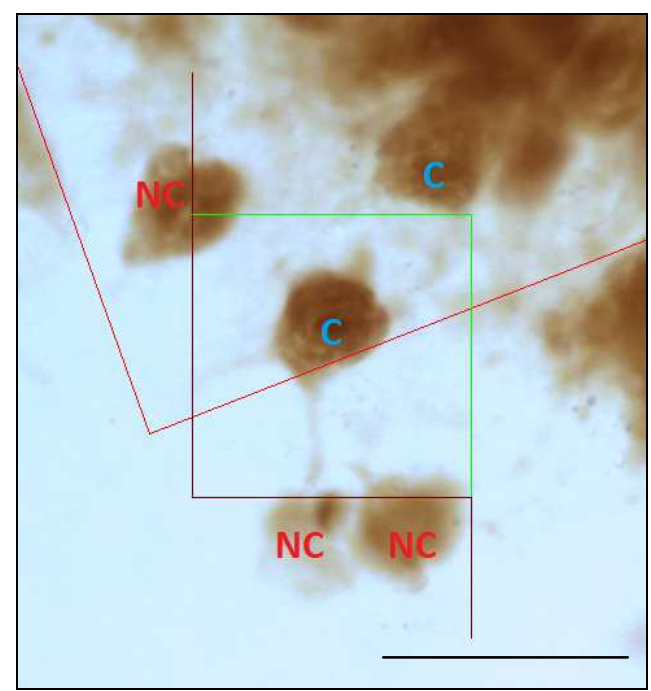

Células nervosas imunorreativas a NeuN na formação hipocampal. C: células contadas são aquelas dentro do quadro de contagem ou que encostam na linha verde sem encostar na linha vermelho-escura. NC: células não-contadas - são aquelas fora do quadro de contagem ou que encostam na linha vermelho-escura, mesmo encostando na linha verde (nem todas as células NC estão indicadas). A linha vermelha mais clara delimita a região contada da secção. Aumento de 40X. Barra de escala $=10 \mu \mathrm{m}$.

A densidade de células positivas foi calculada pelo método estereológico do fracionador óptico (WEST; SLOMIANKA; GUNDERSEN, 1991). Os valores dos parâmetros utilizados na contagem constam na Tabela 3. 
Tabela 3 - Valores dos parâmetros utilizados na contagem

\begin{tabular}{|c|c|}
\hline Parâmetros & Valores \\
\hline Largura do quadro de contagem $(\mathrm{X})(\mu \mathrm{m})$ & 40,0 \\
\hline Altura do quadro de contagem $(\mathrm{Y})(\mu \mathrm{m})$ & 40,0 \\
\hline Área do quadro de contagem $(\mathrm{XY})\left(\mu \mathrm{m}^{2}\right)$ & 1600,0 \\
\hline Largura do retículo $(X)(\mu \mathrm{m})$ & 226,0 \\
\hline Altura do retículo $(\mathrm{Y})(\mu \mathrm{m})$ & 110,0 \\
\hline Área do retículo $(\mathrm{XY})\left(\mu \mathrm{m}^{2}\right)$ & 24860,0 \\
\hline Altura do dissector $(Z)(\mu \mathrm{m})$ & 28,0 \\
\hline Volume do dissector $(\mathrm{XYZ})\left(\mu \mathrm{m}^{3}\right)$ & 44800,0 \\
\hline Distância das zonas de segurança $(\mu \mathrm{m})$ & 1,0 \\
\hline Intervalo entre as secções $(\mu \mathrm{m})$ & 480,0 \\
\hline
\end{tabular}

Os valores das densidades foram submetidos ao teste de normalidade de Shapiro-Wilk e, posteriormente, à análise não-paramétrica de Kruskal-Wallis ( $p \leq$ $0,05)$.

\subsection{Western Blot}

Quando atingiram as idades para Western Blot (P21 e P75) os animais foram anestesiados, decapitados e a formação hipocampal foi retirada bilateralmente. $\mathrm{O}$ material foi armazenado a $4 \stackrel{\circ}{\circ}$ até o momento da extração das proteínas.

Para a extração, o material (contendo ambas as formações hipocampais) foi colocado em $700 \mu \mathrm{l}$ de solução contendo tampão lítico de células de mamíferos, suplementado com benzonase ${ }^{\circledR}$ (Merck KgaA, Darmstadt, HE, Germany) e inibidor de protease. Todos esses produtos vieram de "Qproteome Mammalian Protein Prep Kit” (Qiagen Group). A solução resultante foi homogeneizada e centrifugada a $4 \stackrel{\circ}{ } \mathrm{C}$ por 10 minutos numa velocidade de $14000 \mathrm{xg}$.

O sobrenadante foi separado para quantificação das proteínas por espectrofotometria utilizando o método de Bradford (BRADFORD, 1976), que adota o corante Coomassie briliant blue G-250. 
Após a quantificação, $75 \mu \mathrm{m}$ de proteína foi acrescida em solução contendo Laemmli diluído com DTT 100 mM. Então, as amostras foram colocadas no gel de poliacrilamida de $15 \%$ contendo SDS (SDS-PAGE) (Bio-Rad, Hercules, CA, EUA) para eletroforese. Após este procedimento, foi realizada a transferência das proteínas para membranas de nitrocelulose em $0,2 \%$ Ponceau S.

Após serem bloqueadas por 24 horas, a temperatura de $4 \stackrel{\circ}{\circ} \mathrm{C}$, com leite desnatado (Molico, Nestlê) em tampão Tris-Salina a 5\% e lavadas em tampão TBST (TBS com 0,1\% de Tween 20 [Amresco, Solon, OH, USA]), as membranas foram incubadas com anticorpo primário (anti-sinapsina I feita em coelho [Abcam, Cambridge, MA, USA]) diluído numa concentração de 1:1000 em solução contendo solução basal e leite desnatado $3 \%$ por 24 horas a $4{ }^{\circ} \mathrm{C}$.

Depois, as membranas foram lavadas novamente com solução basal (3X10') e incubadas com anticorpo secundário marcado com peroxidase (Amersham Biosciences, Little Chalfont, Buckinghamshire, UK) diluído numa concentração de 1:1000 por 2 h. Após a última lavagem (3X10') as membranas ficaram imersas em solução de substrato ECL do kit "Ecl western blot detection reagentes" (Amersham Biosciences) e colocadas para revelação no programa Image Studio Digits (LI-COR Biosciences).

Após a revelação as membranas passaram pelo processo de stripping para retirada dos anticorpos e, então, novamente pelos mesmos procedimentos dos dois últimos parágrafos, mas desta vez com anticorpo primário contra $\beta$-actina (Amersham Biosciences, Little Chalfont, Buckinghamshire, UK) e respectivo anticorpo secundário marcado com peroxidase (Amersham Biosciences, Little Chalfont, Buckinghamshire, UK). E, depois, novamente revelada.

Os valores numéricos da intensidade das bandas foram submetidos ao teste de normalidade de Shapiro-Wilk e, posteriormente, à análise não-paramétrica de Kruskal-Wallis $(p \leq 0,05)$. 


\section{RESULTADOS}

\subsection{Crescimento somático}

As curvas de crescimento somático do $2^{\circ}$ ao $21^{\circ}$ dia de vida dos seguintes parâmetros: eixo látero-lateral da cabeça (ELLC), do eixo ântero-posterior da cabeça (EAPC), eixo longitudinal do corpo (EL) e peso corporal (PC) foram iguais. Os grupos EC, SA e EA não apresentaram diferenças significativas entre si, mas exibiram medidas estatisticamente maiores que os do grupo SC, cujos valores foram sempre menores que os dos demais grupos: $\operatorname{ELCC}\left(F_{(3,320)}=82,29 ; p \leq 0,05\right)$ (Fig. 17); $\operatorname{EAPC}\left(F_{(3,320)}=140,42 ; p \leq 0,05\right)$ (Fig. 18); $\operatorname{EL}\left(F_{(3,320)}=233,80 ; p \leq 0,05\right)$ (Fig. 19); $P C\left(F_{(3,320)}=354,26 ; p \leq 0,05\right)$ (Fig. 20). As diferenças entre os grupos apareceram somente a partir do $3^{\circ}, 5^{\circ}$ ou $6^{\circ}$ dias de vida.

Figura 17 - Medida do eixo látero-lateral da cabeça (ELLC) (média £ EP).

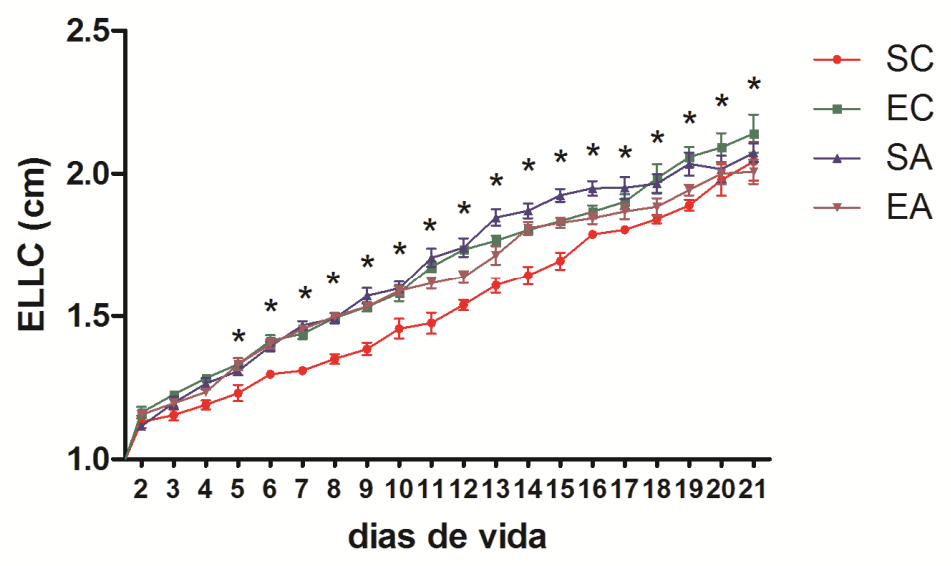

Os asteriscos indicam os dias em que houve diferença estatística entre o grupo SC e os demais. ELLC: eixo látero-lateral; EL: eixo longitudinal do corpo; PC: peso corporal; EAPC: eixo ântero-posterior da cabeça. Os dados foram analisados por ANOVA de medidas repetidas com teste post-hoc de Tukey-Kramer. $n=5$ nos quatro grupos. $p \leq 0,05$. 
Figura 18 - Medida do eixo longitudinal do corpo (EL) (média \pm EP).

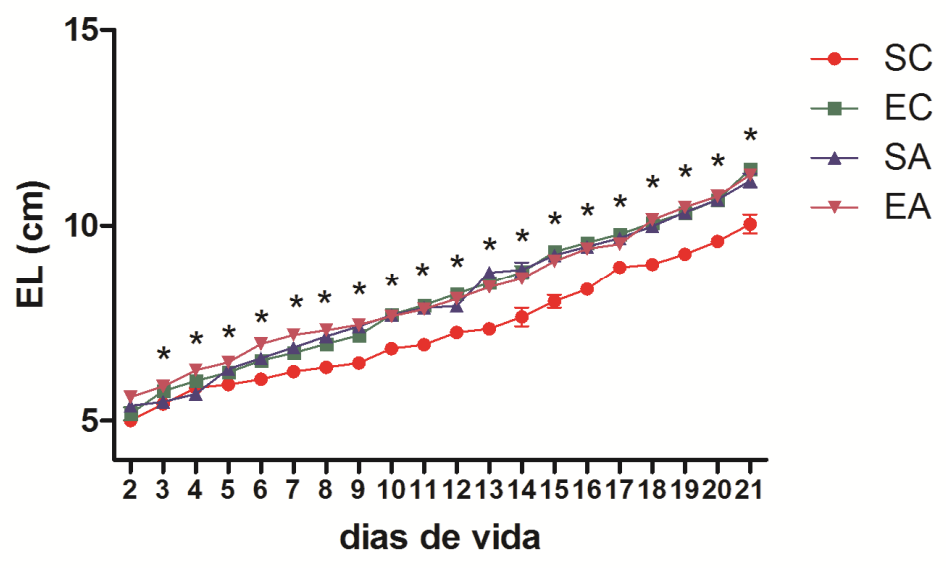

Os asteriscos indicam os dias em que houve diferença estatística entre o grupo SC e os demais. ELLC: eixo látero-lateral; EL: eixo longitudinal do corpo; PC: peso corporal; EAPC: eixo ântero-posterior da cabeça. Os dados foram analisados por ANOVA de medidas repetidas com teste post-hoc de Tukey-Kramer. $n=5$ nos quatro grupos. $p \leq 0,05$.

Figura 19 - Peso corporal (PC) (média \pm EP).

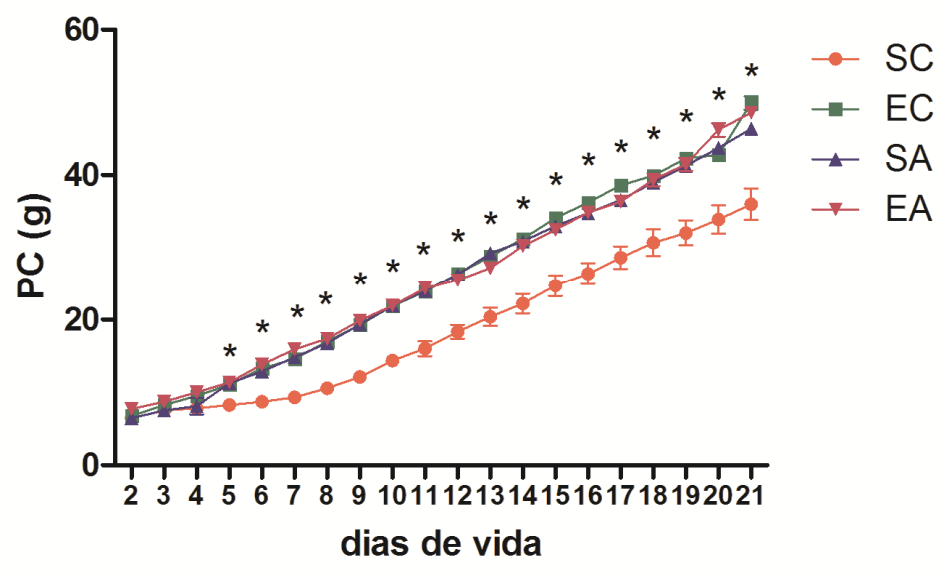

Os asteriscos indicam os dias em que houve diferença estatística entre o grupo SC e os demais. ELLC: eixo látero-lateral; EL: eixo longitudinal do corpo; PC: peso corporal; EAPC: eixo ântero-posterior da cabeça. Os dados foram analisados por ANOVA de medidas repetidas com teste post-hoc de Tukey-Kramer. $n=5$ nos quatro grupos. $p \leq 0,05$. 
Figura 20 - Eixo ântero-posterior da cabeça (EAPC) (média \pm EP).

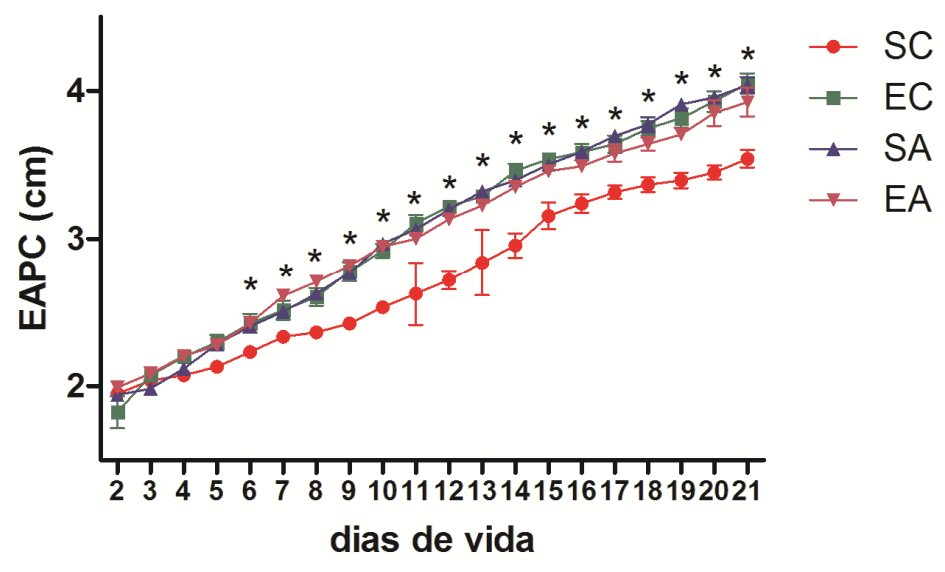

Os asteriscos indicam os dias em que houve diferença estatística entre o grupo SC e os demais. ELLC: eixo látero-lateral; EL: eixo longitudinal do corpo; PC: peso corporal; EAPC: eixo ântero-posterior da cabeça. Os dados foram analisados por ANOVA de medidas repetidas com teste post-hoc de Tukey-Kramer. $n=5$ nos quatro grupos. $p \leq 0,05$.

A análise estatística entre os estímulos exercício materno (E) e sedentarismo (S) revelou valores significantes maiores para $E$, indicando efeito do exercício materno: $\operatorname{ELLC}\left(F_{(1,320)}=49,01 ; p \leq 0,05\right) ; \operatorname{EAPC}\left(F_{(1,130)}=121,92 ; p \leq 0,05\right) ; \operatorname{EL}$ $\left(F_{(1,130)}=276,92 ; p \leq 0,05\right) ; P C\left(F_{(1,130)}=426,28 ; p \leq 0,05\right)$.

Da mesma forma, a análise entre os estímulos anóxia neonatal $(A)$ e controle (C) indicou valores estatisticamente maiores para $A$, mostrando efeito da anóxia neonatal: $\operatorname{ELLC}\left(F_{(1,320)}=35,39 ; p \leq 0,05\right) ; \operatorname{EAPC}\left(F_{(1,320)}=124,30 ; p \leq 0,05\right) ; \operatorname{EL}$ $\left(F_{(1,320)}=276,92 ; p \leq 0,05\right) ; P C\left(F_{(1,320)}=305,35 ; p \leq 0,05\right)$.

\subsection{Maturação de características físicas e ontogênese de reflexos}

A tabela 4 mostra as médias \pm EP dos dias em que as características físicas e os reflexos surgiram nos animais ao longo dos 20 dias de observação. 
Tabela 4 - Surgimento ontogenético dos índices de maturação em dias (média $\pm E P$ ).

\begin{tabular}{|c|c|c|c|c|c|c|}
\hline $\begin{array}{l}\text { Índice de } \\
\text { maturação }\end{array}$ & SC & EC & SA & EA & $\mathbf{F}_{(3,16)}$ & $\mathbf{p}$ \\
\hline \multicolumn{7}{|c|}{ (a) Características físicas } \\
\hline $\begin{array}{l}\text { Desdobramento } \\
\text { do pavilhão } \\
\text { auricular }\end{array}$ & $3,4 \pm 0,21^{\star} \#$ & $3 \pm 0 \&$ & $2 \pm 0 * \&$ & $2,2 \pm 0,17 \#$ & 17,46 & 0,00 \\
\hline $\begin{array}{l}\text { Abertura do } \\
\text { conduto } \\
\text { auditivo }\end{array}$ & $12 \pm 0^{*}$ & $12 \pm 0 \#$ & $12,8 \pm 0,17^{\star} \# \&$ & $12,2 \pm 0,17 \&$ & 7,16 & 0,00 \\
\hline $\begin{array}{l}\text { Abertura dos } \\
\text { olhos }\end{array}$ & $16 \pm 0,28^{\star} \#$ & $14,4 \pm 0,21^{\star} \&$ & $15,6 \pm 0,21 \&$ & $14,8 \pm 0,17 \#$ & 8,20 & 0,00 \\
\hline $\begin{array}{l}\text { Irrupção dos } \\
\text { incisivos } \\
\text { superiores }\end{array}$ & $9,6 \pm 0,6$ & $11 \pm 0,48$ & $9,4 \pm 0,87$ & $9,4 \pm 0,53$ & 1,14 & 0,36 \\
\hline $\begin{array}{l}\text { Irrupção dos } \\
\text { incisivos } \\
\text { inferiores }\end{array}$ & $12,2 \pm 0,59$ & $11,4 \pm 0,35$ & $11,8 \pm 0,17$ & $11,2 \pm 0,17$ & 1,15 & 0,35 \\
\hline \multicolumn{7}{|c|}{ (b) Reflexos sensoriomotores } \\
\hline $\begin{array}{c}\text { Recuperação do } \\
\text { decúbito }\end{array}$ & $4,2 \pm 0,17^{*}$ & $4 \pm 0 \#$ & $6,2 \pm 0,17^{\star} \# \&$ & $4,2 \pm 0,17 \&$ & 35,88 & 0,00 \\
\hline $\begin{array}{c}\text { Colocação pelas } \\
\text { vibrissas }\end{array}$ & $13 \pm 0^{*}$ & $12,2 \pm 0,17^{\star} \# \&$ & $13 \pm 0 \#$ & $12,8 \pm 0,17 \&$ & 3,16 & 0,00 \\
\hline $\begin{array}{l}\text { Aversão ao } \\
\text { precipício }\end{array}$ & $13,2 \pm 0,33^{\star} \#$ & $12,2 \pm 0,33^{*}$ & $16 \pm 0,28$ & $12,6 \pm 0,35 \#$ & 4,82 & 0,01 \\
\hline $\begin{array}{l}\text { Geotaxia } \\
\text { negativa }\end{array}$ & $13,2 \pm 0,33^{\star}$ & $12,2 \pm 0,33 \#$ & $16 \pm 0,28^{\star} \# \&$ & $12,6 \pm 0,35 \&$ & 21,82 & 0,00 \\
\hline $\begin{array}{l}\text { Resposta ao } \\
\text { susto }\end{array}$ & $\begin{array}{c}14,4 \pm \\
0,35^{\star} \# \&\end{array}$ & $12,2 \pm 0,17^{*}$ & $13 \pm 0 \#$ & $12,4 \pm 0,21 \&$ & 15,17 & 0,00 \\
\hline Aceleração & $15 \pm 0^{*}$ & $14 \pm 0$ & $12,8 \pm 0,65^{*}$ & $13,8 \pm 0,43$ & 4,17 & 0,02 \\
\hline $\begin{array}{l}\text { Preensão } \\
\text { palmar }\end{array}$ & $3 \pm 0^{*}$ & $2,2 \pm 0,17 \#$ & $6 \pm 0,48^{\star} \# \&$ & $2,2 \pm 0,17 \&$ & 34,35 & 0,00 \\
\hline
\end{tabular}

Valores marcados com os mesmos símbolos $\left({ }^{*}\right.$, \# e \&) dentro de um parâmetro indicam diferenças entre os grupos. Os dados foram analisados por ANOVA multifatorial com teste post-hoc de Tukey-Kramer. $n=5$ nos quatro grupos. $p \leq 0,05$.

Em relação à abertura do canal auditivo $(\mathrm{ACA})$, à resposta ao decúbito $(\mathrm{RD})$, à geotaxia negativa $(\mathrm{GN})$ e à preensão palmar (PP) houve atraso do seu aparecimento pela anóxia neonatal $(C<A)\left[A C A: F_{(1,16)}=12,50 ; p \leq 0,05\right.$; $R D$ : $\left.F_{(1,16)}=40,33 ; p \leq 0,05 ; G N: F_{(1,16)}=18,96 ; p \leq 0,05 ; P P: F_{(1,16)}=23,68 ; p \leq 0,05\right]$ enquanto o exercício materno adiantou o seu surgimento $(S>E)\left(A C A: F_{(1,16)}=\right.$ 
4,50; $p \leq 0,05 ; R D: F_{(1,16)}=40,33 ; p \leq 0,05 ; G N: F_{(1,16)}=35,85 ; p \leq 0,05 ; P P: F_{(1,16)}=$ 55,68; $p \leq 0,05)$, sendo também capaz de reverter 0 atraso provocado pela anóxia, como mostrado no grupo $E A(S C=E A<A S)\left(A C A: F_{(3,16)}=7,16 ; p \leq 0,05\right.$; RD: $F_{(3,16)}=35,88 ; p \leq 0,05 ; G N: F_{(3,16)}=21,82 ; p \leq 0,05 ; P P: F_{(3,16)}=34,35 ; p \leq$ 0,05).

$\mathrm{Na}$ aversão ao precipício (AP), abertura ocular (AO) e colocação pelas vibrissas $(C V)$ o exercício materno foi capaz de adiantar o seu surgimento $(S>$ E) (AP: $F_{(1,16)}=14,23 ; p \leq 0,05 ; A O: F_{(1,16)}=22,15 ; p \leq 0,05 ; C V: F_{(1,16)}=12,50 ; p \leq$ $0,05)$ e a anóxia neonatal não apresentou efeitos significativos $(C=A)$ ( $A P$ : $\left.F_{(1,16)}=0,11 ; p=0,73 ; A O: F_{(1,16)}=0,00 ; p=1,00 ; C V: F_{(1,16)}=4,5 ; p>0,05\right)$.

$\mathrm{Na}$ resposta ao susto (RS), tanto o exercício materno quanto a anóxia neonatal adiantaram o aparecimento desse reflexo $(S>E)\left(F_{(1,16)}=30,15 ; p \leq\right.$ $0,05)$ e $(C>A)\left(F_{(1,16)}=5,53 ; p \leq 0,05\right)$.

Quanto ao desdobramento do pavilhão auricular (DPA) e à aceleração (A), a anóxia antecipou o surgimento $(C>A)\left(D P A: F_{(1,16)}=48,40 ; p \leq 0,05 ; A: F_{(1,16)}=\right.$ 7,38; $p \leq 0,05)$, enquanto que o exercício não apresentou efeito $(S=E)$ (DPA: $\left.F_{(1,16)}=0,40 ; p=0,53 ; A: F_{(1,16)}=0,00 ; p=1,00\right)$.

Por fim, na irrupção dos incisivos superiores (IIS) e inferiores (III) não houve diferenças significativas entre os grupos (IIS: $F_{(3,16)}=1,14 ; p=0,36 ;$ III: $F_{(3,16)}=$ $1,15 ; p=0,35)$.

\subsection{Labirinto aquático de Morris}

$\mathrm{Na}$ latência (Fig. 21) não houve efeito do exercício $\left(F_{(1,1317)}=2,66 ; p=0,10\right)$ nem da anóxia neonatal $\left(F_{(1,1317)}=2,66 ; p=0,10\right)$ (Fig. 18). Houve efeito da sessão (a latência média de todos os animais diminuiu ao longo das sessões) $\left(F_{(14,1317)}=\right.$ 20,09; $p \leq 0,05$ ) e da tentativa (a latência média de todos os animais diminuiu ao longo das tentativas) $\left(F_{(2,1317)}=402,05 ; p \leq 0,05\right)$, indicando que os animais se comportaram da forma esperada. Também houve interação exercício-anóxia $\left(F_{(1,1317)}=12,06 ; p \leq 0,05\right)$ e interação exercício-tentativa $\left(F_{(2,1317)}=3,19 ; p \leq 0,05\right)$ e sessão-tentativa $\left(F_{(28,13)}=1,50 ; p \leq 0,05\right)$. 
Figura 21 - Latência.(média \pm EP).

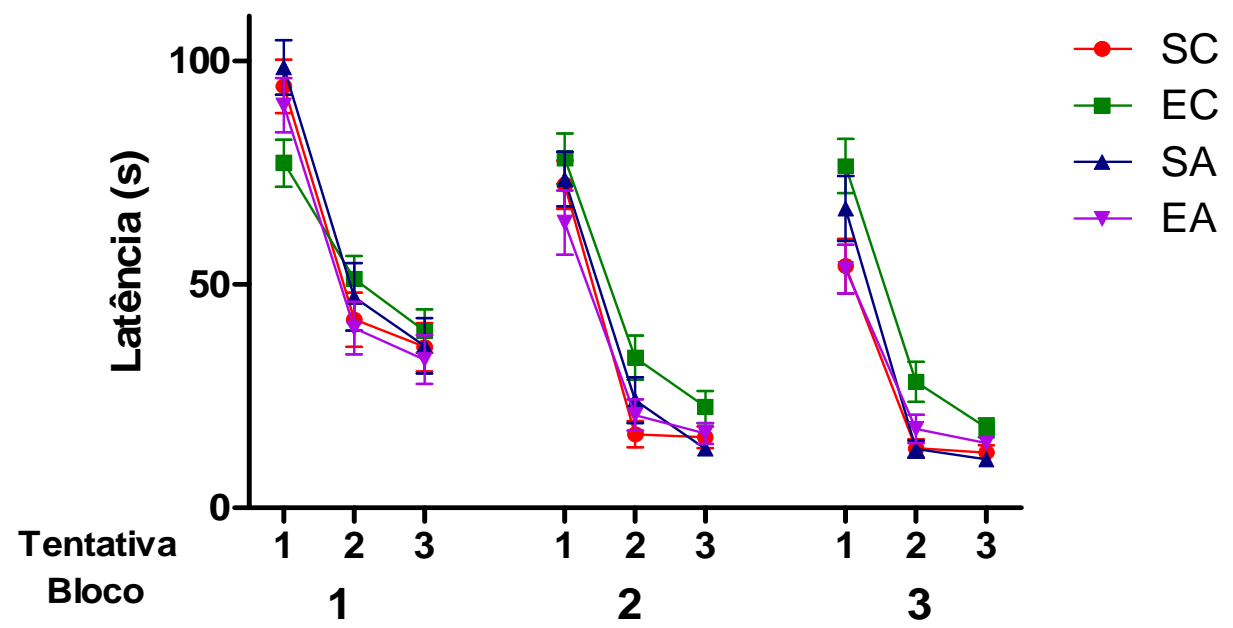

Bloco 1: sessões de 1 a 5. Bloco 2: sessões de 6 a 10. Bloco 3: sessões de 11 a 15 . Os dados foram analisados por ANOVA de medidas repetidas com teste post-hoc de TukeyKramer. SC: $n=10$. EC: $n=17$. SA: $n=11$. EA: $n=14 \cdot p \leq 0,05$.

No percurso (Fig. 22) não houve efeito do exercício $\left(F_{(1,1317)}=3,22 ; p=\right.$ $0,07)$ nem da anóxia $\left(F_{(1,1317)}=2,5 ; p=0,11\right)$. Houve efeito da sessão $\left(F_{(14,1317)}=\right.$ $10,60 ; p \leq 0,05)$, da tentativa $\left(F_{(2,1317)}=311,00 ; p \leq 0,05\right)$ e interação exercícioanóxia $\left(F_{(1,1317)}=9,98 ; p \leq 0,05\right)$, exercício-sessão $\left(F_{(14,1317)}=3,21 ; p \leq 0,05\right)$ e sessão-tentativa $\left(F_{(28,1317)}=1,62 ; p \leq 0,05\right)$.

Figura 22 - Percurso (média \pm EP).

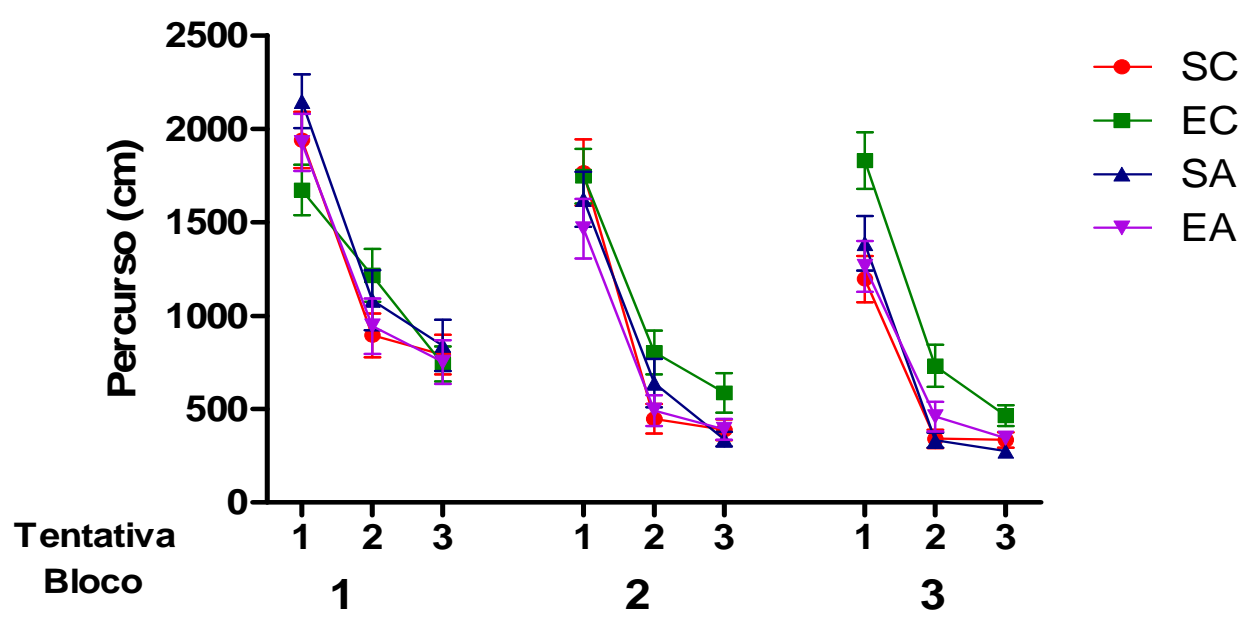

Bloco 1: sessões de 1 a 5. Bloco 2: sessões de 6 a 10. Bloco 3: sessões de 11 a 15. Os dados foram analisados por ANOVA de medidas repetidas com teste post-hoc de TukeyKramer. SC: $n=10$. EC: $n=17$. SA: $n=11$. EA: $n=14 . p \leq 0,05$. 
Na velocidade (Fig. 23) não houve efeito do exercício $\left(F_{(1,1317)}=0,59 ; p=\right.$ $0,80)$, mas houve efeito da anóxia neonatal, em que $C>A\left(F_{(1,1317)}=19,27 ; p \leq\right.$ $0,05)$, efeito de sessão $\left(F_{(14,1317)}=3,72 ; p \leq 0,05\right)$ e de tentativa $\left(F_{(2,1317)}=24,65 ; p \leq\right.$ $0,05)$. Também houve interação exercício-anóxia $\left(F_{(2,1317)}=6,39 ; p \leq 0,05\right)$ e sessão-tentativa $\left(F_{(28,1317)}=1,73 ; p \leq 0,05\right)$.

Figura 23 - Velocidade (média \pm EP).

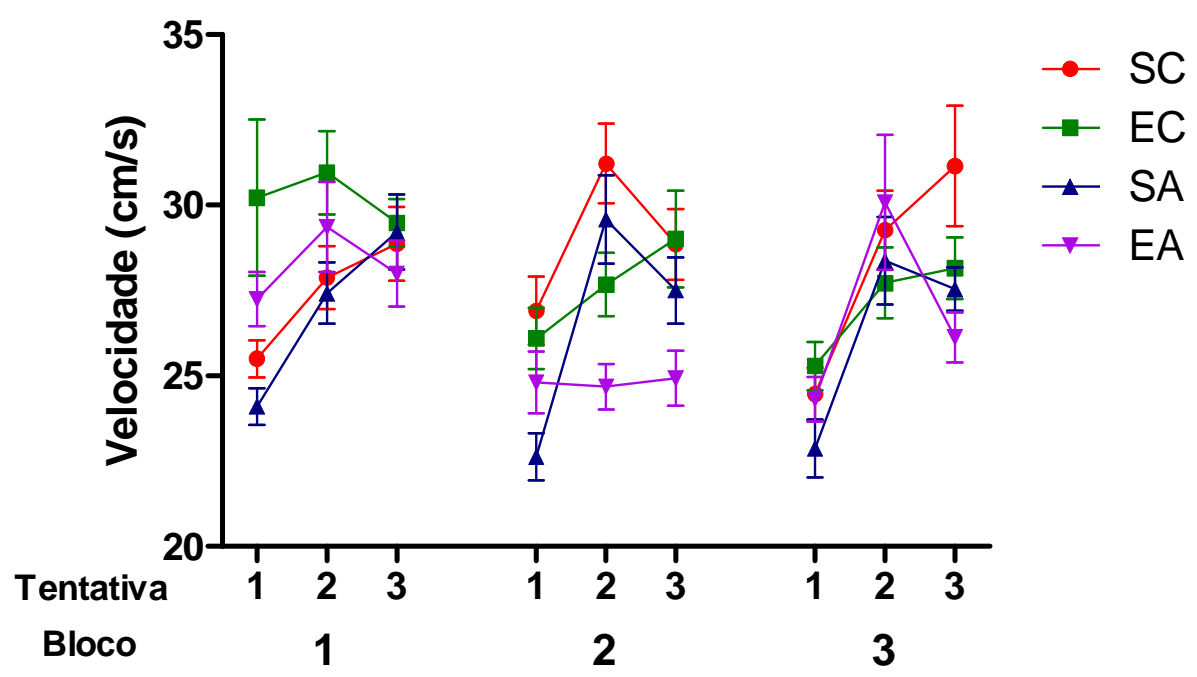

Bloco 1: sessões de 1 a 5. Bloco 2: sessões de 6 a 10. Bloco 3: sessões de 11 a 15. Os dados foram analisados por ANOVA de medidas repetidas com teste post-hoc de TukeyKramer. SC: $n=10$. EC: $n=17 . S A: n=11$. EA: $n=14 . p \leq 0,05$.

\subsection{Densidade de células com NeuN}

Segundo o teste de normalidade de Shapiro-Wilk o número de células imunorreativas a NeuN na formação hipocampal e suas regiões analisadas (GD, CA3 e CA1) não apresentaram distribuição normal, então o número de células foi submetido ao teste não-paramétrico de Kruskal-Wallis. As fotomicrografias das lâminas estão organizadas na Figura 24.

Nas camadas granular e piramidais da formação hipocampal inteira (exceto subículo) não houve diferença entre os grupos dentro de uma mesma idade, nem entre as idades dentro de um mesmo grupo $\left(\mathrm{H}_{(7, \mathrm{~N}=36)}=11,77 ; \mathrm{p}=0,10\right)$ (Fig. 25). 
Figura 24 - Fotomicrografias da formação hipocampal mostrando células imunopositivas a NeuN.

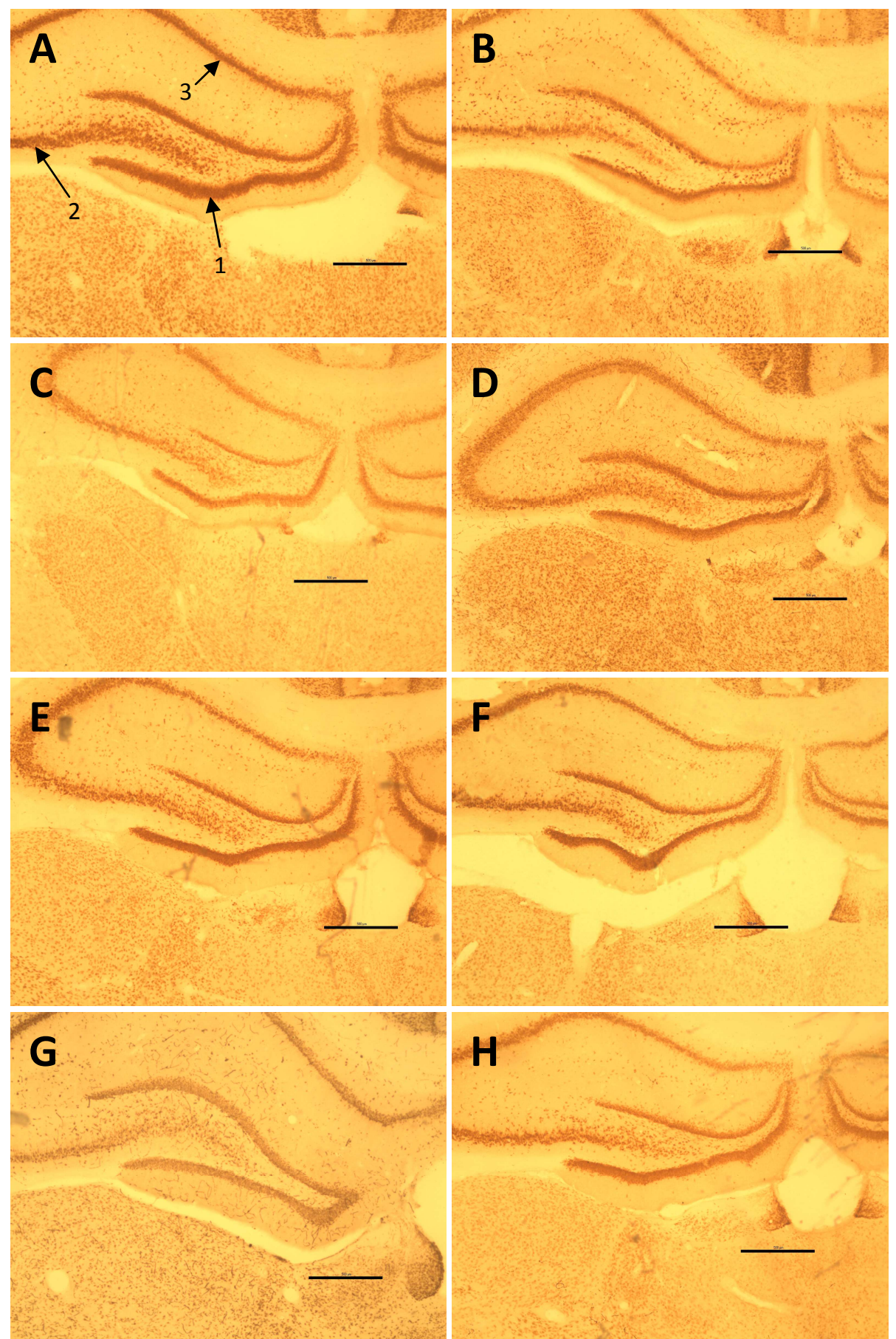

(A) SC-P21; (B) EC-P21; (C) SA-P21; (D) EA-P21; (E) SC-P75; (F) EC-P75; (G) SA-P75; (H) EA-P75. 1 = Camada granular do giro dentado; 2 = Camada piramidal da região CA3; 3 = Camada piramidal da região CA1. Barra de escala $=500 \mu \mathrm{m}$. 
Figura 25 - Densidade de células imunopositivas para NeuN na formação hipocampal (média \pm EP).

Hipocampo

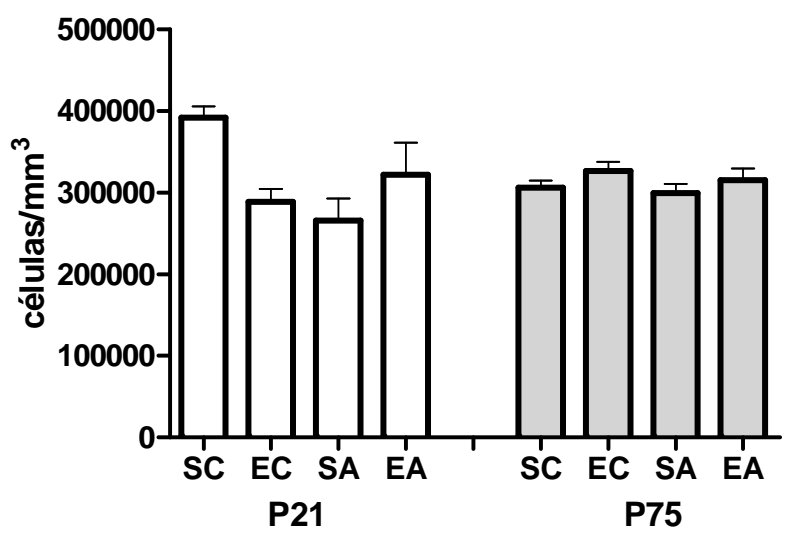

Os dados foram analisados pelo teste não-paramétrico de Kruskal-Wallis. P21-SC: $\mathrm{n}=3$. P21-EC: $n=5$. P21-SA: $n=5$. P21-EA: $n=3$. P75-SC: $n=5$. P75-EC: $n=5$. P75-SA: $n=5$. P75-EA: $n=5 . p \leq 0,05$.

Figura 26 - Densidade de células imunopositivas para NeuN na camada granular do giro dentado (GD).

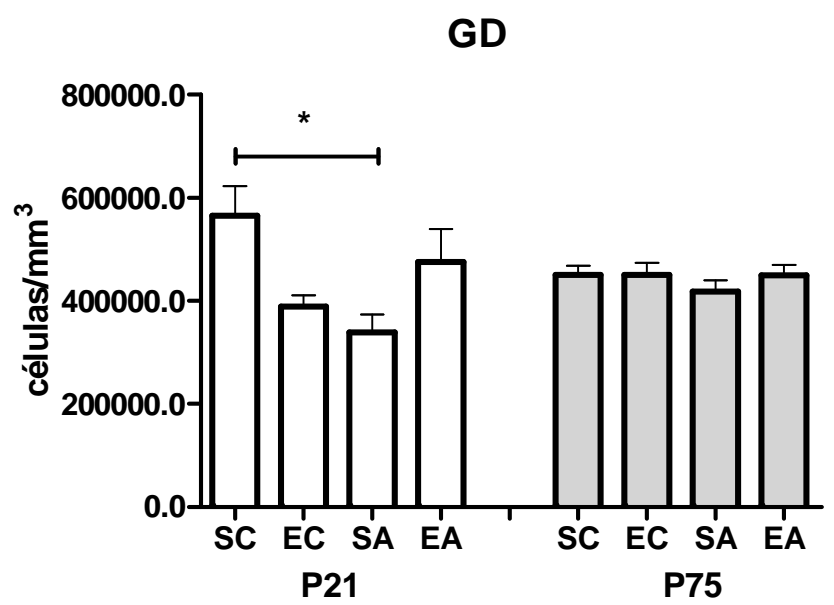

Os dados foram analisados pelo teste não-paramétrico de Kruskal-Wallis. P21-SC: $\mathrm{n}=3$. P21-EC: $n=5$. P21-SA: $n=5$. P21-EA: $n=3$. P75-SC: $n=5$. P75-EC: $n=5$. P75-SA: $n=5$. $P 75-E A: n=5$.

$\mathrm{Na}$ camada granular do giro dentado foi detectada diferença $\left(\mathrm{H}_{(7, \mathrm{~N}=36)}=15,77\right.$; $p \leq 0,05)$ entre os grupos SC e SA $(p \leq 0,05)$, sendo que animais que sofreram 
anóxia apresentaram menor número de células imurreativas a NeuN que os animais controle (Fig. 26).

$\mathrm{Na}$ camada piramidal da região CA3 não houve diferença entre os grupos dentro de uma mesma idade nem entre as idades dentro de um mesmo grupo, exceto entre SC-P21 e SA-P75 (não representada no respectivo gráfico) $\left(\mathrm{H}_{(7, \mathrm{~N}=36)}=\right.$ 13,82; $p \leq 0,05$ ) (Fig. 27).

Figura 27 - Densidade de células imunopositivas para NeuN na camada piramidal de CA3.

\section{CA3}

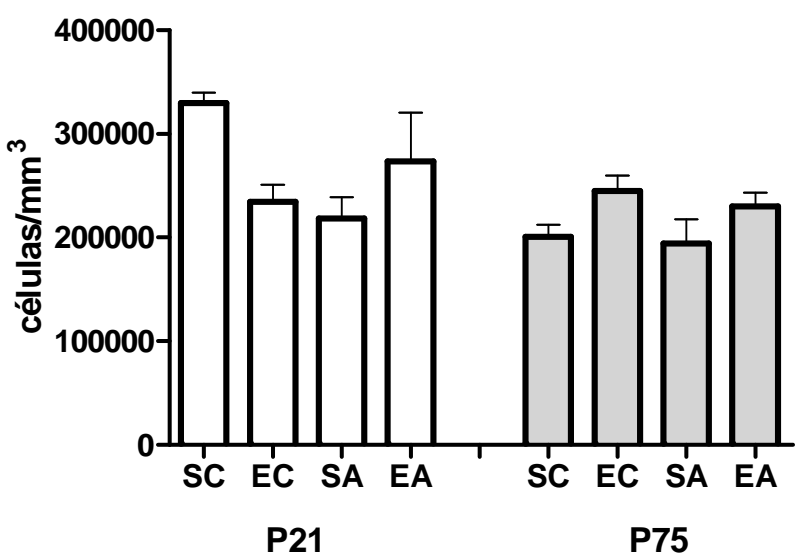

Os dados foram analisados pelo teste não-paramétrico de Kruskal-Wallis. P21-SC: $n=3$. P21-EC: $n=5$. P21-SA: $n=5$. P21-EA: $n=3$. P75-SC: $n=5$. P75-EC: $n=5$. P75-SA: $n=5$. P75-EA: $\mathrm{n}=5$.

$\mathrm{Na}$ camada piramidal da região CA1 não foi detectada diferença entre os grupos dentro de uma mesma idade nem entre as idades de dentro de um mesmo grupo $\left(H_{(7, N=36)}=9,28 ; p=0,23\right)$ (Fig. 28). 
Figura 28 - Densidade de células imunopositivas para NeuN na camada piramidal de CA1.

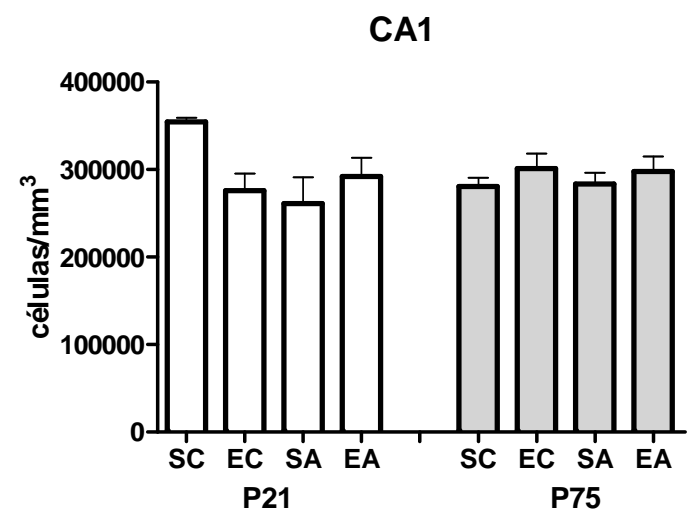

Os dados foram analisados pelo teste não-paramétrico de Kruskal-Wallis. P21-SC: $n=3$. P21-EC: $n=5$. P21-SA: $n=5$. P21-EA: $n=3$. P75-SC: $n=5$. P75-EC: $n=5$. P75-SA: $n=5$. $P 75-E A: n=5$.

\subsection{Western Blot}

Figura 29 - \% de sinapsina I no hipocampo (média \pm EP).

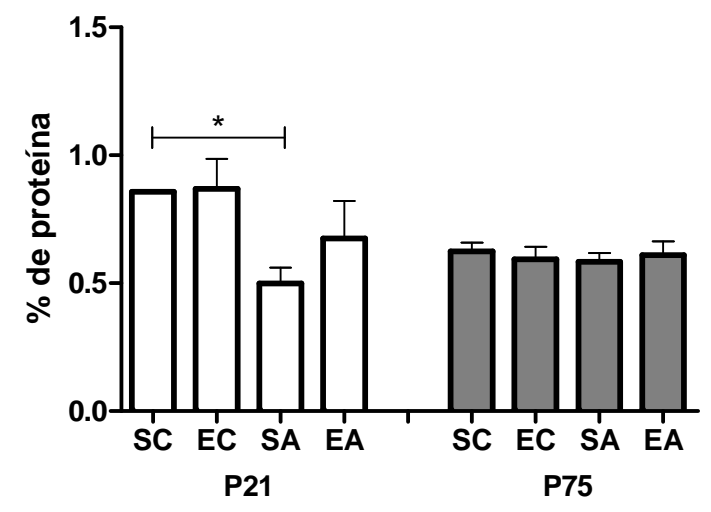

P21

P75

SC EC SA EA

SC EC SA EA

\section{Sinapsina I}
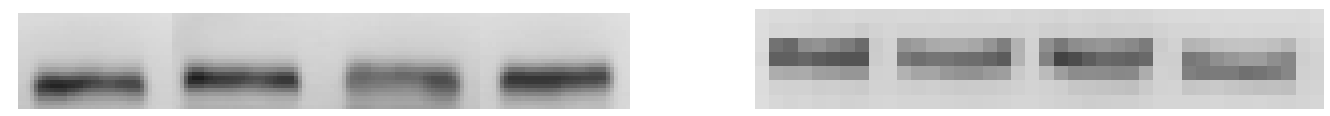

\section{$\beta$-actina}

Os dados foram analisados pelo teste não-paramétrico de Kruskal-Wallis. P21-SC: $n=4$. P21-EC: $n=5$. P21-SA: $n=4$. P21-EA: $n=5$. P75-SC: $n=4$. P75-EC: $n=5$. P75-SA: $n=4$. P75-EA: $n=5$. 
Segundo o teste de normalidade de Shapiro-Wilk os dados da intensidade das bandas da sinapsina I não possuem distribuição normal, então eles foram tratados com o teste não-paramétrico de Kruskal-Wallis.

Foi detectada diferença significativa na expressão relativa de sinapsina I $\left(\mathrm{H}_{(7}\right.$, $\mathrm{N}=36)=15,82 ; \mathrm{p} \leq$ 0,05). Em P21, o grupo SA exibiu valores menores que SC (Fig. 29). 


\section{DISCUSSÃO}

De uma forma geral a anóxia perinatal isoladamente foi prejudicial para os indivíduos em muitos parâmetros estudados neste trabalho, enquanto o exercício físico isoladamente foi benéfico em alguns. Em certos parâmetros, entretanto, os estímulos apresentaram efeitos contrários ao esperado. Ademais, houve casos em que um dos estímulos isoladamente não influenciou os parâmetros analisados, mas a ação conjunta dos dois estímulos promoveu ação significativa. Em outros casos, a ação conjunta foi diferente do que a simples soma dos efeitos dos dois estímulos.

Tanto a anóxia neonatal quanto o exercício materno aumentaram o peso dos animais. Pereira e Procianoy (2003) observaram redução dos níveis de hormônios tireoidianos (T4, T3 e FT4) e do hormônio estimulante da tireoide (TSH) em seres humanos recém-nascidos com 18 a 24 horas de vida após asfixia perinatal, o que pode promover redução do metabolismo e ganho de peso. Rosa et al. (2013) constataram que os filhotes de fêmeas que se exercitaram apresentam maior porcentagem de massa gorda e menor porcentagem de massa magra que os animais controle. Esses autores especulam que esses resultados possam ter advindo de uma redução no nível basal de atividade ou a um aumento na propensão das células-tronco em se diferenciarem em adipócitos ao invés de células musculares, que talvez indique um descompasso entre o ambiente placentário a que estavam expostos e o ambiente pós-natal. Contudo é importante ressaltar que a hipóxia intermitente em seres humanos causa o efeito contrário: ela possivelmente estimula a liberação de leptina no organismo, reduzindo a ingestão calórica e levando à perda de massa (KAYSER; VERGES, 2013). Possivelmente, por ser um estímulo agudo, e não crônico, a anóxia neonatal provocou efeito oposto ao da hipóxia intermitente. Os mecanismos que levam a alterações metabólicas sob condições de pouco oxigênio e de exercício materno, bem como a relação existente entre os dois estímulos no metabolismo, ainda precisam ser melhor explorados.

Quanto ao aumento das dimensões corporais, um dos fatores que influenciam esse parâmetro é o resultado dos processos dinâmicos envolvendo o desenvolvimento, a liberação de cálcio e a reabsorção óssea. Vários fatores estão envolvidos nesses processos, desde a expressão do hormônio de crescimento, que 
está reduzido em indivíduos expostos a algum tipo de asfixia perinatal (RAFF et al., 2001; ZHANG; DU, 2000), a aumentos na reabsorção óssea após exercício materno (ROSA et al., 2013). Outro fator a ser considerado, no caso do exercício materno, é o aumento do tamanho fetal devido à melhora da função placentária, resultante da adaptação às graduais reduções de oxigênio e nutrientes placentários durante o exercício (CLAPP, 2003). Além disso, no crânio, o seu crescimento pode ser resultado de edema encefálico ou de algum tipo de hidrocefalia após asfixia perinatal (FERRARI; NESIC; PEREZ-POLO, 2010; MAO et al., 2014).

Em cada reflexo há o envolvimento de várias estruturas específicas, sendo que o aparecimento ontogenético deles reflete a ocorrência simultânea dos vários eventos sucessivos do desenvolvimento do sistema nervoso central (FOX, 1965).

Em relação à geotaxia negativa $(G N)$, à resposta ao decúbito $(R D)$ e à aceleração (A) é importante observar a existência de três sistemas periféricos envolvidos na regulação e na correção postural: sistema vestibular, extereoceptivo e proprioceptivo (ALTMAN; SUDARSHAN, 1975). A anóxia atrasou o aparecimento das respostas de correção de posição na GN e RD e isso está relacionado aos danos que ela provoca no sistema auditivo e vestibular (KOYAMA et al., 2005). Já o exercício materno adiantou-os, evidenciando efeito neuroprotetor na ontogênese motora (SCHINDER; POO, 2000) e no sistema vestibular (ERNFORS et al., 1995; FRITZSCH et al., 1997), além de reverter o atraso promovido pela anóxia. A preensão palmar (PP) e a aversão ao precipício (AP), que também dependem do desenvolvimento sensoriomotor para a sua execução, sofreram as mesmas influências que a GN e a RD; a anóxia atrasou o seu aparecimento e o exercício adiantou e reverteu o atraso da anóxia. A aceleração, entretanto, sofreu apenas influência positiva da anóxia, indicando que nem todos os reflexos associados à correção da postura são afetados pelo exercício e negativamente pela privação de oxigênio.

Várias neurotrofinas e seus receptores regulam a sobrevivência de neurônios vestibulares e cocleares e provavelmente também os neurônios eferentes e autônomos que inervam o ouvido interno. O BDNF e o NT-3 e os seus respectivos receptores associados são absolutamente necessários para o desenvolvimento normal da inervação aferente do ouvido interno (ERNFORS et al., 1995; FRITZSCH 
et al., 1997). Isso condiz com o fato de que os filhotes de mães exercitadas terem apresentado resposta ao susto (RS) antes dos animais controle. A asfixia perinatal, por sua vez, estimula a apoptose em várias células do ouvido interno (SCHMUTZHARD et al., 2009) sendo necessário maior aprofundamento nessa questão para entender porque ela promoveu o adiantamento da RS.

As vibrissas estão intimamente relacionadas com o córtex somatossensorial primário, o córtex barril e a formação hipocampal em roedores, pois as vibrissas ajudam na navegação espacial (principalmente subterrânea) e no forrageamento (POLLEY; KVASNAK; FROSTIG, 2004). A literatura relata que tanto a estimulação das vibrissas quanto aplicações de BDNF estimulam a plasticidade nessas estruturas, o que, por sua vez, sensibiliza e acentua a resposta das próprias vibrissas (GOMEZ-PINILLA et al., 2011). Tais observações condizem com os resultados encontrados nesta dissertação, pois o exercício materno adiantou o aparecimento da resposta à colocação pela vibrissa $(\mathrm{CV})$, que poderiam estar mais sensibilizadas nos animais do grupo exercício devido à possível ação do BDNF.

A deficiência de tiamina atrasa a abertura ocular em ratos (BÂ, 2012), sendo que o exercício aeróbico aumenta os seus níveis no organismo (FRANK et al., 2000) o que possivelmente influenciou o adiantamento da abertura ocular $(A O)$ dos filhotes de mães exercitadas. A anóxia neonatal não provocou alterações em relação ao tempo de surgimento da característica, indicando que provavelmente ela não atue sobre os mecanismos que levem à $\mathrm{AO}$.

A anóxia adiantou o aparecimento da abertura do conduto auditivo (ACA) e atrasou o surgimento do desdobramento do pavilhão auditivo (DPA), enquanto 0 exercício adiantou o aparecimento de DPA e reverteu o atraso da anóxia. Nenhum dos dois estímulos influenciou na irrupção dos incisivos superiores (IIS) e inferiores (III). Estas características somáticas e a AO são reguladas por diferentes fatores de crescimento e vias moleculares, mostrando que o exercício materno e a anóxia atuam especificamente em certos aspectos do desenvolvimento.

Em animais P21 observamos menor quantidade de células imunopositivas para NeuN (neurônios maduros) em SA que em SC, no GD. O giro dentado está envolvido principalmente nos processos de separação de padrões e reconhecimento de padrões, que melhoram a discriminação entre dois padrões semelhantes no 
momento do seu armazenamento e da sua evocação, diminuindo as chances de serem confundidos (DREW; FUSI; HEN, 2013; HUNSAKER; KESNER, 2013; KESNER, 2007; O'REILLY; MCCLELLAND, 1994; SCHMIDT et al., 2012). Para a execução desses processos é necessária a atuação de neurônios jovens e quanto maior a neurogênese no GD, melhor é o desempenho desses processos (DREW; FUSI; HEN, 2013). Também se discute a função do GD na memória espacial em conjunção com a região CA3 (KESNER, 2007). Ainda nos animais P21, há menor expressão relativa de sinapsina I nos animais do grupo SA que SC, em concordância com a ação degeneradora da anóxia neonatal em estruturas relacionadas às sinapses e no desempenho cognitivo (MORETTO et al., 1999). Assim, além dos prejuízos sensoriomotores, a anóxia também pode provocar prejuízos cognitivos nessa idade.

O exercício materno realizado neste protocolo alterou o desenvolvimento sensório-motor, indicando que o seu efeito se deu principalmente nas regiões do sistema nervoso diretamente relacionadas às respostas motoras, como, por exemplo, na medula espinal, cuja neurogênese ocorre juntamente no período do exercício materno deste projeto (do 5을 $15^{\circ} \mathrm{DG}$ em ratos) (RICE; BARONE, 2000). Talvez o exercício materno afete o neocortex somente e estritamente no período de maior suscetibilidade do mesmo. Ademais, no Western Blot e no GD o grupo EA não foi significativamente diferente dos grupos $S A$ e EC, o que indica que o exercício amenizou os efeitos negativos da anóxia, embora não tenha exercido efeito isoladamente.

A falta de diferença na densidade neuronal e na expressão relativa de sinapsina I em P75 dos animais que sofreram anóxia pode ser resultado de uma possível recuperação do animal. Neste caso, é importante notar que no Labirinto aquático de Morris não houve efeito do exercício nem da anóxia na latência e no percurso. A diferença encontrada na velocidade de nado média pode decorrer da hiperatividade comumente envolvida nos casos de privação de oxigênio (MOROZOVA; BELOUSOVA, 2009).

Estes resultados mostram que o exercício materno espontâneo atua contra os efeitos negativos da anóxia neonatal em vários parâmetros inéditos, como na ontogênese dos reflexos sensoriomotres e das características físicas estudadas, 
bem como na expressão relativa de sinapsina I no giro dentado do hipocampo, fortalecendo ainda mais o efeito neuroprotetor do exercício materno espontâneo. 


\section{CONCLUSÕES}

Neste projeto identificamos diferentes atuações do exercício materno espontâneo e da anóxia neonatal em diferentes aspectos do desenvolvimento somático, sensoriomotor e nervoso. Apesar disso, de uma forma geral, a anóxia neonatal foi prejudicial e o exercício materno foi benéfico para os indivíduos e conseguiu reverter muitos dos problemas decorrentes da anóxia:

- A anóxia neonatal atrasou o aparecimento da abertura do conduto auditivo (ACA), da abertura ocular $(\mathrm{AO})$, da resposta ao decúbito $(\mathrm{RD})$, da aversão ao precipício (AP), da geotaxia negativa (GN) e da preensão palmar (PP) e o exercício materno espontâneo foi capaz de reverter o atraso.

- A anóxia neonatal diminuiu a densidade neuronal e a expressão relativa de sinapsina I no GD de animais P21. O exercício materno espontâneo foi capaz de atenuar tais diminuições.

- Os efeitos da anóxia neonatal e do exercício materno espontâneo não perduraram na vida adulta em relação à densidade de neurônios e expressão relativa de sinapsina I no giro dentado. No Labirinto aquático de Morris não houve efeito do exercício materno espontâneo nem da anóxia neonatal na latência e no percurso, indicando possível recuperação dos animais.

Portanto, o exercício materno espontâneo tem o potencial de ser utilizado antecipadamente como fator atenuador da anóxia neonatal. 


\section{REFERÊNCIAS ${ }^{1}$}

Akhavan MM, Foroutan T, Safari M, Sadighi-Moghaddam B, Emami-Abarghoie M, Rashidy-Pour A. Prenatal exposure to maternal voluntary exercise during pregnancy provides protection against mild chronic postnatal hypoxia in rat offspring. Pak J Pharm Sci. 2012;25(1):233-8.

Allemandi W. Estudo da imunorreatividade da proteína $S 100 \beta$ no hipocampo e núcleo do trato solitário de ratos neonatos submetidos à anóxia. [tese (Doutorado em Ciências Morfofuncionais)]. São Paulo: Instituto de Ciências Biomédicas, Universidade de São Paulo; 2011.

Altman J, Sudarshan K. Postnatal development of locomotion in the laboratory rat. Anim Behav. 1975;23(4):896-920.

Apgar V. A proposal for a new method of evaluation of the newborn infant. Curr Res Anesth Analg. 1953;32(4):260-7.

Armstrong-Wells J, Bernard TJ, Boada R, Manco-Johnson M. Neurocognitive outcomes following neonatal encephalopathy. Neuro Rehabilitation. 2010;26(1):2733.

Bâ A. Paradoxical effects of alcohol and thiamine deficiency on the eye opening in rat pups. J Matern Fetal Neonatal Med. 2012;25(11):2435-40.

Back SA, Rosenberg PA. Pathophysiology of glia in perinatal white matter injury. Glia. 2014;62(11):1790-815.

Barnes DE, Yaffe K, Satariano WA, Tager IB. A longitudinal study of cardiorespiratory fitness and cognitive function in healthy older adults. J Am Geriatr Soc. 2003;51:459-65.

Bell RJ, Palma SM, Lumley JM. The effect of vigorous exercise during pregnancy on birth-weight. Aust N Z J Obstet Gynaecol. 1995;35(1):46-51.

Boog G. Cerebral palsy and perinatal asphyxia (I- Diagnosis). Gynecol Obstet Fertil. 2010;38(4):261-77.

Bradford MM. A rapid and sensitive method for the quantitation of microgram quantities of protein utilizing the principle of protein-dye binding. Anal Biochem. 1976;72:248-54.

\footnotetext{
${ }^{1}$ De acordo com:

International Committee of Medical Journal Editors. [Internet]. Uniform requirements for manuscripts submitted to Biomedical Journal: sample references. [updated 2011 Jul 15]. Available from: http://www.icmje.org
} 
Bungum TJ, Peaslee DL, Jackson AW, Perez MA. Exercise during pregnancy and type of delivery in nulliparae. J ObstetGynecol Neonatal Nurs. 2000;29(3):258-64.

Caputa M, Rogalska J, Wentowska K, Nowakowska A. Perinatal asphyxia, hyperthermia and hyperferremia as factors inducing behavioural disturbances in adulthood: a rat model. Behav Brain Res. 2005;63(2):246-56.

Castillo-Melendez M, Yawno T, Jenkin G, Miller SL. Stem cell therapy to protect and repair the developing brain: a review of mechanisms of action of cord blood and amnion epithelial derived cells. Front Neurosci. 2013;7:194.

Chen $\mathrm{XL}$, Jiang $\mathrm{L}$. [Physical training improves spatial learning and memory impairments following hypoxic ischemic brain damage in neonatal rats]. Zhongguo Dang Dai Er Ke Za Zhi. 2010;12(5):363-7. Chinese.

Choi JH, Kim TS, Park JK, Sim YJ, Kim K, Lee SJ. Short-term treadmill exercise preserves sensory-motor function through inhibiting apoptosis in the hippocampus of hypoxic ischemia injury rat pups. J Exerc Rehabil. 2013;9(5):457-62.

Clapp JF 3rd. The effects of maternal exercise on fetal oxygenation and fetoplacental growth. Eur J Obstet Gynecol Reprod Biol. 2003;110 Suppl 1:S80-5.

Clapp JF 3rd, Kim H, Burciu B, Lopez B. Beginning regular exercise in early pregnancy: effect on fetoplacental growth. Am J Obstet Gynecol. 2000;183(6):14848.

Clerici G1, Luzietti R, Di Renzo GC. Monitoring of antepartum and intrapartum fetal hypoxemia: pathophysiological basis and available techniques. Biol Neonate. $2001 ; 79(3-4): 246-53$.

Coq JO, Strata F, Russier M, Safadi FF, Merzenich MM, Byl NN, Barbe MF. Impact of neonatal asphyxia and hind limb immobilization on musculoskeletal tissues and S1 map organization: implications for cerebral palsy. ExpNeurol. 2008;210(1):95-108.

Crawford JS, Davies P, Pearson JF. Significance of the individual components of the Apgar score. Br J Anaesth. 1973;45(2):148-58.

Cunha AA, Fernandes DS, Melo PF, Guedes MH. Fatores Associados à Asfixia Perinatal. RBGO. 2004;26(10):799-805.

Daripa M, Caldas HMG, Flores LPO, Waldvogel BC, Guinsburg R, Almeida MFB. Perinatal asphyxia associated with early neonatal mortality: populational study of avoidable deaths. Rev Paul Pediatr. 2013;31(1):37-45.

Dayi A, Agilkaya S, Ozbal S, Cetin F, Aksu I, Gencoglu C, Cingoz S, Pekcetin $\mathrm{C}$, Tugyan K, Kayatekin BM, Uysal N. Maternal aerobic exercise during pregnancy can increase spatial learning by affecting leptin expression on offspring's early and late period in life depending on gender. Scientific World Journal. 2012;2012:429-803. 
Deiró TC, Manhães-de-Castro R, Cabral-Filho JE, Souza SL, Freitas-Silva SR, Ferreira LM, Guedes RC, Câmara CR, Barros KM. Neonatal administration of citalopram delays somatic maturation in rats. Braz $\mathrm{J}$ Med Biol Res. 2004;37(10):1503-9.

Deiró TC, Manhães-de-Castro R, Cabral-Filho JE, Barreto-Medeiros JM, Souza SL, Marinho SM, Castro FM, Toscano AE, Jesus-Deiró RA, Barros KM. Sertraline delays the somatic growth and reflex ontogeny in neonate rats. Physiol Behav. 2006;87(2):338-44.

Dell'Anna ME, Calzolari S, Molinari M, luvone L, Calimici R. Neonatal anoxia induces transitory hyperactivity, permanent spatial memory deficits and CA1 cell density reduction in developing rats. Behav Brain Res. 1991;45(2):125-34.

Dobbing J, Smart JL. Vulnerability of developing brain and behaviour. Br Med Bull. 1974;30(2):164-8.

Drew LJ, Fusi S, Hen R. Adult neurogenesis in the mammalian hippocampus: why the dentate gyrus? Learn Mem. 2013;20(12):710-29.

Dwarkanath P, Muthayya S, Vaz M, Thomas T, Mhaskar A, Mhaskar R, Thomas A, Bhat $S$, Kurpad A. The relationship between maternal physical activity during pregnancy and birth weight. Asia Pac J Clin Nutr. 2007;16(4):704-10.

Ernfors P, Van De Water T, Loring J, Jaenisch R. Complementary roles of BDNF and NT-3 in vestibular and auditory development. Neuron. 1995;14(6):1153-64.

Ezmerli NM. Exercise in pregnancy. Prim Care Update Ob Gyns. 2000;7(6): 260-5.

Ferrari DC, Nesic O, Perez-Polo JR. Perspectives on neonatal hypoxia/ischemiainduced edema formation. Neurochem Res. 2010;35(12):1957-65.

Finster M, Wood M. The Apgar score has survived the test of time. Anesthesiology. 2005;102(4):855-7.

Fox WM. Reflex-ontogeny and behavioural development of the mouse. Anim Behav. 1965;13(2):234-41.

Francisco RPV, Yamamoto RM, Miyadahira S, Cunha CL, Zugaib M. Correlação entre testes para avaliação da vitalidade fetal, $\mathrm{pH}$ da artéria umbilical e os resultados neonatais em gestações de alto risco. Ver Bras Ginecol Obstetr. 2000;22(8):503-10.

Frank T, Kühl M, Makowski B, Bitsch R, Jahreis G, Hübscher J. Does a 100-km walking affect indicators of vitamin status? Int J Vitam Nutr Res. 2000;70(5):238-50. 
Fritzsch B, Silos-Santiago I, Bianchi LM, Fariñas I. The role of neurotrophic factors in regulating the development of inner ear innervation. Trends Neurosci. 1997;20(4):159-64.

Funayama CAR. Anóxia neonatal e sequelas neurológicas. Campinas: Átomo; 2005.

Galeano P, Blanco Calvo E, Madureira de Oliveira D, Cuenya L, Kamenetzky GV, Mustaca AE, Barreto GE, Giraldez-Alvarez LD, Milei J, Capani F. Long-lasting effects of perinatal asphyxia on exploration, memory and incentive downshift. Int $\mathbf{J}$ Dev Neurosci. 2011;29(6):609-19.

Gomez-Pinilla F, Ying Z, Agoncillo T, Frostig R. The influence of naturalistic experience on plasticity markers in somatosensory cortex and hippocampus: effects of whisker use. Brain Res. 2011;1388:39-47.

Gulczyńska E, Gadzinowski J. Therapeutic hypothermia for neonatal hypoxicischemic encephalopathy. Ginekol Pol. 2012;83(3):214-8.

Hamasaki MY. Avaliação temporal e expressão gênica e proteica de $S 100 \beta$ no encéfalo de ratos neonatos submetidos à anóxia. [tese (Mestrado em Ciências Morfofuncionais)]. São Paulo: Instituto de Ciências Biomédicas, Universidade de São Paulo; 2013.

Hatch MC, Shu XO, McLean DE, Levin B, Begg M, Reuss L, Susser M. Maternal exercise during pregnancy, physical fitness, and fetal growth. Am J Epidemiol. 1993;137(10):1105-14.

Heffernan AE. Exercise and pregnancy in primary care. Nurse Pract. 2000;25(3):42, 49, 53-6 passim.

Herrera-Marschitz M, Neira-Pena T, Rojas-Mancilla E, Espina-Marchant P, Esmar D, Perez R, Muñoz V, Gutierrez-Hernandez M, Rivera B, Simola N, Bustamante D, Morales P, Gebicke-Haerter PJ. Perinatal asphyxia: CNS development and deficits with delayed onset. Front Neurosci. 2014;8:47.

Hillman $\mathrm{CH}$, Snook EM, Jerome GJ. Acute cardiovascular exercise and executive control function. Int J Psychophysiol. 2003;48:307-14.

Hopkins SA, Baldi JC, Cutfield WS, McCowan L, Hofman PL.Exercise training in pregnancy reduces offspring size without changes in maternal insulin sensitivity. J Clin Endocrinol Metab. 2010;95(5):2080-8.

Horvath G, Reglödi D, Farkas J, Vadasz G, Mammel B, Kvarik T, Bodzai G, Kiss-Illes B, Farkas D, Matkovits A, Manavalan S, Gaszner B, Tamas A, Kiss P. Perinatal positive and negative influences on the early neurobehavioral reflex and motor development. Adv Neurobiol. 2015;10:149-67. 
Hunsaker MR, Kesner RP. The operation of pattern separation and pattern completion processes associated with different attributes or domains of memory. Neurosci Biobehav Rev. 2013;37(1):36-58.

Ito $\mathrm{PH}$. Avaliação comportamental de ratos submetidos à anóxia neonatal. [tese (Mestrado em Neurociências e Comportamento)]. São Paulo: Instituto de Psicologia, Universidade de São Paulo; 2010.

Jacobs SE, Berg M, Hunt R, Tarnow-Mordi WO, Inder TE, Davis PG. Cooling for newborns with hypoxic ischaemic encephalopathy. Cochrane Database Syst Rev.2013.

Jeneson A, Squire LR. Working memory, long-term memory, and medial temporal lobe function. Learn Mem. 2011;19(1):15-25.

$\begin{array}{llll}\text { Ji Y, Pang PT, Feng L, Lu } & \text { B. Cyclic AMP controls BDNF- }\end{array}$ induced TrkB phosphorylation and dendritic spine formation in mature hippocampal neurons. Nat Neurosci. 2005;8(2):164-72.

Kamijo K, Nishihira Y, Higashiura T, Kuroiwa K. The interactive effect of exercise intensity and task difficulty on human cognitive processing. Int $\mathrm{J}$ Psychophysiol. 2007;65:114-21.

Kayser B, Verges S. Hypoxia, energy balance and obesity: from pathophysiological mechanisms to new treatment strategies. Obes Rev. 2013;14(7):579-92.

Kesner RP. A behavioral analysis of dentate gyrus function. Prog Brain Res. 2007;163:567-76.

Kim H, Lee SH, Kim SS, Yoo JH, Kim CJ. The influence of maternal treadmill running during pregnancy on short-term memory and hippocampal cell survival in rat pups. Int J Dev Neurosci. 2007;25(4):243-9.

Kleim JA, Cooper NR, VandenBerg PM. Exercise induces angiogenesis but does not alter movement representations within rat motor cortex. Brain Res. 2002;934(1):1-6.

Koyama S, Kaga K, Sakata H, lino Y, Kodera K. Pathological findings in the temporal bone of newborn infants with neonatal asphyxia. Acta Otolaryngol. 2005;125(10):1028-32.

Kramer AF, Hahn S, Cohen NJ, Banich MT, McAuley E, Harrison CR. Ageing, fitness and neurocognitive function. Nature. 1999;400:418-9.

Kurinczuk JJ, White-Koning M, Badawi N. Epidemiology of neonatal encephalopathy and hypoxic-ischaemic encephalopathy. Early Hum Dev. 2010;86(6):329-38.

Lee HH, Kim H, Lee JW, Kim YS, Yang HY, Chang HK, Lee TH, Shin MC, Lee MH, Shin MS, Park S, Baek S, Kim CJ. Maternal swimming during pregnancy enhances 
short-term memory and neurogenesis in the hippocampus of rat pups. Brain Dev. $2006 ; 28(3): 147-54$.

Lin TW, Chen SJ, Huang TY, Chang CY, Chuang JI, Wu FS, Kuo YM, Jen CJ. Different types of exercise induce differential effects on neuronal adaptations and memory performance. Neurobiol Learn Mem. 2012;97(1):140-7.

Lobo N, Yang B, Rizvi M, Ma D. Hypothermia and xenon: novel noble guardians in hypoxic-ischemic encephalopathy? J Neurosci Res. 2013;91(4):473-8.

Lohmann C, Kessels HW. The developmental stages of synaptic plasticity. J Physiol. 2014;592(Pt 1):13-31.

Lokey EA, Tran ZV, Wells CL, Myers BC, Tran AC. Effects of physical exercise on pregnancy outcomes: a meta-analytic review. Med Sci Sports Exerc. $1991 ; 23(11): 1234-9$.

Lorek A, Takei Y, Cady EB, Wyatt JS, Penrice J, Edwards AD, Peebles D, Wylezinska M, Owen-Reece H, Kirkbride V. Delayed ("secondary") cerebral energy failure after acute hypoxia-ischemia in the newborn piglet: continuous 48-hour studies by phosphorus magnetic resonance spectroscopy. Pediatr Res. 1994;36(6):699-706.

MacDonald HM, Mulligan JG, Allen AC, Taylor PM. Neonatal asphyxia. I. Relationship to obstetrical and neonatal complications to neonatal mortality in 38,405 consecutive deliveries. J Pediatr. 1980;96:898-902.

Majeed R, Memon Y, Majeed F, Shaikh NP, Rajar UD. Risk factors of birth asphyxia. J Ayub Med Coll Abbottabad. 2007;19(3):67-71.

Mao J, Yu JL, Fu XM, Wang TH. [Changes on the expression of aquaporin-4 is associated with edema of brain in neonatal rats subjected to hypoxic Ischemic brain damage]. Sichuan Da Xue Xue Bao Yi Xue Ban. 2014;45(3):386-9, 409. [Chinese].

Marcelino TB, Longoni A, Kudo KY, Stone V, Rech A, de Assis AM, Scherer EB, da Cunha MJ, Wyse AT, Pettenuzzo LF, Leipnitz G, Matté C. Evidences that maternal swimming exercise improves antioxidant defenses and induces mitochondrial biogenesis in the brain of young Wistar rats. Neuroscience. 2013;246:28-39.

Marcondes FK, Bianchi FJ, Tanno AP. Determination of the estrous cycle phase of rats: some helpful considerayions. Braz J Biol. 2002;62(4A):609-14.

Marques-Aleixo I, Oliveira PJ, Moreira PI, Magalhães J, Ascensão A. Physical exercise as a possible strategy for brain protection: evidence from mithocondrialmediated mechanisms. Prog Neurobiol. 2012;99(2):149-62.

Marsál K, Löfgren O, Gennser G.Fetal breathing movements and maternal exercise. Acta Obstet Gynecol Scand. 1979;58(2):197-201. 
McMorris T, Collard K, Corbett J, Dicks M, Swain JP. A test of the catecholamines hypothesis for an acute exercise-cognition interaction. Pharmacol Biochem Behav. 2008;89(1):106-15.

Moretto MB, de Mattos-Dutra A, Arteni N, Meirelles R, de Freitas MS, Netto CA, Pessoa-Pureur R. Effects of neonatal cerebral hypoxia-ischemia on the in vitro phosphorylation of synapsin 1 in rat synaptosomes. Neurochem Res. 1999;24(10):1263-9.

Morozova EA, Belousova MB. Attention deficit hyperactivity syndrome: evolution, clinical presentations, treatment. Zh Nevrol Psikhiatrlm S S Korsakova. 2009;109(2):31-4.

Morris RG, Garrud P, Rawlins JN, O'Keefe J. Place navigation impaired in rats with hippocampal lesions. Nature. 1982;297(5868):681-33.

Nakajima W, Ishida A, Lange MS, Gabrielson KL, Wilson MA, Martin LJ, Blue ME, Johnston MV. Apoptosis has a prolonged role in the neurodegeneration after hypoxic ischemia in the newborn rat. $\mathrm{J}$ Neurosci. 2000;20(21):7994-8004.

Nomura RMY, Francisco RPV, Miyadahira S, Zugaib M. Cardiotocografia em gestações com diástole zero ou reversa nas artérias umbilicais: análise dos resultados perinatais. Ver Assoc Med Bras. 2003;49(1):79-85.

Northington FJ, Chavez-Valdez R, Martin LJ. Neuronal cell death in neonatal hypoxia-ischemia. Ann Neurol. 2011;69(5):743-58.

O'Reilly RC, McClelland JL. Hippocampal conjunctive encoding, storage, and recall: avoiding a trade-off. Hippocampus. 1994;4(6):661-82.

Otellin VA, Khozhai LI, Shishko TT. [Reactions of the interneuronal synapses of rat brain to hypoxia during the early postnatal period]. Morfologiia. 2014;145(1):7-12. [Russian].

Park CY, Lee SH, Kim BK, Shin MS, Kim CJ, Kim H. Treadmill exercise ameliorates impairment of spatial learning ability through enhancing dopamine expression in hypoxic ischemia brain injury in neonatal rats. J Exerc Rehabil. 2013;9(4):406-12.

Park JW, Kim MH, Eo SJ, Lee EH, Kang JS, Chang HK, Leem YH. Maternal exercise during pregnancy affects mitochondrial enzymatic activity and biogenesis in offspring brain. Int J Neurosci. 2013;123(4):253-64.

Parnpiansil $P$, Jutapakdeegul N, Chentanez T, Kotchabhakdi N. Exercise during pregnancy increases hippocampal brain-derived neurotrophic factor mRNA expression and spatial learning in neonatal rat pup. Neurosci Lett. 2003;352(1):45-8. 
Paxinos G, Watson C. The rat brain: in stereotaxic coordinates. 4th ed. San Diego: Academic Press; 1998. Paginação irregular.

Paxinos G. The rat nervous system. 3rd ed. San Diego, USA: Elsevier; 2004. 1320 p.

Pereira DN, Procianoy RS. Effect of perinatal asphyxia on thyroid-stimulating hormone and thyroid hormone levels. Acta Paediatr. 2003;92(3):339-45.

Pin TW, Eldridge B, Galea MP. A review of developmental outcomes of term infants with post-asphyxia neonatal encephalopathy. Eur J Paediatr Neurol. 2009;13(3):22434.

Ploughman M. Exercise is brain food: the effects of physical activity on cognitive function. Dev Neurorehabil. 2008;11(3):236-40.

Polley DB, Kvasnák E, Frostig RD. Naturalistic experience transforms sensory maps in the adult cortex of caged animals. Nature. 2004;429(6987):67-71.

Puka-Sundvall M, Wallin C, Gilland E, Hallin U, Wang X, Sandberg M, Karlsson $\mathrm{J}$, Blomgren $\mathrm{K}$, Hagberg $\mathrm{H}$. Impairment of mitochondrial respiration after cerebral hypoxia-ischemia in immature rats: relationship to activation of caspase-3 and neuronal injury. Dev. Brain Res. 2000;125:43-50.

Puyal J, Ginet V, Clarke PG. Multiple interacting cell death mechanisms in the mediation of excitotoxicity and ischemic brain damage: a challenge for neuroprotection. Prog Neurobiol. 2013;105:24-48.

Rades, E, Bittar RE, Zugaib M. Determinantes diretos do parto prematuro eletivo e os resultados neonatais. Rev Bras Ginecol Obstet. 2004;26(8):655-62.

Raff H, Bruder ED, Jankowski BM, Colman RJ. Effect of neonatal hypoxia on leptin, insulin, growth hormone and body composition in the rat. Horm Metab Res. $2001 ; 33(3): 151-5$.

Ramos HAC, Cuman RKN. Risk factors for prematurity: document search. Esc Anna Nery Rev Enferm. 2009;13(2):297-304.

Rice D, Barone S Jr. Critical periods of vulnerability for the developing nervous system: evidence from humans and animal models. Environ Health Perspect. 2000;108 Suppl 3:511-33.

Rogalska J, Danielisova V, Caputa M. Effect of neonatal body temperature on postanoxic, potentially neurotoxic iron accumulation in the rat brain. NeurosciLett. 2006;393(2-3):249-54.

Rosa BV, Blair HT, Vickers MH, Dittmer KE, Morel PC, Knight CG, Firth EC. Moderate exercise during pregnancy in Wistar rats alters bone and body composition of the adult offspring in a sex-dependent manner. PLoS One. 2013;8(12):e82378. 
Schinder AF, Poo M. The neurotrophin hypothesis for synaptic plasticity. Trends Neurosci. 2000;23(12):639-45.

Schmidt B, Marrone DF, Markus EJ. Disambiguating the similar: the dentate gyrus and pattern separation. Behav Brain Res. 2012;226(1):56-65.

Schmidt-Kastner R, Freund TF. Selective vulnerability of the hippocampus in brain ischemia. Neuroscience. 1991;40(3):599-636.

Schmutzhard J, Glueckert R, Sergi C, Schwentner I, Abraham I, Schrott-Fischer A. Does perinatal asphyxia induce apoptosis in the inner ear? Hear Res. 2009;250(12):1-9.

Shevell MI. The "Bermuda triangle" of neonatal neurology: cerebral palsy, neonatal encephalopathy, and intrapartum asphyxia. Semin Pediatr Neurol. 2004;11(1):24-30.

Shin MS, Ko IG, Kim SE, Kim BK, Kim TS, Lee SH, Hwang DS, Kim CJ, Park JK, Lim BV. Treadmill exercise ameliorates symptoms of methimazole-induced hypothyroidism through enhancing neurogenesis and suppressing apoptosis in the hippocampus of rat pups. Int J Dev Neurosci. 2013;31(3):214-23.

Simola N, Bustamante D, Pinna A, Pontis S, Morales P, Morelli M, Herrera-Marschitz M. Acute perinatal asphyxia impairs non-spatial memory and alters motor coordination in adult male rats. Exp Brain Res. 2008;185(4):595-601.

Souza E, Santos JFK, Bancher MM, Bertini AM, Camano L. Considerações sobre a prematuridade eletiva na Universidade Federal de São Paulo - Escola Paulista de Medicina. Rev Bras Ginecol Obstet. 1995;17:583-9.

Squire LR. Memory and the Hippocampus: A Synthesis From Findings With Rats, Monkeys, and Humans. Psychological Review. 1992;99(2):195-231.

Sternfeld B, Quesenberry CP Jr, Eskenazi B, Newman LA. Exercise during pregnancy and pregnancy outcome. Med Sci Sports Exerc. 1995;27(5):634-40.

Suguihara C, Lessa AC. [Strategies to minimize lung injury in extremely low birth weight infants]. J Pediatr (Rio J). 2005;81(1 Suppl):S69-78. [Portuguese].

Sykes GS, Molloy PM, Johnson P, Gu W, Ashworth F, Stirrat GM, Turnbull AC. Do Apgar scores indicate asphyxia? Lancet. 1982;1(8270):494-6.

Takada SH, Sampaio CA, Allemandi W, Ito PH, Takase LF, Nogueira MI. A modified rat model of neonatal anoxia: Development and evaluation by pulseoximetry, arterial gasometry and Fosimmunoreactivity. J Neurosci Methods. 2011;198(1):62-9.

Takada SH, Dos Santos Haemmerle CA, Motta-Teixeira LC, Machado-Nils AV, Lee VY, Takase LF, Cruz-Rizzolo RJ, Kihara AH, Xavier GF, Watanabe IS, Nogueira MI. 
Neonatal anoxia in rats: Hippocampal cellular and subcellular changes related to cell death and spatial memory. Neuroscience. 2015;284:247-59.

Tang AC, Nakazawa M. Neonatal novelty exposure ameliorates anoxia-induced hyperactivity in the open field. Behav Brain Res. 2005;163(1):1-9.

Taylor DL, Edwards AD, Mehmet $\mathrm{H}$. Oxidative metabolism, apoptosis and perinatal brain injury. Brain Pathol. 1999;9(1):93-117.

Titomanlio L, Kavelaars A, Dalous J, Mani S, El Ghouzzi V, Heijnen C, Baud O, Gressens P. Stem cell therapy for neonatal brain injury: perspectives and challenges. Ann Neurol. 2011;70(5):698-712.

Tsuji M, Aoo N, Harada K, Sakamoto Y, Akitake Y, Irie K, Mishima K, Ikeda T, Fujiwara M. Sex differences in the benefits of rehabilitative training during adolescence following neonatal hypoxia-ischemia in rats. Exp Neurol. $2010 ; 226(2): 285-92$.

Uzendoski AM, Latin RW, Berg KE, Moshier S. Physiological responses to aerobic exercise during pregnancy and post-partum. J Sports Med Phys Fitness. $1990 ; 30(1): 77-82$.

Vannucci RC. Hypoxic-ischemic encephalopathy. American Journal of Perinatology. 2000;17(3):113-20.

Vasconcelos RG. Efeito da influência da anóxia neonatal no comportamento maternal e no desenvolvimento somático se sensório-motor de ratos Wistar. [tese (Doutorado em Neurociências e Comportamento)]. São Paulo: Instituto de Psicologia, Universidade de São Paulo; 2013.

Vicario-Abejón C, Collin C, McKay RD, Segal M. Neurotrophins induce formation of functional excitatory and inhibitory synapses between cultured hippocampal neurons. J Neurosci. 1998;18(18):7256-71.

Volpe JJ. Brain injury in the premature infant: overview of clinical aspects, neuropathology, and pathogenesis. Semin Pediatr Neurol. 1998;5(3):135-51.

Weitzdoerfer R, Gerstl N, Pollak D, Hoeger H, Dreher W, Lubec G. Long-term influence of perinatal asphyxia on the social behavior in aging rats. Gerontology. $2004 ; 50(4): 200-5$.

Weitzdoerfer R, Pollak A, Lubec B. Perinatal asphyxia in the rat has lifelong effects on morphology, cognitive functions, and behavior. SeminPerinatol. 2004;28(4):24956.

West MJ, Slomianka L, Gundersen HJ. Unbiased stereological estimation of the total number of neurons in the subdivisions of the rat hippocampus using the optical fractionator. Anat Rec. 1991;231(4):482-97. 
Wilson-Costello D, Friedman H, Minich N, Fanaroff AA, Hack M. Improved survival rates with increased neurodevelopmental disability for extremely low birth weight infants in the 1990s. Pediatrics. 2005;115(4):997-1003.

Winter B, Breitenstein C, Mooren FC, Voelker K, Fobker M, Lechtermann A, Krueger K, Fromme A, Korsukewitz C, Floel A, Knecht S. High impact running improves learning. Neurobiol Learn Mem. 2007;87(4):597-609.

Yanagita S, Amemiya S, Suzuki S, Kita I. Effects of spontaneous and forced running on activation of hypothalamic corticotropin-releasing hormone neurons in rats. Life Sci. 2007;80(4):356-63.

Zhang YS, Du JZ. The response of growth hormone and prolactin of rats to hypoxia. Neurosci Lett. 2000;279(3):137-40. 


\section{NEONATAL ANOXIA IN RATS: HIPPOCAMPAL CELLULAR AND SUBCELLULAR CHANGES RELATED TO CELL DEATH AND SPATIAL MEMORY}

\author{
S. H. TAKADA, ${ }^{a, b *}$ C. A. DOS SANTOS HAEMMERLE, ${ }^{a}$ \\ L. C. MOTTA-TEIXEIRA, ${ }^{\circ}$ A. V. MACHADO-NILS, \\ V. Y. LEE, ${ }^{a}$ L. F. TAKASE, ${ }^{d}$ R. J. CRUZ-RIZZOLO, ${ }^{e}$ \\ A. H. KIHARA, ${ }^{b}$ G. F. XAVIER, ${ }^{\circ}$ I.-S. WATANABE ${ }^{a}$ AND \\ M. I. NOGUEIRA ${ }^{a}$ \\ ${ }^{a}$ Departamento de Anatomia, Instituto de Ciências Biomédicas, \\ Universidade de São Paulo, São Paulo, Brazil \\ ${ }^{\mathrm{b}}$ Núcleo de Cognição e Sistemas Complexos, Centro de \\ Matemática, Computação e Cognição, Universidade Federal \\ do ABC, Santo André, Brazil \\ ${ }^{\mathrm{c}}$ Departamento de Fisiologia, Instituto de Biociências, \\ Universidade de São Paulo, São Paulo, Brazil \\ ${ }^{d}$ Departamento de Morfologia e Patologia, Centro de \\ Ciências Biológicas e da Saúde, Universidade Federal de \\ São Carlos, São Carlos, Brazil \\ e Departamento de Ciências Básicas, Campus de Araçatuba, \\ Universidade Estadual Paulista, Araçatuba, Brazil
}

\begin{abstract}
Neonatal anoxia in rodents has been used to understand brain changes and cognitive dysfunction following asphyxia. This study investigated the time-course of cellular and subcellular changes and hippocampal cell death in a non-invasive model of anoxia in neonatal rats, using Terminal deoxynucleotidyl transferase-mediated dUTP Nick End Labeling (TUNEL) to reveal DNA fragmentation, Fluoro-Jade ${ }^{\circledR} B(F J B)$ to show degenerating neurons, cleaved caspase-3 immunohistochemistry (IHC) to detect cells undergoing apoptosis, and transmission electron microscopy (TEM) to reveal fine ultrastructural changes related to cell death. Anoxia was induced by exposing postnatal day 1 (P1) pups to a flow of $100 \%$ gaseous nitrogen for $25 \mathrm{~min}$ in a chamber maintained at $37^{\circ} \mathrm{C}$. Control rats were similarly exposed to this chamber but with air flow instead of nitrogen. Brain changes following anoxia were evaluated at postnatal days 2, 14, 21 and 60 (P2, P14, P21 and P60). In addition, spatial reference memory following anoxia and control treatments was evaluated in the Morris water maze, starting at P60. Compared to their respective controls, P2 anoxic rats exhibited (1) higher TUNEL labeling in cornus ammonis (CA) 1 and the dentate gyrus (DG), (2) higher FJB-positive cells in the CA2-3, and (3) somato-dendritic
\end{abstract}

\footnotetext{
*Correspondence to: S. H. Takada, Pós-doutoranda, Laboratório de Neurogenética, Centro de Matemática, Computação e Cognição, Universidade Federal do ABC, Brazil.

E-mail address: silviahonda@usp.br (S. H. Takada).

Abbreviations: ANOVA, analysis of Variance; CA, cornus ammonis; DAPI, 4',6-diamidino-2-phenylindole; DG, dentate gyrus; FJB, FluoroJade $^{\circledR}$ B; IHC, immunohistochemistry; ITI, intertrial interval; PBS, phosphate-buffered saline; TEM, transmission electron microscopy; TUNEL, Terminal deoxynucleotidyl transferase-mediated dUTP Nick End Labeling.
}

swelling, mitochondrial injury and chromatin condensation in irregular bodies, as well as other subcellular features indicating apoptosis, necrosis, autophagy and excitotoxicity in the CA1, CA2-3 and DG, as revealed by TEM. At P14, P21 and $\mathrm{P} 60$, both groups showed small numbers of TUNELpositive and FJB-positive cells. Stereological analysis at $\mathrm{P} 2, \mathrm{P} 14, \mathrm{P} 21$ and $\mathrm{P} 60$ revealed a lack of significant differences in cleaved caspase-3 IHC between anoxic and control subjects. These results suggest that the type of hippocampal cell death following neonatal anoxia is likely independent of caspase-3 activation. Neonatal anoxia induced deficits in acquisition and performance of spatial reference memory in the Morris water maze task. Compared to control subjects, anoxic animals exhibited increased latencies and path lengths to reach the platform, as well as decreased searching specifically for the platform location. In contrast, no significant differences were observed for swimming speeds and frequency within the target quadrant. Together, these behavioral results indicate that the poorer performance by anoxic subjects is related to spatial memory deficits and not to sensory or motor deficits. Therefore, this model of neonatal anoxia in rats induces hippocampal changes that result in cell losses and impaired hippocampal function, and these changes are likely related to spatial memory deficits in adulthood. (c) 2014 IBRO. Published by Elsevier Ltd. All rights reserved.

Key words: apoptosis, hippocampal cell death, spatial memory, neonatal hypoxia, asphyxia, transmission electron microscopy.

\section{INTRODUCTION}

Neonatal anoxia is a major cause of brain injury at birth. It affects $0.1-0.3 \%$ of full-term infants (Kurinczuk et al., 2010 ) and approximately $60 \%$ of low-weight premature infants, thus constituting a major public health concern (Vannucci et al., 1999; Suguihara and Lessa, 2005). Long-lasting cognitive consequences of neonatal anoxia include deficits in spatial learning and memory (Buwalda et al., 1995; Cannon et al., 2002; Caputa et al., 2005; Rogalska et al., 2006), which may be related to hippocampal damage (Leuner et al., 2006; Winocur et al., 2006).

The mammalian brain is extremely vulnerable to oxygen deprivation. Such episodes trigger cascades of biochemical events, including disruption of energy metabolism, acid-base imbalance, accumulation of reactive oxygen species and excitatory amino acids in 
the extracellular medium, loss of cellular water content, and they induce either injury or death in susceptible cells (Engidawork et al., 1997; Vexler and Ferriero, 2001; Lutz and Prentice, 2002). Hippocampal vulnerability to oxygen deprivation has been described using rodent models of both hypoxia-ischemia and hypoxia (Johnston, 2001; Daval and Vert, 2004; Liu et al., 2008; Yang et al., 2011); this vulnerability appears to be related to hippocampal plasticity (Shors et al., 1989).

Takada et al. (2011) reported an animal model of global anoxia involving exposure of neonatal rats to continuous $100 \%$ nitrogen gas flow, at $3 \mathrm{~L} / \mathrm{min}$ and $101.7 \mathrm{kPa}$, in a non-hermetic chamber, at $37^{\circ} \mathrm{C}$ for $25 \mathrm{~min}$. Fos immunoreactivity revealed neuronal activation in brain areas related to respiratory control. In addition, peripheral arterial oxygen saturation decreased by $75 \%$ from its initial value, $\mathrm{pH}$ and partial pressure of oxygen decreased, and partial pressure of carbon dioxide increased, thus indicating metabolic acidosis. Further, the subjects exhibited hypoxemia and hypercapnia, symptoms also present in human neonatal anoxia. The brain cell death and its functional consequences using this anoxia model have not previously been described. Because this anoxia model provides precise and standardized control of the anoxic condition, it represents a valuable non-invasive and practical animal model for identifying the brain changes that follow neonatal anoxia and the mechanisms underlying those changes. Thus, its potential use may extend to investigations of novel therapeutic strategies to prevent consequences of neonatal anoxia.

This study aimed to investigate the effects of neonatal anoxia, as reported by Takada et al. (2011), on both (1) the time-course of hippocampal neuronal changes by combining techniques such as the Terminal deoxynucleotidyl transferase (TdT)-mediated dUTP nick end labeling (TUNEL), which allows evaluation of DNA fragmentation and is considered a gold standard to detect apoptosis in situ (Galluzzi et al., 2012), Fluoro-Jade ${ }^{\circledR}$ B (FJB), an anionic fluorescein derivative that is useful for the histological staining of neurons undergoing degeneration (Schmued and Hopkins, 2000), immunohistochemistry (IHC) for cleaved caspase-3, which allows the identification of caspase-3-dependent apoptosis (Galluzzi et al., 2012), and transmission electron microscopy (TEM), to visualize the fine ultrastructural modifications that accompany cell death (Galluzzi et al., 2012), in independent groups of rats at the postnatal days 2, 14, 21 and 60 (P2, P14, P21 and P60, respectively), and (2) spatial learning and memory in young adult rats (P60) using the Morris water maze task.

Although cognitive changes and cerebral cell death have been extensively investigated using other animal models of oxygen deprivation, the approach employed in the present study provides advantages. First, noninvasive global oxygen deprivation in neonatal rats up to $30 \mathrm{~h}$ after birth appears to parallel the experience of low-weight premature infants because the rats are subjected to anoxia at a brain maturation stage that corresponds to that of humans born prematurely (Semple et al., 2013), thus representing an analogously valid model. Second, one of the main findings following oxygen deprivation at this period in rodent models corresponds to white matter damage associated with no gross morphological alterations in gray matter (Puyal et al., 2013). The hypothesis to be evaluated in this study is that cellular and subcellular alterations that follow anoxia may also be revealed in hippocampal neurons by using the above-mentioned techniques. Thus, at the behavioral level, it is expected that rats subjected to neonatal anoxia will show disruption of spatial learning and memory in the Morris water maze, a behavioral task known to be sensitive to hippocampal function (Morris et al., 1982; Xavier et al., 1999). In addition to further characterizing this animal model of neonatal anoxia, the understanding of the neuronal alterations and cognitive disruption that follow anoxia using this procedure may open new possibilities for evaluating possible treatments and procedures to prevent the adverse effects of neonatal anoxia.

\section{EXPERIMENTAL PROCEDURES}

\section{Animals and groups}

One hundred and eight male Wistar pups, approximately $30 \mathrm{~h}$ old, weighing $6-8 \mathrm{~g}$, from litters reduced to eight pups per dam, were obtained from the animal facility of the Department of Anatomy at the Institute of Biomedical Sciences, University of São Paulo (USP). The dams and corresponding litters were housed at a controlled temperature $\left(22 \pm 1^{\circ} \mathrm{C}\right)$, with a 12-h light/ dark period (lights on at 7:00 AM), and they were provided with food and water ad libitum. The litters were assigned to either the anoxia or the corresponding control treatments (see below) such that each of the resulting groups was composed of subjects coming from at least two different litters. After exposure to either anoxia or the control treatment, the pups were returned to their mothers' cages, where they remained until perfusion. Weaning, when applicable, occurred at P21. To evaluate the time-course of the ensuing brain changes, independent groups of subjects exposed to anoxia or control treatments were perfused either at P2 (24 $\mathrm{h}$ after the treatment), P14, P21 or P60, adopting protocols adequate for later processing using $\mathrm{IHC}$, TUNEL and FJB techniques. For TEM analysis, brain processing occurred at $\mathrm{P} 2$. The number of subjects included in each condition for each technique is summarized in Table 1.

All experimental procedures complied with the Ethical Principles for Use of Animals in Scientific Research formulated by the Brazilian College of Animal Experimentation (COBEA) and were approved by the Ethics Committee of the Institute of Biomedical Sciences of the University of São Paulo (Protocol No. 134, book 2).

\section{Neonatal anoxia}

Anoxia was induced in 30-h-old rats using the procedure previously adapted and validated by Takada et al. (2011). In short, subjects were submitted to continuous flow ( $3 \mathrm{~L} / \mathrm{min}$ ) of $100 \%$ nitrogen $\left(\mathrm{N}_{2}\right)$ for $25 \mathrm{~min}$ at $37^{\circ} \mathrm{C}$ and $101.7 \mathrm{kPa}$ in a non-hermetic chamber (Anoxia 
Table 1. Numbers of subjects included in each group as a function of both the age at perfusion (P2, P14, P21 and P60) and treatment (anoxia vs. control), as well as the technique used for evaluation of either hippocampal (FJB, TUNEL, IHC or TEM) or behavioral changes (Morris water maze)

\begin{tabular}{|c|c|c|c|c|c|c|c|c|}
\hline \multirow[t]{3}{*}{ Technique } & \multicolumn{8}{|c|}{ Number of subjects } \\
\hline & \multicolumn{2}{|l|}{$\mathrm{P} 2$} & \multicolumn{2}{|l|}{ P14 } & \multicolumn{2}{|l|}{ P21 } & \multicolumn{2}{|l|}{ P60 } \\
\hline & Control & Anoxia & Control & Anoxia & Control & Anoxia & Control & Anoxia \\
\hline FJB & 4 & 4 & 3 & 3 & 3 & 3 & 3 & 3 \\
\hline TUNEL & 4 & 4 & 3 & 3 & 3 & 3 & 3 & 3 \\
\hline $\mathrm{IHC}$ & 5 & 5 & 5 & 5 & 5 & 5 & 5 & 5 \\
\hline TEM & 2 & 2 & - & - & - & - & - & - \\
\hline Morris water maze & - & - & - & - & - & - & 7 & 5 \\
\hline Total & 15 & 15 & 11 & 11 & 11 & 11 & 18 & 16 \\
\hline
\end{tabular}

Treatment). Control subjects were exposed to continuous air flow in the same chamber for the same period of time and with the same temperature and pressure (Control Group). After exposure to the chamber, the pups were returned to their mothers' cages, where they remained until transcardial perfusion occurring either $24 \mathrm{~h}$ later (P2), or at $\mathrm{P} 14, \mathrm{P} 21$ or $\mathrm{P} 60$, or until the beginning of the behavioral testing.

\section{Tissue processing}

The pups whose brain tissue was processed for FJB, TUNEL and caspase-3 IHC were deeply anesthetized with an intraperitoneal injection of chloral hydrate (33\%) and perfused transcardially with $0.9 \%$ saline followed by $4 \%$ paraformaldehyde in $0.1 \mathrm{M}$ phosphate-buffered saline (PBS), $\mathrm{pH} 7.4$, at $4{ }^{\circ} \mathrm{C}$. The brains were dissected and subjected to overnight post-fixation in the latter fixative solution, followed by immersion in a cryoprotective solution composed of $0.1 \mathrm{M}$ PBS and $20 \%$ sucrose for $48 \mathrm{~h}$. The brains were then frozen in a solution of water-soluble glycols and resin (Tissue-Tek ${ }^{\circledR}$ O.C.T. ${ }^{\mathrm{T}}$ Compound, Sakura, Tokyo, Japan) and stored at $-80^{\circ} \mathrm{C}$ until sectioning in a cryostat (CM 1950, Leica Biosystems, Wetzlar, Germany), in serial sections of either 30- (for FJB and TUNEL) or 40- $\mu \mathrm{m}$ thickness (for $\mathrm{IHC}$ ).

The samples for TEM were prepared using the fixative modified Karnovsky solution containing $2 \%$ paraformaldehyde and $2.5 \%$ glutaraldehyde in $0.1 \mathrm{M}$ sodium cacodylate buffer ( $\mathrm{pH} 7.4$ ) (Watanabe et al., 2013). Blocks of dissected hippocampal samples were immersed in the same fixative solution for $3 \mathrm{~h}$ at room temperature, rinsed with $0.1 \mathrm{M}$ sodium cacodylate buffer and sectioned frontally (50- $\mu \mathrm{m}$ thick) using a vibratome (Vibratome 3000 sectioning system, The Vibratome Company, St. Louis, MO, USA) equipped with a bath cooling system (VB 900r, The Vibratome Company, St. Louis, MO, USA). The sections were post-fixed in $1 \%$ OsO4 for $2 \mathrm{~h}$ at $4{ }^{\circ} \mathrm{C}$, washed in $0.9 \%$ saline and immersed in $0.5 \%$ aqueous uranyl acetate solution for $8 \mathrm{~h}$ at room temperature. Following dehydration in ethanol and propylene oxide, the samples were immersed in 1:1 Spurr resin and propylene oxide (Electron Microscopy Sciences, Hatfield, PA, USA) for $4 \mathrm{~h}$. Next, they were embedded in pure Spurr resin for $16 \mathrm{~h}$ at room temperature. Then, the sections were embedded in Spurr resin between acetate sheets for $1 \mathrm{~h}$ at $37^{\circ} \mathrm{C}$ and for $96 \mathrm{~h}$ at $60^{\circ} \mathrm{C}$. The subfields of the hippocampus samples were isolated and sectioned at $2 \mu \mathrm{m}$ with a glass knife on an LKB ultramicrotome (Leica Ultracut UCT, Leica Microsystems, Vienna, Austria) and mounted and stained with $2 \%$ toluidine blue for light microscopy. Ultra-thin sections $(90 \mathrm{~nm})$ of the selected areas were cut and collected in a 200-mesh copper grid, counterstained with uranyl acetate and lead citrate (Watanabe and Yamada, 1983) and examined using a JEOL 1010 transmission electron microscope (JEOL USA Inc., Peabody, MA, USA).

\section{IHC for cleaved caspase-3}

IHC for cleaved caspase-3 was employed to identify caspase-3-dependent apoptosis via stereological quantification. Brain sections $(40-\mu \mathrm{m}$ thick) were washed with $0.1 \mathrm{M}$ PBS and then quenched in boiling $0.01 \mathrm{M}$ citric acid solution ( $\mathrm{pH} 6$ ) for $7 \mathrm{~min}$ for antigen retrieval. After cooling for $20 \mathrm{~min}$, the sections were washed in PBS and blocked for $40 \mathrm{~min}$ in $0.3 \%$ Triton $\mathrm{X}-100$ in PBS containing $5 \%$ normal goat serum (NGS, Vector Laboratories, Burlingame, CA, USA) and then incubated in blocking solution containing anti-cleaved caspase- 3 primary antibody (1:100, ABCAM, Cambridge, MA, USA) for $48 \mathrm{~h}$ at $8^{\circ} \mathrm{C}$. Then, the sections were washed and incubated in biotinylated antibody solution (1:1000, ABCAM, Cambridge, MA, USA) in $0.3 \%$ Triton $X-100$ in PBS for $90 \mathrm{~min}$ at room temperature. The sections were washed again in PBS and incubated with an avidin-biotin complex (1:500, Vector Laboratories, Burlingame, CA, USA), followed by three washes of $10 \mathrm{~min}$ each and stained with 3,3'-diaminobenzidine (DAB) substrate. The sections were then counterstained with thionin, dehydrated with an increasing series of ethanol, diaphanized in xylene and coverslipped with DPX as the mounting medium (Millipore Corporate Headquarters, Billerica, MA, USA).

\section{Fluoro-Jade B staining}

Fluoro-Jade B staining was performed on cryostat-sliced 30- $\mu \mathrm{m}$ brain sections, collected on gelatin-coated slides, allowed to dry at room temperature and stored at $-20^{\circ} \mathrm{C}$. Before staining, the sections were quickly immersed in $0.1 \mathrm{M} \mathrm{PBS}$ and dried at $37^{\circ} \mathrm{C}$ for $24 \mathrm{~h}$. Next, the slides were immersed in $100 \%$ ethanol for $3 \mathrm{~min}, 70 \%$ ethanol for $1 \mathrm{~min}$ and distilled water for $1 \mathrm{~min}$. Then, the slides were placed in a solution of 
$0.06 \%$ potassium permanganate on a shaker for $15 \mathrm{~min}$ and washed two or three times with distilled water for $1 \mathrm{~min}$. From this step onward, the procedures were conducted under low light. The slides were placed in $0.001 \%$ FJB solution on a shaker for $30 \mathrm{~min}$ and immersed three times in distilled water for $1 \mathrm{~min}$. To counterstain the investigated structures, the subsequent series were stained with thionine. Next, the slides were diaphanized in xylene and coverslipped using DPX mounting medium.

\section{TUNEL staining}

The Dead End ${ }^{\text {TM }}$ Fluorometric TUNEL System (Promega, Madison, WI, USA) was used with minimal protocol modifications for $30-\mu m$-thick sections. After washing in $\mathrm{PBS}$, the sections were permeabilized in Proteinase $\mathrm{K}$ solution (1:500), followed by washing in PBS and incubation in Equilibration Buffer solution for $5 \mathrm{~min}$ at room temperature. Then, Terminal deoxynucleotidyl transferase $(\mathrm{TdT})$ reaction mix solution was pipetted onto the sections, and the sections were incubated at $37^{\circ} \mathrm{C}$ for $1 \mathrm{~h}$ in a humidified chamber protected from light. Next, the slides were immersed in $20 \times$ SSC solution for $15 \mathrm{~min}$, washed in PBS and coverslipped with DAPI/Antifade (Millipore, Billerica, MA, USA).

\section{FJB and TUNEL quantification analysis}

FJB- and TUNEL-positive cells of P2 subjects exposed to either anoxia or control treatment were counted throughout the dentate gyrus (DG) and the cornus ammonis (CA) 2-3 and CA1 hippocampal subfields in six semi-serial coronal hippocampal sections $(30 \mu \mathrm{m})$ spaced $360 \mu \mathrm{m}$ apart, beginning approximately $2.28 \mathrm{~mm}$ caudal to Bregma. The sections were analyzed under a fluorescence microscope (Nikon Eclipse E-1000, Nikon Instruments Inc., Melville, NY, USA) using 450-490-nm light for excitation. The photomicrographs were captured using a camera (DFC 295, Leica Microsystems, Wetzlar, Germany) coupled to a fluorescence microscope (DM 5500, Leica Microsystems, Wetzlar, Germany) and using the deconvolution mode of the Leica Application Suite Advanced Fluorescence software (LAS AF, Leica Microsystems, Wetzlar, Germany). No quantification was performed for subjects at P14, P21 and P60 because they did not present extensive FJB- or TUNEL-positive cells.

\section{Stereological analysis of cleaved caspase-3 immunoreactivity}

Cells immunoreactive for cleaved caspase-3 were estimated in the five subjects of each group, using 40$\mu \mathrm{m}$-thick serial coronal sections spaced $400 \mu \mathrm{m}$ apart. The thickness was chosen based on the minimum thickness accepted for Optical Fractionator probes considering tissue shrinkage after processing. An optical microscope coupled to a camera (Nikon Instruments Inc., Melville, NY, USA), connected to a motorized stage (Ludl Electronic Products, Hawthorne, NY, USA) controlled by Stereo Investigator software (MBF
Biosciences, Williston, VT, USA) was employed. A contour of the hippocampal subfields was delineated at $4 \times$ magnification using Nissl counterstaining. To standardize the subfield delineations in different hippocampal regions (ventral and dorsal), the hilus was included in the analysis of the DG, and CA2 and CA3 were not differentiated because Nissl staining does not allow precise differentiation of these regions. The immunoreactive cells presenting strong and visible labeling were counted at $40 \times$ magnification. The counting frame size and the sampling grid were established based on pilot studies (Table 2) (West and Gundersen, 1990).

\section{Morris water maze apparatus and behavioral procedure}

The Morris water maze apparatus and the procedures employed were similar to those already described (Xavier et al., 1999). The pool was a round, black fiberglass tank, $200 \mathrm{~cm}$ in diameter, $50 \mathrm{~cm}$ in height, filled to a depth of $25 \mathrm{~cm}$ with water $\left(26 \pm 1^{\circ} \mathrm{C}\right)$. A movable circular plastic platform $9 \mathrm{~cm}$ in diameter, mounted on a plastic column, was placed in the center of one of the quadrants of the pool, approximately $2 \mathrm{~cm}$ below the water surface. For descriptive data analyses, the critical counter was defined as the area centered on the platform and measuring three times the platform diameter. The frequency of entrances within the critical counter and the percentage of time spent in that area relative to the time spent in the rest of the pool provided specific indices of spatial location. The water maze was located within a $3.13 \times 3.5-\mathrm{m}$ room with several salient cues hanging on the walls.

Each trial consisted of placing the rat facing the wall near the pool border (in one of the variable starting locations) and allowing it to swim until the platform was found. If the rat did not find the platform within $120 \mathrm{~s}$, the animal was then manually guided to the platform, where it remained for $10 \mathrm{~s}$. In such cases, a latency score of $120 \mathrm{~s}$ was assigned. The trials were recorded using a computerized video-tracking system (Ethovision Pro, Noldus Information Technologies, Wageningen, The Netherlands) that allowed the measurement of the latency, the path length and the time spent within and frequency across the critical counter.

In the water maze spatial reference memory-training task, the platform was located in a single, fixed position in the center of the critical quadrant for the entire training period. Each animal was subjected to four trials per session, one session per day, with an intertrial interval (ITI) of $10 \mathrm{~min}$, for six sessions. Due to a technical failure, data from the first session were not recorded.

Acquisition of the spatial reference memory task was assessed by decreases in latency and path length and by increases in both the percentage of time spent within the critical counter and frequency across this area, which corresponded to the platform location. Training proceeded until the subjects reached an asymptotic level of performance, which occurred by the 6th session. 
Table 2. Parameters used for stereological estimation of cleaved caspase-3 IHC-positive cells at each time points following neonatal anoxia

\begin{tabular}{|c|c|c|c|c|}
\hline Parameters of stereology quantification & $\mathrm{P} 2$ & $\mathrm{P} 14$ & $\mathrm{P} 21$ & P60 \\
\hline Counting frame area $(X Y)\left(\mu \mathrm{m}^{2}\right)$ & 1600 & 1600 & 1600 & 1600 \\
\hline Disector height $(Z)(\mu \mathrm{m})$ & 10 & 10 & 10 & 10 \\
\hline Guard zone distance ( $\mu \mathrm{m})$ & 01 & 01 & 01 & 01 \\
\hline Counting frame width $(X)(\mu \mathrm{m})$ & 40 & 40 & 40 & 40 \\
\hline Counting frame height $(Y)(\mu \mathrm{m})$ & 40 & 40 & 40 & 40 \\
\hline Sampling grid $(X)(\mu \mathrm{m})$ & 271 & 271 & 353 & 396 \\
\hline Sampling grid $(Y)(\mu \mathrm{m})$ & 114 & 114 & 240 & 233 \\
\hline Section evaluation interval & 10 & 12 & 24 & 24 \\
\hline
\end{tabular}

A probe test, with the platform removed, was conducted $24 \mathrm{~h}$ after the end of the training phase. During this test, the animals were allowed to swim freely in the pool for $3 \mathrm{~min}$. The percentage of time the animal spent within the critical counter and counter frequency, in three time bins of $60 \mathrm{~s}$ each, allowed the assessment of long-term memory for the platform location through the extent of the spatial bias toward its location in the first time bin and the evaluation of the rate of extinction of this behavior by comparing the same parameter over the three consecutive time bins.

\section{Statistical analyses}

The estimated numbers of TUNEL- and FJB-positive cells in the CA1 and CA2-3 hippocampal subfields and DG for P2 subjects exposed to either anoxia or control treatments were compared using the Mann-Whitney (Wilcoxon) $W$-test to compare medians, alpha value $=0.05$

The estimated numbers of IHC-positive cells in the CA1, CA2-3 and DG for subjects at P2, P14, P21 and $\mathrm{P} 60$, after exposure to either anoxia or control treatments, were subjected to an analysis of variance (ANOVA) using Treatments and Postnatal day of perfusion as the between-subject factors, followed, when required, by the Tukey post hoc test. An independent ANOVA was run for each brain region.

TEM analysis was descriptive only, and the objective was to identify possible differences between control and anoxia subjects at the ultrastructural level.

Scores on the water maze spatial reference memory test were analyzed using a repeated-measures ANOVA using Treatments as the between-subject factor and Sessions and Trials as within-subject factors (SAS Institute Inc., Cary, NC, USA). Probe-test scores were analyzed using Treatments as the between-subject factor and time bin as the within-subject factor. An independent ANOVA was run for each score. Differences were considered significant when $p<0.05$. Tukey-Kramer post hoc analyses were conducted when $p$ values reached significance. The data are presented as means \pm S.E.M.

\section{RESULTS}

\section{Morphological data as revealed by TUNEL, FJB, IHC and TEM techniques}

Briefly, as compared to their respective controls, P2 anoxic rats exhibited (1) higher levels of TUNEL labeling in the CA1 and DG, (2) more FJB-positive cells in the CA2-3, and (3) somato-dendritic swelling, mitochondrial injury and chromatin condensation in irregular bodies and subcellular findings indicating apoptosis, necrosis, autophagy and excitotoxicity in the CA1, CA2-3 and DG, as revealed by TEM. At P14, P21 and P60, each group showed only a few TUNEL-positive and FJBpositive cells. Stereological analysis revealed no significant differences in the levels of cleaved caspase-3 between anoxic and control subjects, at P2, P14, P21 or $\mathrm{P} 60$, suggesting that the observed hippocampal cell death following neonatal anoxia is likely independent of caspase-3 activation.

TUNEL and FJB. Representative photomicrographs of TUNEL-positive cells in the hippocampal CA1 subfield at $24 \mathrm{~h}$ after neonatal anoxia are shown in Fig. 1B-D, counterstained with 4',6-diamidino-2-phenylindole (DAPI) for histological reference (Fig. 1A). The number of TUNEL-positive cells as a function of the treatments, for subjects perfused at P2, is estimated in Fig. 1E. Relative to the quantification of TUNEL-positive cells (control, $n=4$; anoxia, $n=4$ ), significant differences between anoxic and control groups were observed in CA1 (anoxia: $175.5 \pm 6.5$; control: $52.5 \pm 7.5, \quad W=0$, $p=0.03$ ) and in DG (anoxia: $68.5 \pm 7.7$; control: $23.5 \pm 6.5, W=0, p=0.03$ ); the number of TUNELpositive cells in CA2-3 did not differ between treatments (anoxia: $41.5 \pm 13.2$; control: $33.5 \pm 6.4, \quad W=8$, $p=0.89$ ). Fig. $1 \mathrm{E}$ shows that the number of TUNEL-positive cells in those brain areas was greater for subjects exposed to anoxia than for subjects exposed to the control treatment.

The FJB-positive cells in P2 subjects exposed to anoxia appear as green fluorescence distributed in the strata of the CA2-3 hippocampal subfield (Fig. 2B). Using the Nissl staining as a histological reference (Fig. 2A), the FJB labeling can be observed to stand out in the stratum oriens and stratum pyramidale, with slightly fewer cells in the stratum radiatum. Relative to the estimated number of FJB-positive cells at P2 following oxygen deprivation, significant differences were observed in CA2-3 between subjects exposed to anoxia $(n=4)$ and their respective controls $(n=4)$ (anoxia: $256.25 \pm 18.1$; control: $118.25 \pm 23.9, W=0$, $p=0.03$ ); no differences were observed in the numbers of FJB-positive cells in the DG (anoxia: $52.25 \pm 4.7$; control: $42.25 \pm 13.2, \quad W=4, p=0.31)$ or in CA1 (anoxia: $74.5 \pm 10.8 ; \quad$ control: $65 \pm 8.6$ ),$\quad W=6$, $p=0.67$ (Fig. 2E). 

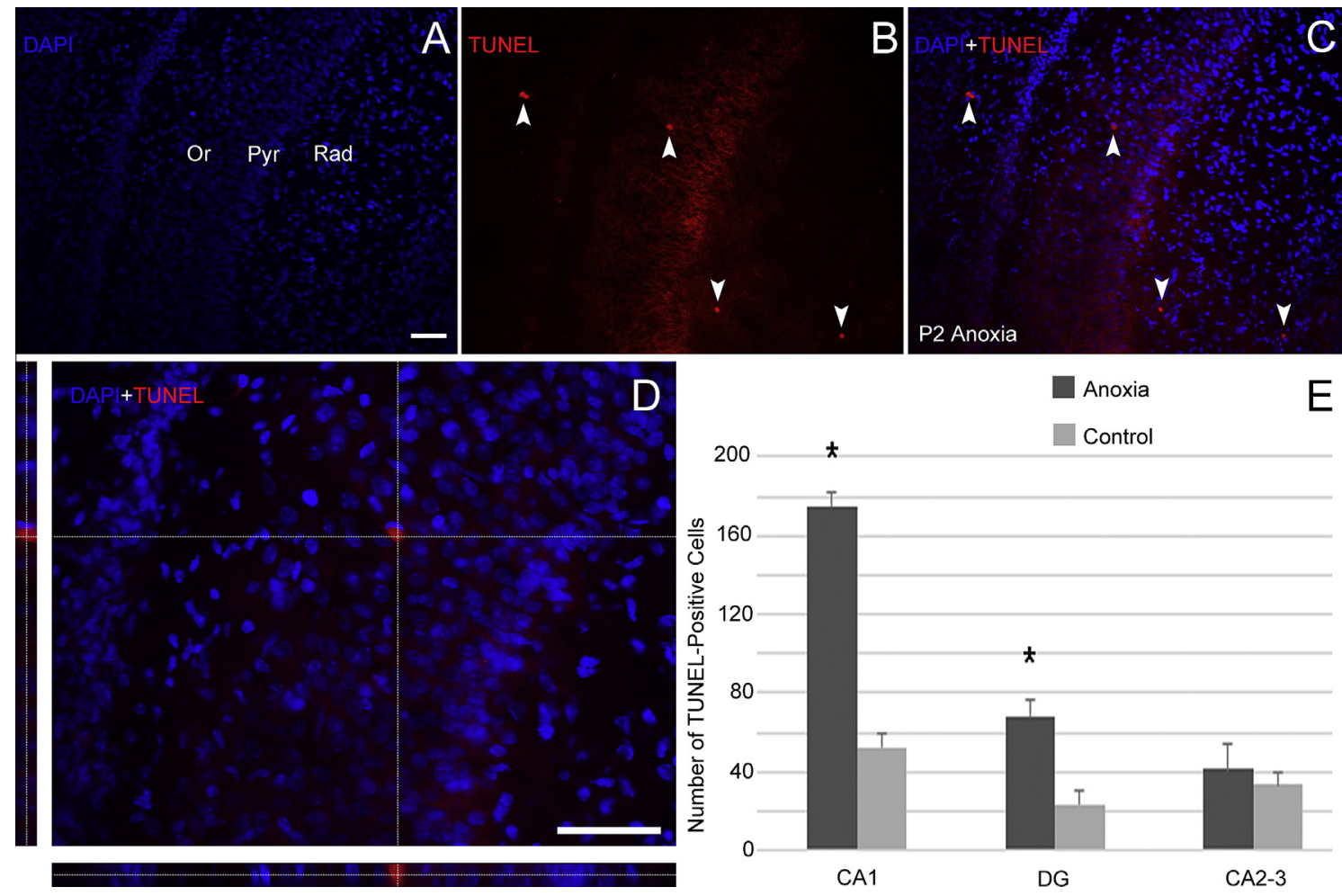

Fig. 1. TUNEL-positive cells in the rat hippocampus $24 \mathrm{~h}$ after neonatal anoxia. Photomicrographs of coronal sections of rat hippocampal CA1 subfield showing: (A) Strata Oriens (Or), Pyramidale (Pyr) and Radiatum (Rad) with DAPI staining; (B) TUNEL-positive cells (white arrows); (C) TUNEL (red) + DAPI (blue) counterstaining, showing the distribution of TUNEL-positive cells (D) Magnified photomicrograph of TUNEL-positive cells counterstained with DAPI. Scale bars $=$ (A) $100 \mu \mathrm{m}$; (D) $50 \mu \mathrm{m}$. (E) Quantification of TUNEL-positive cells (control, $n=4$; anoxia, $n=4$ ) reveals increased TUNEL-positive cells in CA1, $W=0, p=0.03$; and in DG, $W=0, p=0.03$, in anoxia subjects. The numbers of TUNEL-positive cells in CA2-3 did not show significant differences between treatments, $W=8, p=0.89$. ${ }^{*} p<0.05$. (For interpretation of the references to color in this figure legend, the reader is referred to the web version of this article.)
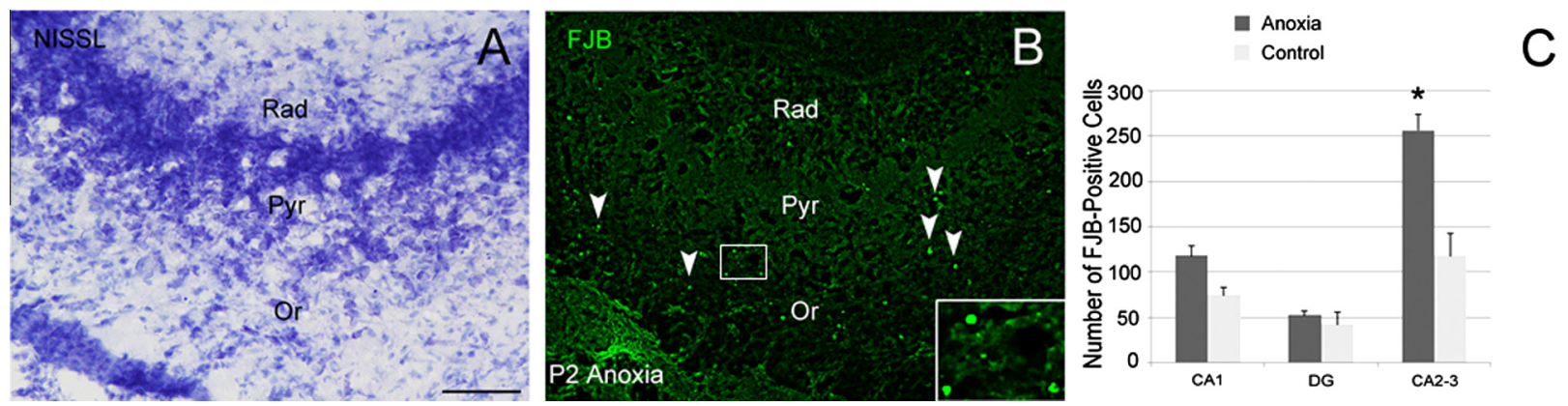

Fig. 2. FJB-positive cells in the rat hippocampus $24 \mathrm{~h}$ after neonatal anoxia. Photomicrographs of coronal sections of rat hippocampus depict: (A) Nissl staining identifying Strata Oriens (Or), Pyramidale (Pyr), and Radiatum (Rad); (B) FJB-positive cells stained green (white arrows); rectangle in detail: magnification of the CA2-3 subfield; (C) Quantification of FJB-positive cells (control, $n=4$; anoxia, $n=4$ ) showing increased FJB-positive cells in CA2-3, $W=0, p=0.013$, in anoxia subjects; no differences in the number of FJB-positive cells were observed in DG, $W=4, p=0.673$, or in CA1, $W=6, p=0.428 .{ }^{*} p<0.05$. Scale bar $=100 \mu \mathrm{m}$. (For interpretation of the references to color in this figure legend, the reader is referred to the web version of this article.)

Cleaved caspase-3 IHC. Cells immunoreactive for cleaved caspase-3 are shown in representative photomicrographs of the hippocampal subfields CA1, CA2-3 and DG of a P2 subject exposed to neonatal anoxia (Fig. $3 \mathrm{~A}-\mathrm{C}$, respectively). Concerning the density of cleaved caspase-3 immunoreactive cells assessed by stereological analysis, results revealed a lack of significant Treatment effect for all hippocampal subfields evaluated, independently of the age at which the subjects were perfused $(p>0.05)$ (Fig. 3D).

Differences between studied ages were observed in both groups. In the CA1 subfield cleaved caspase-3 density decreased from $\mathrm{P} 2$ to $\mathrm{P} 14$ and from $\mathrm{P} 14$ to $\mathrm{P} 21$. In the CA2-3 and DG subfields, there was a decrease in cleaved caspase- 3 density from $\mathrm{P} 2$ to $\mathrm{P} 14$ and from $\mathrm{P} 14$ to $\mathrm{P} 60$, showing no alterations between $\mathrm{P} 14$ and P21. 

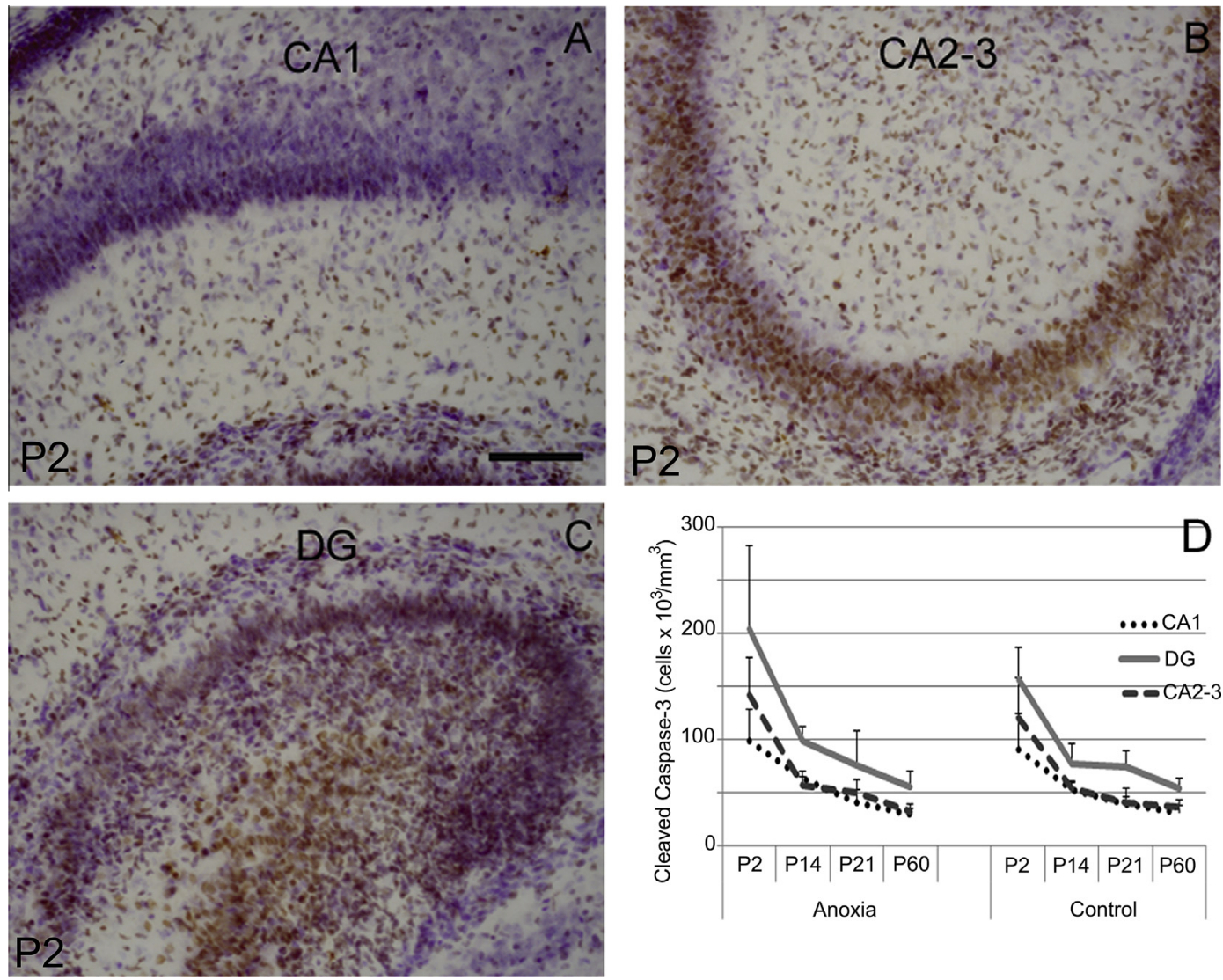

Fig. 3. Cleaved caspase-3 immunoreactivity in the rat hippocampus $24 \mathrm{~h}$ following neonatal anoxia. Photomicrographs of coronal sections showing the rat hippocampus (A) and hippocampal subfields CA1 (B), CA2-3 (C) and the DG (D) subjected to cleaved caspase-3 immunohistochemistry and thionin counterstaining $24 \mathrm{~h}$ after neonatal anoxia. There were no differences between the control and anoxia groups at any of the studied time points (E; control, $n=5$ per time point; anoxia, $n=5$ per time point, $p>0.05$ ). Scale bar $=($ A) $100 \mu \mathrm{m}$; (B) $200 \mu \mathrm{m}$.

TEM. The ultrastructural analysis conducted on P2 animals revealed preserved neuronal cells and some neurons with discrete condensation of chromatin in the CA1 (Fig. 4A), and similar conditions were observed in other subfields, possibly indicating early apoptosis, both in subjects exposed to anoxia and in control subjects (Fig. 4A).
Unlike the control condition, in subjects exposed to anoxia, CA1 neurons displayed intense chromatin condensation and an apparent loss of nuclear membrane integrity, exhibiting autophagic vacuoles and partial absence of cytoplasmic organelles (Fig. 4B, C). Intense vacuolization was frequently present, along with cytoplasmic and nuclear membrane shrinkage, as well
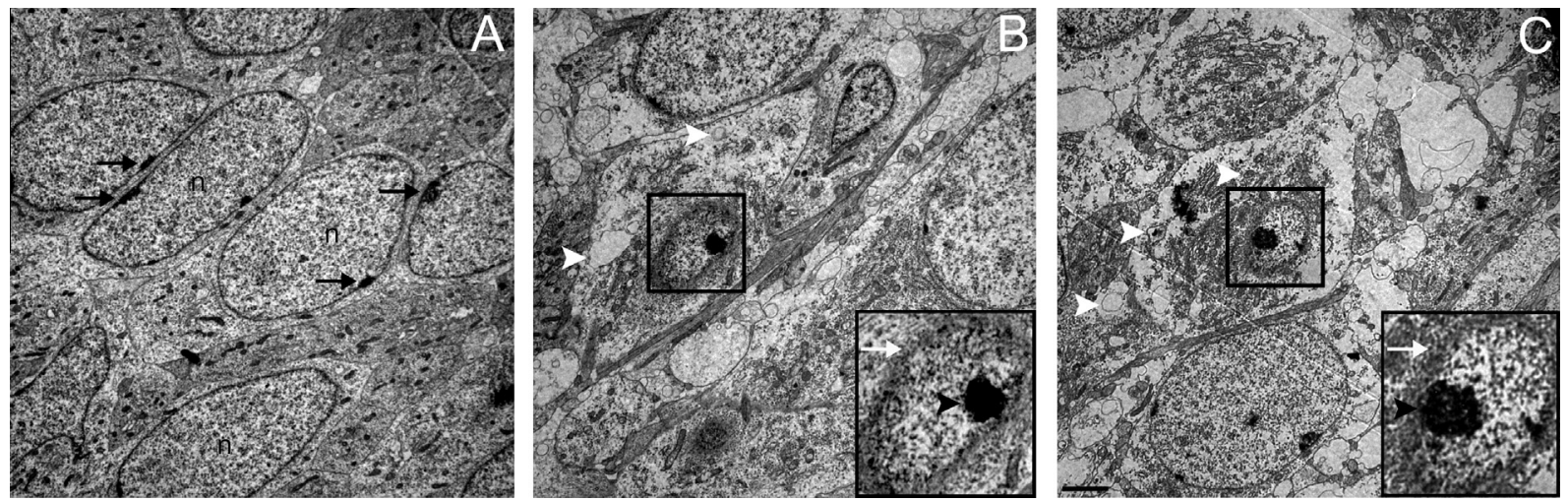

Fig. 4. Ultrastructural overview of the CA1 subfield $24 \mathrm{~h}$ after neonatal anoxia. (A) shows that the canonical morphology of CA1 neurons is still preserved $(n)$, and anoxia-related cell death could be predicted based on the slight condensation of chromatin observed at the edges of the nuclei (black arrows). (B) and (C) show CA1 neurons undergoing intense chromatin condensation (black arrow-heads) with loss of nuclear membrane integrity (white arrows), exhibiting autophagic vacuoles (white arrow-heads) and partial remotion of cytoplasmic organelles. Scale bar $=1 \mu \mathrm{m}$. 
as whole-chromatin condensation and random digestion of chromatin. Furthermore, despite close proximity to anoxia-affected cells, several neighboring cells did not express early cell death patterns; in these cases, the cellular organelles, including granular endoplasmic reticula and mitochondria, were observed to be intact (Fig. 5)

Early chromatin condensation, characterized by condensed bodies distributed in the periphery of the nucleus, and preserved cell membrane and mitochondria were observed in the CA1 and DG subfields in P2 anoxia subjects (Fig. 6). The asterisks in Fig. 6A show vacuoles characteristic of complete degeneration of neural elements and which may be correlated to autophagy, initiated by autophagosomes.

Autophagic vacuoles presenting varied morphologies, based on the size and type of organelles to be engulfed, were abundant as key elements of cell death in the hippocampus $24 \mathrm{~h}$ after neonatal anoxia. As expected, anoxia induced degeneration of both amyelinic fibers and mitochondria in the anoxia group. Amyelinic fibers presented intense vacuolization and dilated microtubules, and degenerating mitochondria were observed within the axoplasm as swollen organelles presenting dark granules (Fig. 7).

Because no cell death was found at P14, P21 or P60, TEM analysis was not performed for subjects at these ages.

\section{Behavioral data in the Morris water maze task}

The subjects were exposed to 6 days of testing in the reference-memory version of the water maze task (with four trials per day and an ITI of $10 \mathrm{~min}$ ) starting at P60, followed by a Probe Test. This allowed the evaluation of spatial memory acquisition and retention.

Reference memory. Subjects exposed to anoxia exhibited significantly longer latencies (Fig. 8A) and path lengths (Fig. 8B) compared to the corresponding controls. Repeated-measures ANOVA revealed significant main Treatment $\left(F_{(1,197)}=37.92-38.42\right.$, $p<0.05)$ and Session $\left(F_{(4,197)}=12.13-15.54\right.$, $p<0.05)$ effects for both latency and path length, and a significant main Trial effect for path length $\left(F_{(3,197)}=4.74, \quad p<0.05\right)$. ANOVA also revealed a significant Session $\times$ Trial interaction effect for path length $\left(F_{(12,197)}=2.29, \quad p<0.05\right)$ and significant Treatment $\times$ Session $\times$ Trial interaction effects for latency and path length $\left(F_{(12,197)}=1.84-5.18\right.$, $p<0.05)$. In contrast, there were no significant differences between the swimming speeds of subjects exposed to anoxia and controls, thus indicating that the above reported differences are not related to motor disruption.

Probe test. During the probe test, for which the platform was removed, the Control subjects performed as expected, searching for the platform at its former location, indicating memory of that spatial information (Fig. 9). Although subjects exposed to anoxia also searched for the platform at its former location, their scores were poorer than those of the Control subjects, indicating that anoxia had disrupted their spatial memory. Further, anoxia subjects exhibited a marked disruption of performance, as reflected by significant reductions of the percentage of time spent within the critical quadrant (Fig. 9A, C) and critical counter (Fig. $9 \mathrm{~B}$ and $\mathrm{D}, \quad p<0.05) \quad \mathrm{r} \quad\left(F_{(1,30)}=6.25-6.75\right.$
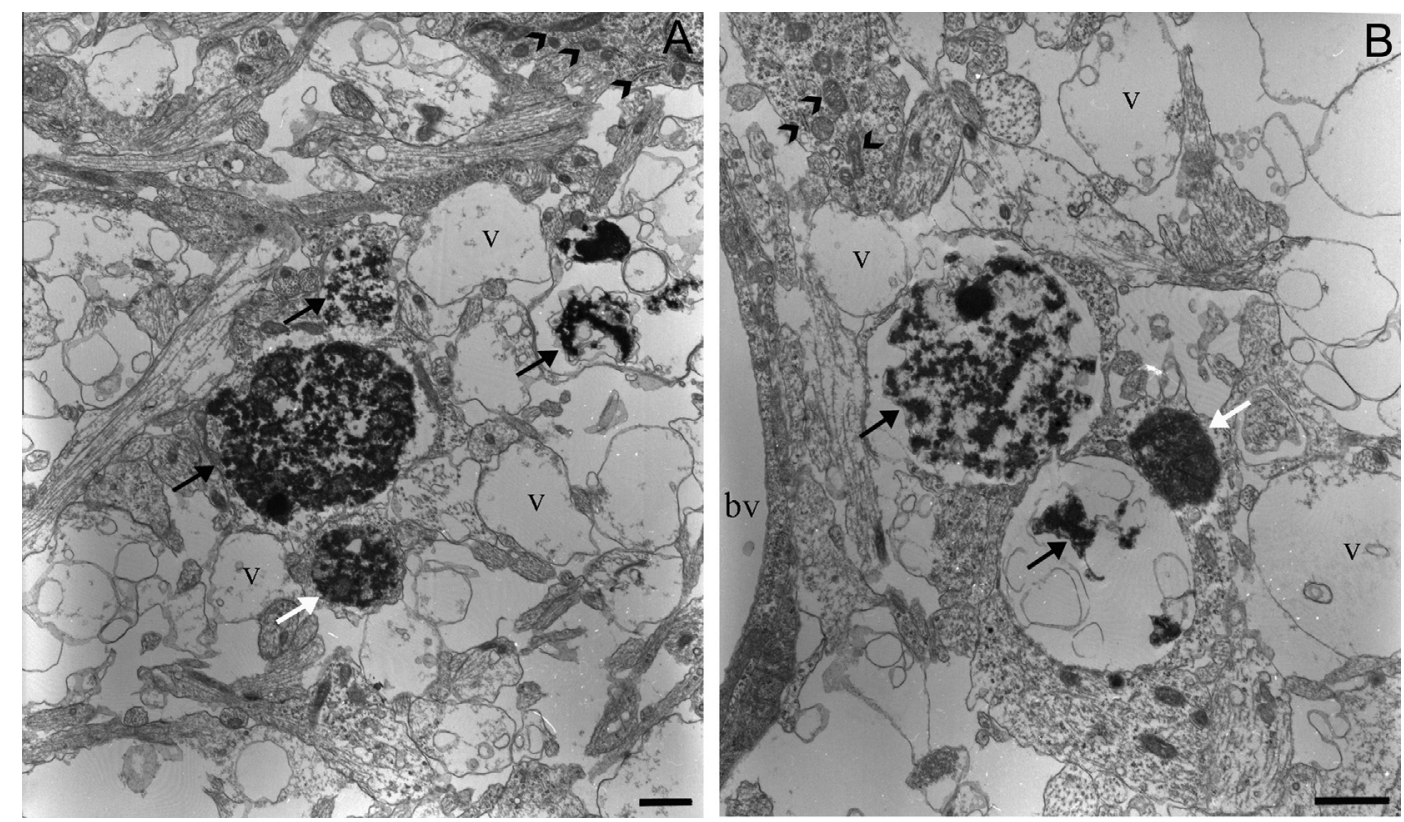

Fig. 5. Ultrastructural details of patterns of cell death in the rat hippocampus $24 \mathrm{~h}$ after neonatal anoxia. (A) and (B) show intense vacuolization (v), cytoplasmic and nuclear membrane shrinkage, whole chromatin condensation (white arrows) and random digestion of chromatin (black arrows). Integrity of cellular organelles, including granular endoplasmic reticula and mitochondria, are clearly shown (arrow-heads in A and B). Legend: v, vacuole; bv, blood vessel. Scale bar $=1 \mu \mathrm{m}$. 

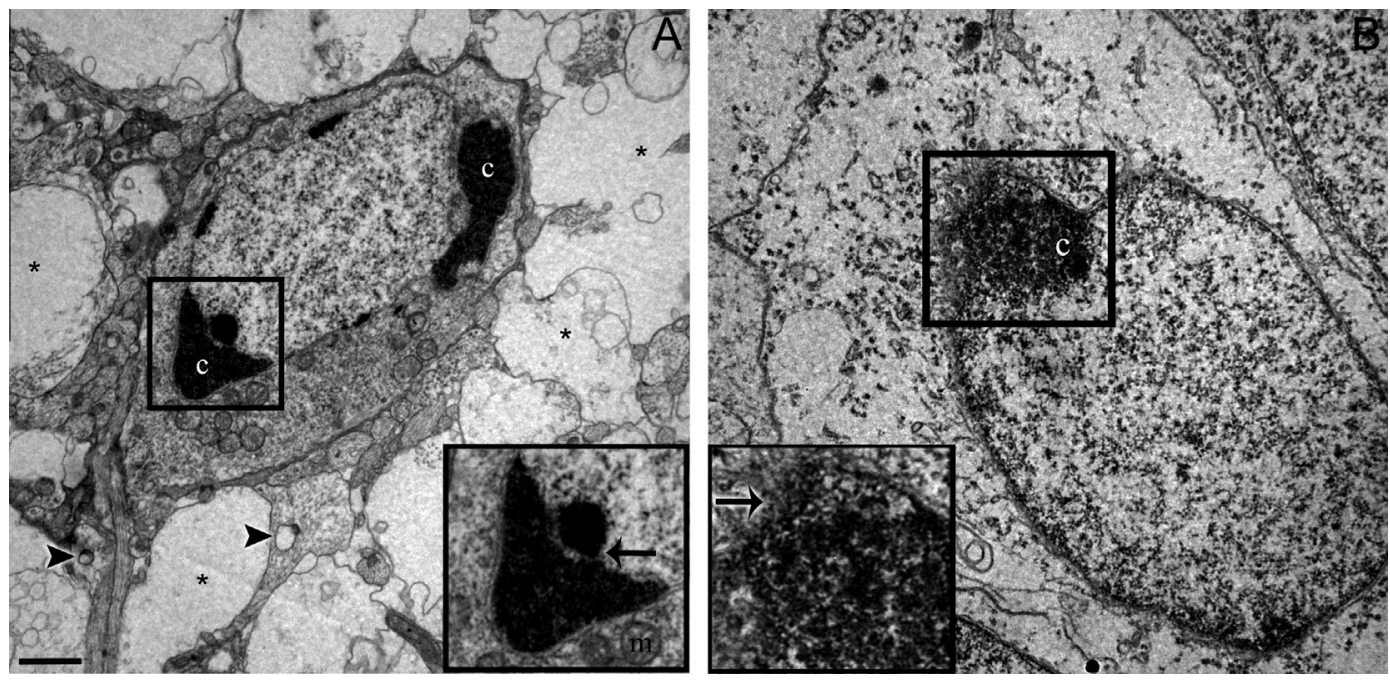

Fig. 6. Ultrastructural findings regarding chromatin condensation in neurons from different hippocampal subfields at $24 \mathrm{~h}$ after neonatal anoxia. Neurons from CA1 and DG subfields are shown in (A) and (B), respectively. (A) and (B) show strong electron density/condensation at the edge of each nucleus. However, in (A), small and large pieces of condensed bodies are distributed in the periphery of the nucleus. Note that these condensed bodies and a rounded body, classically described as early chromatin condensation, are relatively far apart (arrow in detail); the cell membrane and mitochondria are preserved. In (B), invagination and a rupture of the nuclear membrane (arrow in detail) are near the chromatin condensation. The asterisks in (A) show vacuoles characteristic of complete degeneration of neural elements and which may be correlated to autophagy initiated by autophagosomes (arrow-heads in A). Legend: c, condensed chromatin; m, mitochondria. Scale bar $=1 \mu \mathrm{m}$.
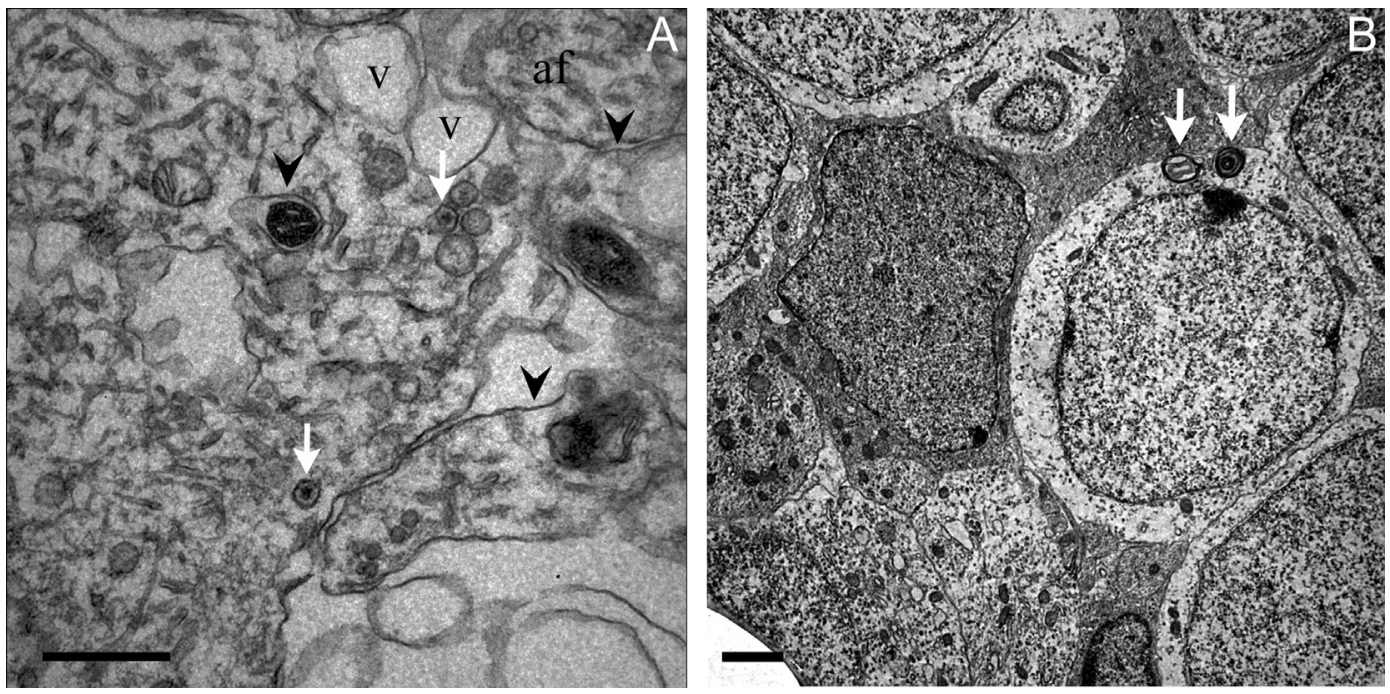

Fig. 7. Autophagic vacuoles as key elements of hippocampal cell death $24 \mathrm{~h}$ after neonatal anoxia. In (A), organelles such as mitochondria are sequestered and clustered by autophagic vacuoles (black arrow-heads) through a process that leads to degeneration and complete vacuolization (v). These autophagic vacuoles have varied morphologies based on the size and sort of organelles to be engulfed (white arrows). In (B), early autophagic vacuoles - autophagosomes (white arrows) - are present in a hippocampal neuron likely undergoing the initiation of degeneration, corroborated by the slight condensation of chromatin visible at the edge of the nucleus. Legend: af, amyelinic fiber; $v$, vacuole. Scale bar $=1 \mu \mathrm{m}$.

$p<0.05)$. Control subjects spent more time within the critical counter, indicating that the animals remembered that spatial information, whereas anoxia subjects demonstrated memory and prominent learning deficits.

\section{DISCUSSION}

Neonatal anoxia, a serious public health concern, is a major cause of brain injury in premature babies (Barrett et al., 2007) and may lead to long-lasting sensorimotor, cognitive and behavioral sequelae. Strategies for minimizing deleterious brain effects of neonatal anoxia are to be welcomed. Animal models have been used to investigate brain mechanisms triggered in response to anoxic insults in developing brains. For instance, Takada et al. (2011) adapted and validated a non-invasive model of global neonatal anoxia in rats, focusing on the primary event of asphyxia or anoxia at birth, a common occurrence in premature humans. This animal model of anoxia was employed in the present study to investigate brain changes following the anoxic insult.

Results of the present study revealed that neonatal anoxia causes neurodegeneration, as demonstrated by both positive FJB and TUNEL staining in hippocampal 

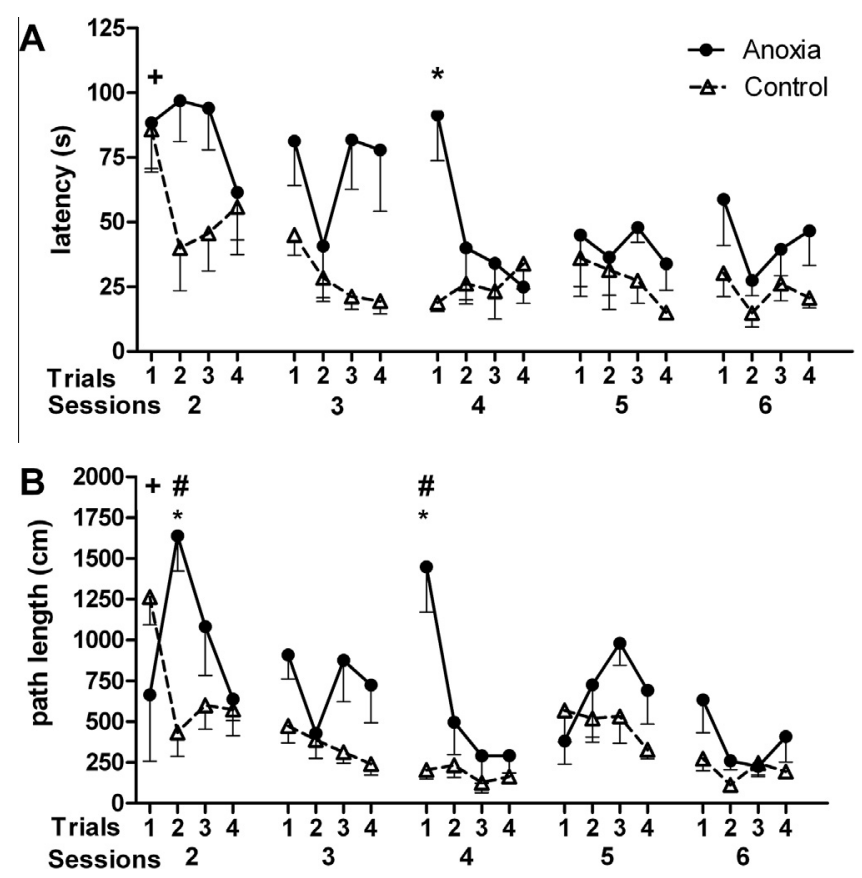

Fig. 8. Effect of anoxia on the acquisition of a spatial navigation reference memory task in the water maze task over 6 training sessions (4 trials per session), as revealed by latency (A) and path length (B). Data ( \pm S.E.M.) were analyzed using repeated-measures analysis of variance (ANOVA), using the groups (Control and Anoxia) as the between-subject factor and the day or trial as the within-subject factor. Post-hoc analyses with the Tukey-Kramer test are indicated as follows: ${ }^{+}$Trial significant difference within control group; ${ }^{~}$ Trial significant difference within anoxia group * Group significant difference. The significance level adopted was $p<0.05$.

A

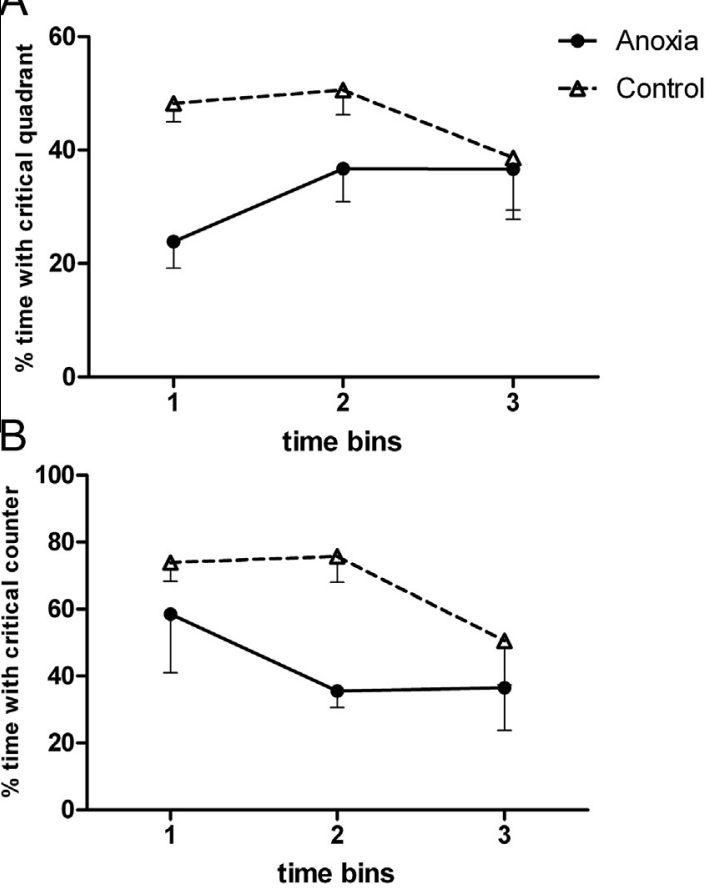

C

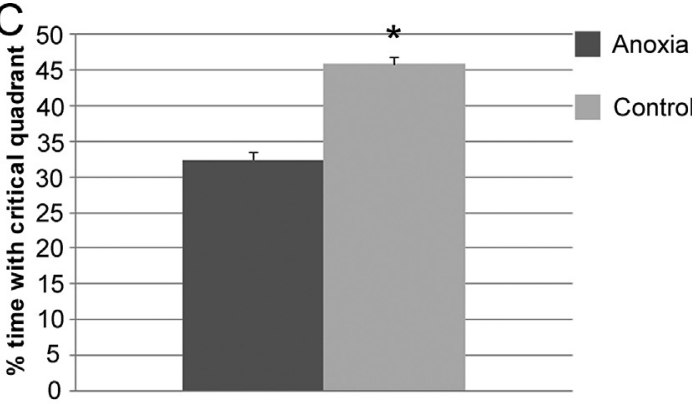

$\mathrm{D}$

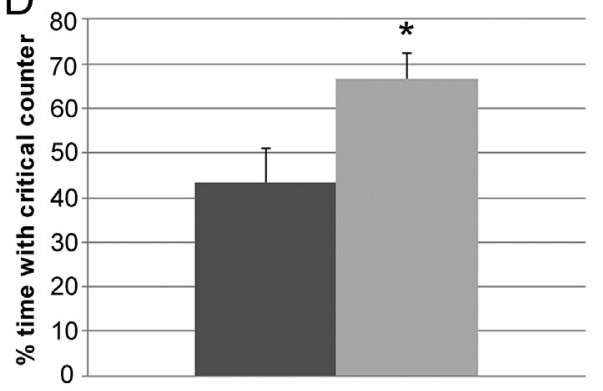

Fig. 9. Effect of anoxia on the platform removal 3-min probe test, represented as the percentage of time within the training counter (A and $\mathrm{C}$ ) and the frequency of entering the counter (B and D), in each of three 1-min consecutive time bins. Probe-test scores were analyzed using Treatments as the between-subject factor and time bin as the within-subject factor. An independent ANOVA was run for each score. Post-hoc analyses using the Tukey-Kramer test are indicated as follows: * Group significant difference. The significance level adopted was $p<0.05$.

subfields and TEM findings at P2. Results revealed increases in TUNEL-positive cells in CA1 and DG and FJB-positive cells in CA2-3 in anoxia-treated subjects.
TEM analysis showed subcellular evidence of necrosis and apoptosis, as well as mixed features of both types of cell death in subjects submitted to anoxia. Curiously, 
the density of cleaved caspase- 3 revealed no differences between treatments in any hippocampal subfield evaluated, independently of the age at which the subjects were perfused, although significant differences between ages were observed. Furthermore, this oxygen deprivation model was observed to impair spatial memory, suggesting some correlation between histological findings and behavioral results. The substantial increases in TUNEL-positive cells in the CA1 and DG and in FJB-positive cells in CA2-3 at P2 supports the well-known vulnerability of the hippocampus to oxygen deprivation (Kirino, 2000; Pimentel et al., 2011; Zhao et al., 2013), particularly in the CA1 subfield (Daval and Vert, 2004; Zhao et al., 2013), as shown by TUNEL analysis.

Interestingly, the CA2-3 subfields, described as being more resistant to ischemic events such as myocardial infarctions in humans (Petito et al., 1987) or brain ischemia models in other rodent species (Kirino, 1982), presented more FJB-positive cells in rats submitted to anoxia treatment. Similarly, there has been a report of a pronounced delay in neuronal death in the CA2-3 subfields of P13 rats, $24 \mathrm{~h}$ after unilateral hypoxia-ischemia (Towfighi and Mauger, 1998).

Intense labeling for cleaved caspase- 3 was observed following both anoxia and control treatments, in all investigated subfields, with stronger staining at younger ages. Stereological analysis revealed no significant differences in the expression of cleaved caspase- 3 independent of the age at which the subjects were perfused, leading to the conclusion that this staining reflects the usual apoptosis occurring during brain development. In a study of the distribution of caspase-3 in the hippocampal subfields during postnatal development (Liu et al., 2008), the expression of cleaved caspase- 3 was observed to peak at P7 in the CA1 and at $\mathrm{P} 2$ in the CA3 and to subsequently decrease with age. Our results showed a peak of cleaved caspase- 3 in DG at P2 in both treatments, with slightly but non-significantly stronger staining in anoxia subjects, as well as an increase in TUNEL labeling. Because the rodent DG is not completely developed at birth, one may hypothesize that neuronal death in this area reflects neurogenesisrelated cell death (Liu et al., 2008).

Notably, the involvement and participation of different caspases, including caspase- 3 , in processes other than cell death are under investigation (Lamkanfi et al., 2007; Snigdha et al., 2012). In the early phases of central nervous system development, cleaved caspase-3 contributes to apoptosis and connectivity; in the adult brain, it participates in the modulation of synaptic function and some forms of memory (Snigdha et al., 2012).

Based on this evidence, we can conclude that the present model of neonatal anoxia causes diverse results with respect to caspase-3, FJB and TUNEL. This is likely because different types of cell death are revealed by these techniques and because the subfields develop at different rates (Jabes et al., 2011). In addition, the type of neuronal death present after neonatal anoxia may be caspase-3-independent (Uchiyama et al., 2008) with an unanticipated type of cell death occurring in the resistant CA2-3 that could only be detected by FJB staining. In P2 anoxia subjects, the CA2 -3 subfield and the CA1 and DG showed subcellular evidence of apoptosis, necrosis and mixed degeneration. Necrosis is a major phenotype of neuronal cell death following hypoxia-ischemia injury in P7 rats (Carloni et al., 2007). The TEM results consistently indicated the presence of necrotic cells, characterized by loss of membrane integrity and organelle release, but only in the subjects submitted to anoxia. This leads to the conclusion that the present animal model of neonatal anoxia was effective in promoting cell death by necrosis, as previously reported for hypoxia-ischemia. This is an interesting result because it indicates that asphyxia alone, not associated with ischemia, promotes cell death by necrosis.

Although morphological, histochemical and molecular results have confirmed that hypoxia-ischemia-induced cell death is mainly related to apoptosis and necrosis (Banasiak and Haddad, 1998; Nakajima et al., 2000), much evidence suggests that a continuum of other types of cell death, exhibiting characteristics of both apoptosis and necrosis, is often found in models of neonatal hypoxia-ischemia (Portera-Cailliau et al., 1997; Carloni et al., 2007; Northington et al., 2007). The presence of this mixed effect may indicate excitotoxic cell death (Portera-Cailliau et al., 1997). Analysis by TEM revealed cells with these latter morphological characteristics in the hippocampus of animals exposed to anoxia at $\mathrm{P} 1$, including somato-dendritic swelling, mitochondrial injury and chromatin condensation in irregular bodies (Orrenius et al., 2003; Northington et al., 2011). These findings corroborate those of Sheldon and colleagues (Sheldon et al., 2001), in which TEM analysis revealed that the punctate appearance of the nuclei corresponded to clumped chromatin $24 \mathrm{~h}$ following unilateral hypoxiaischemia in P7 rats. They concluded that, although dying cells had an appearance consistent with apoptosis in light microscopy, cells were neither necrotic nor apoptotic at the ultrastructural level.

As expected, TEM showed typical characteristics of early apoptosis, such as chromatin condensation, in both the anoxia and control subjects, as well as features of autophagy, such as intense vacuolization and autophagosomes, the latter being more abundant in anoxia subjects. Different sizes of vacuoles were observed, depending on the engulfed material as well as different phases of activation and the progression of autophagy, leading to complete degeneration demonstrated by the presence of large and empty vacuoles (Eskelinen et al., 2011).

Several of the subcellular morphological features observed by TEM under similar conditions could not be found in the literature because the majority of models are based on $\mathrm{H}-\mathrm{I}$ in 7-day-old rats. Models that better approximate the present one are the perinatal anoxia model (Stigger et al., 2013) and the perinatal asphyxia model, in which subcellular evidence of cell death was observed in striatum post-synaptic densities 30 days after asphyxia (Grimaldi et al., 2012). Although differences in the maturation and cellular morphological characteristics 
of neonatal rats of different ages may cause divergent findings, we draw attention to the findings provided by this model of neonatal anoxia, initially considered unable to induce histological changes (Nakajima et al., 1999). In particular, we focused TEM analysis on the extensive and complex acute death of hippocampal cells as characterized by different and specific morphological features at the ultrastructural level.

Previous studies have shown that neonatal anoxia leads to spatial learning and memory deficits (Buwalda et al., 1995; Dell'Anna et al., 1997; Cannon et al., 2002; Caputa et al., 2005; Rogalska et al., 2006). Data from the present study confirm this through the poorer performance in latency and path length in subjects exposed to anoxia, indicating that these animals exhibited acquisition deficits. The information of platform location is disrupted in anoxia subjects as demonstrated by the probe test, which also confirms deficits in memory retention.

Galeano et al. (2011) observed impairments in spatial reference and working memory in rats submitted to perinatal asphyxia but no differences in anxiety-related behaviors at 3 months of age. Interestingly, in another study using the same perinatal asphyxia model, rats with long-duration exposure to hypoxia (15 and $20 \mathrm{~min}$ of asphyxia) showed reduced anxiety-related behavior and no abnormalities in the elevated plus maze condition (Hoeger et al., 2000).

An intriguing result of the present study was that the anoxia-treated animals did not demonstrate the typical pattern of decreasing latency scores, suggesting that the anoxia subjects do not retain spatial information during the time required to perform a task. This suggests a possible impairment in working memory tasks. Retention time can be a factor influencing the deficit in spatial memory. Further investigations are necessary to evaluate possible spatial working memory deficits considering different inter-trial intervals.

In summary, we conclude that this novel model of neonatal anoxia leads to different types and stages of neuronal degeneration in hippocampal formation, as observed through both cellular and subcellular analyses. Furthermore, our data reveal that the model of neonatal anoxia used in this research caused long-lasting cognitive impairments in spatial reference memory.

Based on these results, we suggest that this noninvasive model with global effects can be used as a tool to explore the underlying mechanisms of hippocampal neuronal cell death in premature human infants suffering from oxygen deprivation at birth and to propose various strategies to overcome, prevent or ameliorate its longterm effects.

Acknowledgments-We would like to especially acknowledge Rosana Prisco for statistical analysis, Sonia Almeida, Diego Cury and Fernando José Dias for assistance with transmission electronic microscopy, Guilherme S.V. Higa for arranging and organizing the figures and Professor Jackson C. Bittencourt for the stereology system facilities. We also acknowledge Associação Brasil-Japão de Pesquisadores (SBPN) for the fellowship to S.H.T., Fundação de Amparo à Pesquisa do Estado de São Paulo (FAPESP) for funding the project (grant 2010/01488-9, 2011/19747-3) and for the doctoral grant bestowed to S.H.T.
(2009/51557-0), the Conselho Nacional de Desenvolvimento Científico e Tecnológico (CNPq) for the undergraduate research grant bestowed to V.Y.L. and Oxilúmen Ltd. for lending us the gas cylinder.

\section{REFERENCES}

Banasiak KJ, Haddad GG (1998) Hypoxia-induced apoptosis: effect of hypoxic severity and role of p53 in neuronal cell death. Brain Res 797:295-304.

Barrett RD, Bennet L, Davidson J, Dean JM, George S, Emerald BS, Gunn AJ (2007) Destruction and reconstruction: hypoxia and the developing brain. Birth Defects Res C Embryo Today 81:163-176.

Buwalda B, Nyakas C, Vosselman HJ, Luiten PG (1995) Effects of early postnatal anoxia on adult learning and emotion in rats. Behav Brain Res 67:85-90.

Cannon TD, van Erp TG, Rosso IM, Huttunen M, Lonnqvist J, Pirkola T, Salonen O, Valanne L, Poutanen VP, StandertskjoldNordenstam CG (2002) Fetal hypoxia and structural brain abnormalities in schizophrenic patients, their siblings, and controls. Arch Gen Psychiatry 59:35-41.

Caputa M, Rogalska J, Wentowska K, Nowakowska A (2005) Perinatal asphyxia, hyperthermia and hyperferremia as factors inducing behavioural disturbances in adulthood: a rat model. Behav Brain Res 163:246-256.

Carloni S, Carnevali A, Cimino M, Balduini W (2007) Extended role of necrotic cell death after hypoxia-ischemia-induced neurodegeneration in the neonatal rat. Neurobiol Dis 27:354-361.

Daval JL, Vert P (2004) Apoptosis and neurogenesis after transient hypoxia in the developing rat brain. Semin Perinatol 28:257-263.

Dell'Anna E, Chen Y, Engidawork E, Andersson K, Lubec G, Luthman J, Herrera-Marschitz M (1997) Delayed neuronal death following perinatal asphyxia in rat. Exp Brain Res 115:105-115.

Engidawork E, Chen Y, Dell'Anna E, Goiny M, Lubec G, Ungerstedt U, Andersson K, Herrera-Marschitz M (1997) Effect of perinatal asphyxia on systemic and intracerebral $\mathrm{pH}$ and glycolysis metabolism in the rat. Exp Neurol 145:390-396.

Eskelinen EL, Reggiori F, Baba M, Kovacs AL, Seglen PO (2011) Seeing is believing: the impact of electron microscopy on autophagy research. Autophagy 7:935-956.

Galeano P, Blanco Calvo E, Madureira de Oliveira D, Cuenya L, Kamenetzky GV, Mustaca AE, Barreto GE, Giraldez-Alvarez LD, Milei J, Capani F (2011) Long-lasting effects of perinatal asphyxia on exploration, memory and incentive downshift. Int J Dev Neurosci 29:609-619.

Galluzzi L, Kepp O, Kroemer G (2012) Mitochondria: master regulators of danger signalling. Nat Rev Mol Cell Biol 13:780-788.

Grimaldi M, Romer I, de Apodaca MT, Iturbe L, Catania ID, Gonzalez J, Kolliker-Fres R, Barreto G, Capani F (2012) Early changes in the synapses of the neostriatum induced by perinatal asphyxia. Nutr Neurosci 15:103-110.

Hoeger H, Engelmann M, Bernert G, Seidl R, Bubna-Littitz $H$, Mosgoeller W, Lubec B, Lubec G (2000) Long term neurological and behavioral effects of graded perinatal asphyxia in the rat. Life Sci 66:947-962.

Jabes A, Lavenex PB, Amaral DG, Lavenex P (2011) Postnatal development of the hippocampal formation: a stereological study in macaque monkeys. J Comp Neurol 519:1051-1070.

Johnston MV (2001) Excitotoxicity in neonatal hypoxia. Ment Retard Dev Disabil Res Rev 7:229-234.

Kirino T (1982) Delayed neuronal death in the gerbil hippocampus following ischemia. Brain Res 239:57-69.

Kirino T (2000) Delayed neuronal death. Neuropathology 20(suppl.):S95-S97.

Kurinczuk JJ, White-Koning M, Badawi N (2010) Epidemiology of neonatal encephalopathy and hypoxic-ischaemic encephalopathy. Early Hum Dev 86:329-338.

Lamkanfi M, Festjens N, Declercq W, Vanden Berghe T, Vandenabeele P (2007) Caspases in cell survival, proliferation and differentiation Cell Death Differ 14:44-55. 
Leuner B, Gould E, Shors TJ (2006) Is there a link between adult neurogenesis and learning? Hippocampus 16:216-224.

Liu JP, Chang LR, Gao XL, Wu Y (2008) Different expression of caspase-3 in rat hippocampal subregions during postnatal development. Microsc Res Tech 71:633-638.

Lutz PL, Prentice HM (2002) Sensing and responding to hypoxia, molecular and physiological mechanisms. Integr Comp Biol 42:463-468.

Morris RG, Garrud P, Rawlins JN, O'Keefe J (1982) Place navigation impaired in rats with hippocampal lesions. Nature 297:681-683.

Nakajima W, Ishida A, Lange MS, Gabrielson KL, Wilson MA, Martin LJ, Blue ME, Johnston MV (2000) Apoptosis has a prolonged role in the neurodegeneration after hypoxic ischemia in the newborn rat. J Neurosci 20:7994-8004.

Nakajima W, Ishida A, Takada G (1999) Anoxic and hypoxic immature rat model for measurement of monoamine using in vivo microdialysis. Brain Res Brain Res Protoc 3:252-256.

Northington FJ, Chavez-Valdez R, Martin LJ (2011) Neuronal cell death in neonatal hypoxia-ischemia. Ann Neurol 69:743-758.

Northington FJ, Zelaya ME, O'Riordan DP, Blomgren K, Flock DL, Hagberg H, Ferriero DM, Martin LJ (2007) Failure to complete apoptosis following neonatal hypoxia-ischemia manifests as "continuum" phenotype of cell death and occurs with multiple manifestations of mitochondrial dysfunction in rodent forebrain. Neuroscience 149:822-833.

Orrenius S, Zhivotovsky B, Nicotera P (2003) Regulation of cell death: the calcium-apoptosis link. Nat Rev Mol Cell Biol 4:552-565.

Petito CK, Feldmann E, Pulsinelli WA, Plum F (1987) Delayed hippocampal damage in humans following cardiorespiratory arrest. Neurology 37:1281-1286.

Pimentel VC, Pinheiro FV, Kaefer M, Moresco RN, Moretto MB (2011) Assessment of uric acid and lipid peroxidation in serum and urine after hypoxia-ischemia neonatal in rats. Neurol Sci 32:59-65.

Portera-Cailliau C, Price DL, Martin LJ (1997) Excitotoxic neuronal death in the immature brain is an apoptosis-necrosis morphological continuum. J Comp Neurol 378:70-87.

Puyal J, Ginet V, Clarke PG (2013) Multiple interacting cell death mechanisms in the mediation of excitotoxicity and ischemic brain damage: a challenge for neuroprotection. Prog Neurobiol 105:24-48.

Rogalska J, Danielisova V, Caputa M (2006) Effect of neonatal body temperature on postanoxic, potentially neurotoxic iron accumulation in the rat brain. Neurosci Lett 393:249-254.

Schmued LC, Hopkins KJ (2000) Fluoro-Jade B: a high affinity fluorescent marker for the localization of neuronal degeneration. Brain Res 874:123-130.

Semple BD, Blomgren K, Gimlin K, Ferriero DM, Noble-Haeusslein LJ (2013) Brain development in rodents and humans: identifying benchmarks of maturation and vulnerability to injury across species. Prog Neurobiol 106-107:1-16.

Sheldon RA, Hall JJ, Noble LJ, Ferriero DM (2001) Delayed cell death in neonatal mouse hippocampus from hypoxia-ischemia is neither apoptotic nor necrotic. Neurosci Lett 304:165-168.
Shors TJ, Seib TB, Levine S, Thompson RF (1989) Inescapable versus escapable shock modulates long-term potentiation in the rat hippocampus. Science 244:224-226.

Snigdha S, Smith ED, Prieto GA, Cotman CW (2012) Caspase-3 activation as a bifurcation point between plasticity and cell death. Neurosci Bull 28:14-24.

Stigger F, Lovatel G, Marques M, Bertoldi K, Moyses F, Elsner V, Siqueira IR, Achaval M, Marcuzzo S (2013) Inflammatory response and oxidative stress in developing rat brain and its consequences on motor behavior following maternal administration of LPS and perinatal anoxia. Int J Dev Neurosci 31:820-827.

Suguihara C, Lessa AC (2005) Strategies to minimize lung injury in extremely low birth weight infants. J Pediatr (Rio J) 81:S69-S78.

Takada SH, Sampaio CA, Allemandi W, Ito PH, Takase LF, Nogueira MI (2011) A modified rat model of neonatal anoxia: development and evaluation by pulse oximetry, arterial gasometry and Fos immunoreactivity. J Neurosci Methods 198:62-69.

Towfighi J, Mauger D (1998) Temporal evolution of neuronal changes in cerebral hypoxia-ischemia in developing rats: a quantitative light microscopic study. Brain Res Dev Brain Res 109:169-177.

Uchiyama Y, Koike M, Shibata M (2008) Autophagic neuron death in neonatal brain ischemia/hypoxia. Autophagy 4:404-408.

Vannucci RC, Connor JR, Mauger DT, Palmer C, Smith MB, Towfighi J, Vannucci SJ (1999) Rat model of perinatal hypoxic-ischemic brain damage. J Neurosci Res 55:158-163.

Vexler ZS, Ferriero DM (2001) Molecular and biochemical mechanisms of perinatal brain injury. Semin Neonatol 6:99-108.

Watanabe I, Yamada E (1983) The fine structure of lamellated nerve endings found in the rat gingiva. Arch Histol Jpn 46:173-182.

Watanabe IS, Dias FJ, Mardegan Issa JP, dos Santos Haemmerle CA, Cury DP, Takada SH, Sosthenes MC, Pereira da Silva MC, Campos LM, Nogueira MI, lyomasa MM (2013) Immunohistochemistry and ultrastructural characteristics of nerve endings in the oral mucosa of rat. Microscopy (Oxf) 62:259-270.

West MJ, Gundersen HJ (1990) Unbiased stereological estimation of the number of neurons in the human hippocampus. J Comp Neurol 296:1-22.

Winocur G, Wojtowicz JM, Sekeres M, Snyder JS, Wang S (2006) Inhibition of neurogenesis interferes with hippocampusdependent memory function. Hippocampus 16:296-304.

Xavier GF, Oliveira-Filho FJ, Santos AM (1999) Dentate gyrusselective colchicine lesion and disruption of performance in spatial tasks: difficulties in "place strategy" because of a lack of flexibility in the use of environmental cues? Hippocampus 9:668-681.

Yang T, Zhuang L, Terrando N, Wu X, Jonhson MR, Maze M, Ma D (2011) A clinically relevant model of perinatal global ischemic brain damage in rats. Brain Res 1383:317-323.

Zhao YD, Ou S, Cheng SY, Xiao Z, He WJ, Zhang JH, Ruan HZ (2013) Dendritic development of hippocampal CA1 pyramidal cells in a neonatal hypoxia-ischemia injury model. J Neurosci Res 91:1165-1173. 